\title{
LA TRANSICIÓN ENTRE LAS TRADICIONES DE LOS OASIS DEL DESIERTO Y DE LAS QUEBRADAS ALTAS DEL LOA SUPERIOR: ETNOBOTÁNICA DEL VALLE DEL RÍO GRANDE, $2^{\text {a }}$ REGIÓN, CHILE
}

\author{
Marcela Romo $^{*}$, Victoria Castro ${ }^{* *}$, Carolina Villagrán $^{* * *}$ y Claudio Latorre ${ }^{* * *}$
}

Se presentan los resultados de un estudio etnobotánico realizado en las comunidades de Río Grande y Machuca. Para las 131 plantas consultadas en Río Grande y Machuca se obtuvieron 265 nombres vernaculares y 231 usos. La mayoría de los nombres son españoles (48\%), o español combinado con algún término indígena (14\%); $7 \%$ son quechuas y $5 \%$ aymaras, mientras que un $16 \%$ tienen significados en ambos idiomas; $3 \%$ son kunza y $5 \%$ incluye algún término en este idioma. Este espectro evidencia el fuerte proceso de hispanización que afecta al área andina de la $2^{\mathrm{a}}$ Región. En el ámbito ceremonial, en Río Grande y Machuca destaca la misma especie utilizada con fines rituales en Caspana y Ollagüe, en el Loa superior, Fabiana squamata (koa). Como complemento se usa la koa hembra, Parastrephia quadrangularis, la principal especie ceremonial del Salar de Atacama. Frente a la pregunta acerca del eventual rol de transición intercultural que tendría el área de estudio se puede postular que, junto con las comunidades del Loa superior, las comunidades de Río Grande constituyen una tradición unitaria (que hemos llamado la "tradición de las quebradas altas circumpuneñas"), con algunos rasgos propios y, en conjunto, representando una amplia transición entre las culturas altiplánicas más puras de la I Región y las atacameñas en torno al Salar de Atacama.

Palabras claves: Etnobotánica, Andes Chile, etnoclasificación, transición intercultural.

An ethnobotanical study from the Rio Grande valley and Machuca (in northern Chile's II Region) shows 265 common names and 224 uses for the 131 plant species consulted. Most of the names come from the Spanish language (48\%) or are a combination of Spanish and an indigenous term (14\%); $7 \%$ of the names were quechua and 5\% aymara, while $16 \%$ of the names had meanings in both languages. Only $3 \%$ of the names were kunza while 5\% had some term from this language. This spectra shows the evident hispanization of the area. In the ceremonial ambit we find significant relationships. In Rio Grande and Machuca, koa corresponds to the same species used in the upper Loa (Fabiana squamata). Yet, when this species is not available, the koa hembra is used, Parastrephia quadrangularis, which is the very same species used in the Salar de Atacama. Based on this study, we postulate that Rio Grande, together with the communities from the upper Loa river constitute an unified tradition with some proper features, that as a whole represents a transition between the purer altiplanic culture of the I Region, and those surrounding the Salar de Atacama, while both exhibit the stronger atacamenean influences of the region.

Key words: Ethnobotany, Chilean Andes, ethnoclassification, intercultural transitions.

Históricamente, el concepto de identidad ha estado subsumido en las controversias sobre etnicidad, lenguas y territorios, aun cuando los términos comprenden diferentes extensiones y no tienen por qué presentar una adecuación necesaria entre sí. La identidad puede significar la noción de pertenencia a un grupo, asumiendo la participación de un código cultural compartido, lo que supone una conciencia de las diferencias, respecto a otro grupo, y se sustenta fuertemente en una memoria colectiva y en una flexibilidad, que le otorgan la posibilidad de continuidades y cambios. En ese sentido, creemos que la población indígena de la $2^{\text {a }}$ Región de Chile ha hecho los arreglos necesarios para seguir teniendo una identidad, muchas veces re-creada a través del tiempo, lo que obviamente no hace sino complejizar aún más el problema para arqueólogos, etnohistoriadores y etnólogos (Castro 1998).

En los Andes del Norte Grande de Chile se perciben improntas de variados procesos coloniales y republicanos que han afectado a las poblaciones locales. No obstante, es posible vislumbrar elementos propios de tradiciones andinas de raigambre prehispánica. En efecto, entre los rasgos culturales que caracterizan a las comunidades andinas de esta

\footnotetext{
* Departamento de Nutrición Pública, Instituto de Nutrición y Tecnología de Alimentos, Universidad de Chile. José Pedro Alessandri 5540, Macul, Casilla 138-11, Santiago, Chile. E- mail: mromo@uec.inta.uchile.cl

** Departamento de Antropología, Facultad de Ciencias Sociales, Universidad de Chile, Ignacio Carrera Pinto 1045, Ñuñoa, Casilla 10115, Santiago, Chile. E- mail: vcastro@uchile.cl

*** Laboratorio de Palinología, Facultad de Ciencias, Universidad de Chile, Las Palmeras 3425, Nuñoa, Casilla 653, Santiago, Chile.E-mail: cvillagr@uchile.cl
} 
región se encuentran elementos de una tradición que se ha denominado "Tradición Altiplánica", integrando las comunidades genéricamente agrupadas bajo el concepto de "aymara", con elementos de influencia quechuaparlantes y de otros grupos que pueblan el altiplano. Por otra parte, están presentes elementos de otra tradición que, sobre la base de evidencias arqueológicas, ha sido denominada "Tradición del Desierto" (Castro et al. 1984) y cuya representación más nítida involucra a las poblaciones asentadas en el Salar de Atacama. Entre una y otra hay comunidades que exhiben, más fuertemente, situaciones de interdigitación entre ambas tradiciones, sin duda, resultado de largos procesos históricos, como parece ser el caso de las comunidades de quebradas altas del Loa Superior.

¿Es factible reconocer la transición entre las comunidades con Tradición Altiplánica y del Desierto? Resulta sugerente destacar que, tanto los habitantes de la cuenca del Loa como los del extremo sur del Salar de Atacama visualizan a Toconao como un punto de articulación, más allá del cual ambos sectores ven disminuir sus vínculos y relaciones. Un caso singular es el de Río Grande, en la cuenca del río Vilama, al norte de San Pedro de Atacama. Un sector de Río Grande, llamado "quebrada abajo", se identifica con San Pedro de Atacama, mientras que los habitantes de Peñaliri y San Juan, igualmente constitutivos de Río Grande, se identifican con Caspana. Se genera así una curiosa situación de "bisagra" entre el poblamiento de la cuenca del Salar de Atacama con la del río Loa (Castro y Martínez 1996). El objetivo del presente trabajo es investigar sobre la base de la etnobotánica de la región de Río Grande la eventual situación de transición cultural de este territorio y sus relaciones etnobotánicas con los sectores aledaños, situados tanto hacia el sur como al norte.

\section{Área de Estudio, Comunidades y Métodos}

\section{Flora y vegetación}

El estudio se realizó en el territorio comprendido entre San Pedro de Atacama, Guatín, Machuca y el Valle del Río Grande, coordenadas geográficas $22^{\circ} 50^{\prime} 0^{\prime \prime} \mathrm{W}$, hasta $22^{\circ} 37^{\prime} 30^{\prime \prime} \mathrm{S}-68^{\circ} 01^{\prime} 05^{\prime}$ " W (Ver Figura 1).
El análisis de la vegetación se realizó sobre la base de un transecto altitudinal, trazado desde San Pedro de Atacama, Guatín y Machuca hasta el límite superior de la vegetación, en el Cerro Jorqueral (2.700-4.300 msm). En este transecto se llevaron a cabo muestreos distanciados cada $100 \mathrm{~m}$ de altitud (en total, 18 muestreos, con una réplica cada uno). En la Figura 2 se muestra la distribución altitudinal de las coberturas totales y de las distintas formas de vida. Estas últimas definen el cambio de los pisos altitudinales de vegetación (pisos de arbustos, pajas y cojines). Se observa que existe un predominio de vegetación arbustiva entre los 2.700 a los $3.700 \mathrm{~m}$ de altitud (pisos Prepuneño y Puneño). A partir de los $3.800 \mathrm{~m}$, y hasta los $4.300 \mathrm{~m}$, dominan el paisaje las pajas y plantas en cojín (pisos Altoandino y Subnival), decreciendo los arbustos. En la Tabla 1 se muestra la distribución altitudinal de los distintos taxa, y los quiebres fisionómicoflorísticos que permiten definir los rangos altitudinales de los pisos de vegetación, a saber:

Piso Prepuneño, 2.700-3.000 m. Caracterizado por la preponderancia de Ambrosia artemisioides, Ephedra breana y Opuntia camachoi, y con menor frecuencia, Tarasa operculata, Tiquilia atacamensis, Adesmia atacamensis y Atriplex imbricata. Las coberturas son muy bajas y, en total, no llegan al $10 \%$.

Piso Puneño, 3.000-3.800 m. Una serie de arbustos caracterizan este piso de Tolar, pero las coberturas se mantienen bajas a lo largo de todo el rango (10-20\%). Entre los arbustos característicos destacan: Fabiana ramulosa, $F$. denudata, Acantholippia deserticola, Chuquiraga atacamensis, Parastrephia quadrangularis, Adesmia spinosissima y Junellia seriphioides.

Piso Altoandino, 3.850-4.100 m. Una cobertura vegetal muy alta, y que corresponde a la máxima del transecto (20-30\%), caracteriza al piso. Es la mezcla de arbustos con pajas la que explica esta alta cubierta. Entre los arbustos encontramos Parastrephia quadrangularis, Adesmia spinosissima, Junellia seriphioides y Baccharis tola y entre las pajas: Stipa chrysophylla, Festuca chrysophylla, Anatherostipa venusta y Deyeuxia cabrerae.

Piso Subnival, 4.100-4.250 m. En este piso solamente se mantiene Deyeuxia cabrerae, entre las pajas, asociada a los cojines Pycnophyllum bryoides y Azorella compacta. Las coberturas totales se mantienen altas, entre 16 y $27 \%$. 


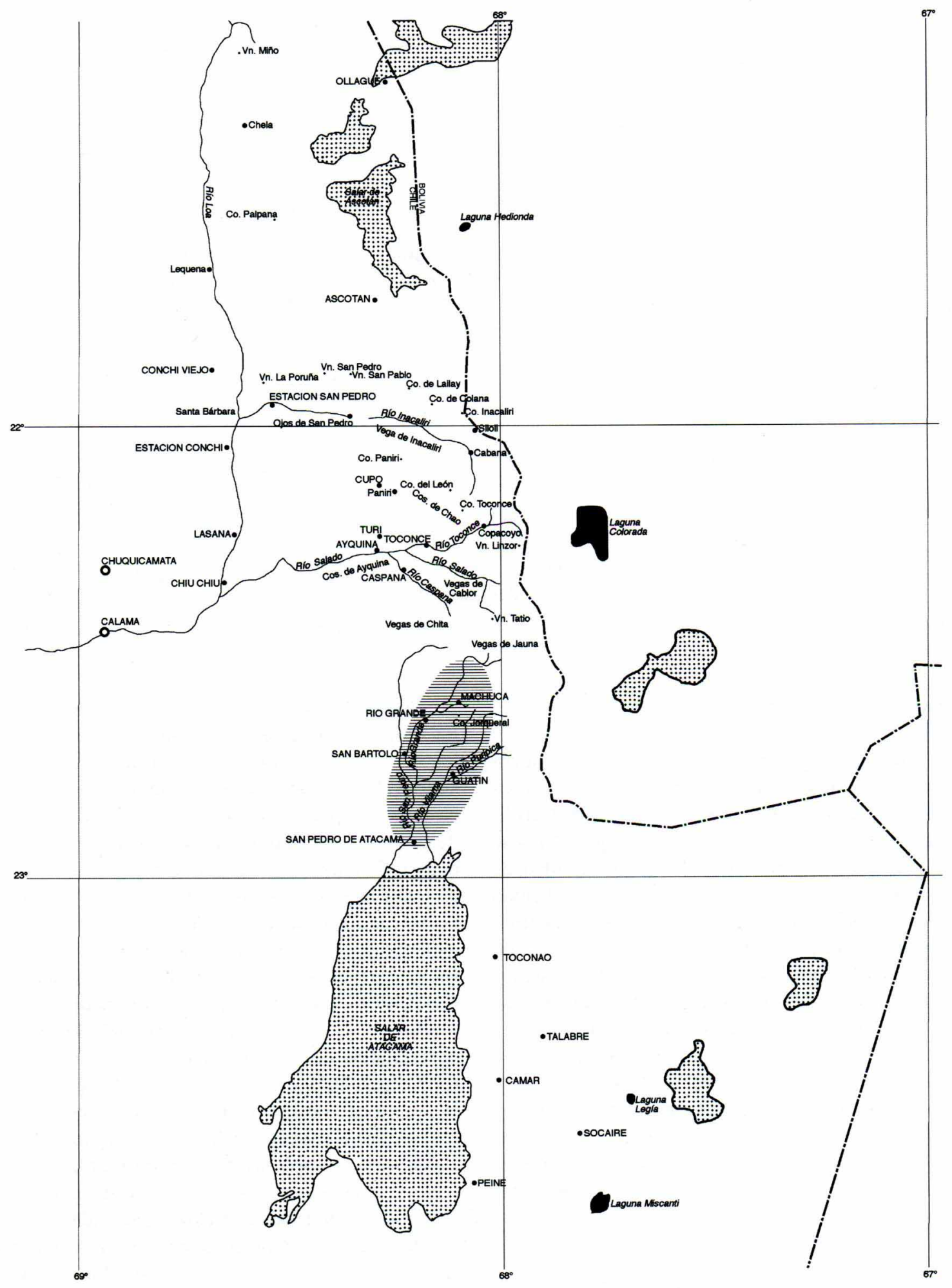

Figura 1. Se señala la localización del área en el contexto regional. 


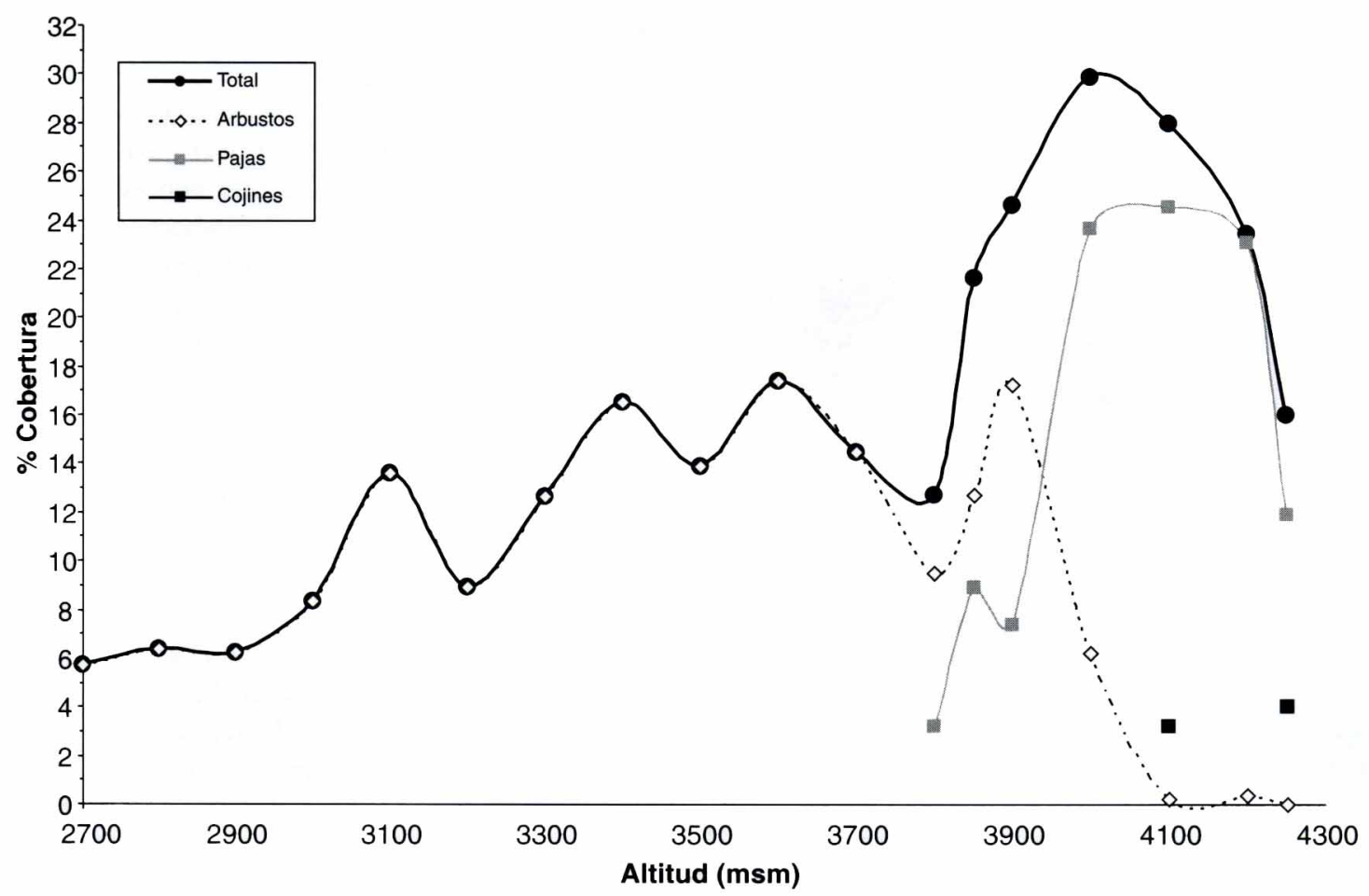

Figura 2. Distribución de las comunidades vegetacionales y la cobertura total en el transecto San Pedro de Atacama-Guatín-Cerro Jorqueral (Machuca).

\section{Las comunidades entrevistadas}

En el Anexo 1 se enumeran los 131 taxa coleccionados para las entrevistas etnobotánicas y los números de los ejemplares del Herbario de Carolina Villagrán ${ }^{1}$. Duplicados de estos ejemplares se conservan en el Herbario de la Universidad de Concepción. En el mismo Anexo 1 se detalla toda la información etnobotánica obtenida y las etimologías de los nombres vernaculares recopilados. En el Anexo 2 se listan alfabéticamente los vernáculos y los idiomas de los mismos. Para las entrevistas se usaron dos muestrarios correspondientes a la flora zonal (Cuaderno 1) y a la flora azonal de humedales, quebradas y chacras (Cuaderno 2). Se entrevistaron en total 21 personas, 3 en Machuca y 18 en Río Grande. Las entrevistas fueron grabadas con duplicados. A continuación se describen brevemente las comunidades donde se hicieron las consultas.

\section{Río Grande}

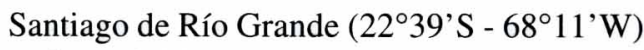
se localiza a $3.360 \mathrm{msm}$, al este de Calama y a 71 km de San Pedro de Atacama. Hasta ahora, para los tiempos coloniales, no hemos encontrado datos sobre esta localidad. En el primer cuarto del siglo XIX, Risopatrón (1924) lo describe como un caserío, compuesto por una capilla y una decena de casas, pobladas por "indios atacameños", con cultivo de quinoa, maíz y alfalfa y ganadería de llamas y ovejas. Serracino y Barón (1979) postulan su calidad de tambo desde tiempos indeterminados, cumpliendo similar función en el presente. Esta aseveración tiene sentido, si se considera que Río Grande es uno de los puntos intermedios para viajeros, a pie o en transporte animal, desde la subregión de río Salado a San Pedro de Atacama. Río Grande dista $25 \mathrm{~km}$ del pueblo de Caspana (en la cuenca del Salado), comunidad con la que, históricamente, ha mantenido fuertes nexos parentales, económicos y religiosos. Antes de cruzar el río para ingresar al pueblo, existe un calvario con una cruz en la parte superior de la piedra escalonada, y una canaleta interior debajo de la cruz, que desemboca en un orificio lateral. Es probable que allí se vierta la sangre de animales sacrificados y/u ofrendas de vino. El centro del pueblo lo marca la iglesia, que está rodeada por un muro perimetral, que forma 
Tabla 1. Cobertura y distribución altitudinal de las especies y pisos de vegetación en el transecto San Pedro de Atacama-Guatín-Machuca.

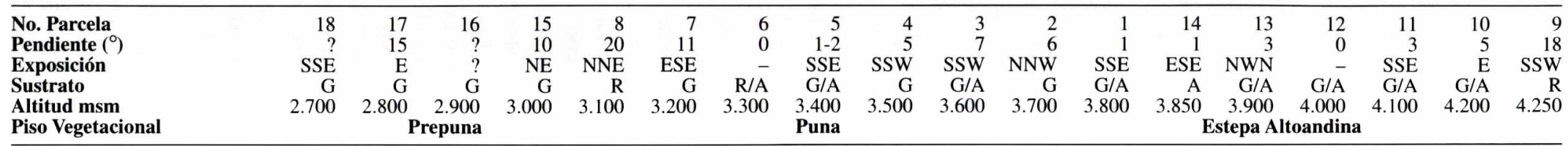

\section{TAXA}

Arbustos, subarbustos y suculentas

$\begin{array}{lr}\text { Ambrosia artemisioides } & 0,77 \\ \text { Ephedra breana } & 2,69\end{array}$

Ephedra breana

Tarasa operculata

Tiquilia atacamensis

Adesmia atacamensi.

Atriplex imbricata

Opuntia sp.

Fabiana ramulosa

Acantholippia deserticola

Fabiana denudata

Chuquiraga atacamensis

Parastrephia quadrangulari

Adesmia spinosissima

Aunellia seriphioides

Baccharis tola ssp. tola

Baccharis tola ssp. tola
Werneria glaberrima

Werneria glaberrima

Estepa Altoandina

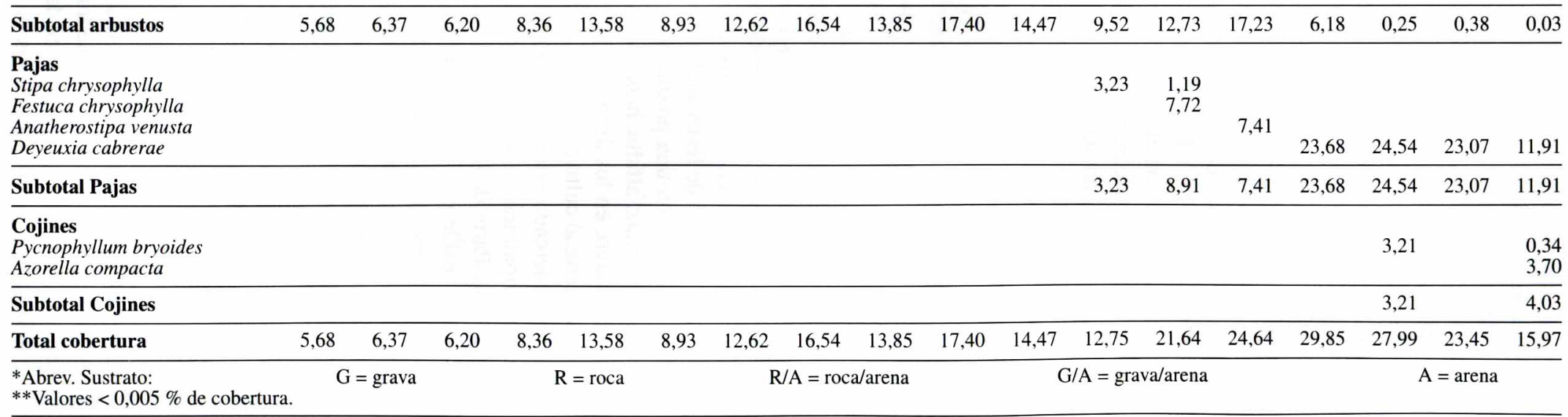


una plaza interior, cuyo acceso mira hacia el norte. Enfrentando este acceso hay un calvario que habitualmente conserva en su superficie restos de hojas de coca y vino seco; son trazas de las ofrendas periódicas que ofrecen los lugareños en las diferentes conmemoraciones de su calendario ceremonial. El cementerio actual está en la cumbre de un cerro al sur del pueblo y a una altura de $60 \mathrm{~m}$ sobre el río, a $3.200 \mathrm{msm}$. Es interesante constatar que en las cruces de las sepulturas predominan apellidos que también son comunes en el altiplano de Iquique y de Lípez (sur Bolivia), tanto nativos como españoles (Castro 1997). Las imágenes más reconocidas en la iglesia son el Santo Patrono Santiago, San Antonio, San Juan, San Francisco y la Virgen del Carmen. Se conmemora a San Santiago el 25 de julio, a la Asunción el 15 de agosto, La Cruz el 3 de mayo, Limpia de Canales el 28 de julio, Todos los Santos el 2 de noviembre y enfloramientos en el mes de febrero (Serracino y Barón 1979). Es muy probable que, por las características socioculturales y económicas de la comunidad, se celebre también a San Antonio "llamero" (patrono de los llamos) y a San Juan, santos que articulan y reactualizan antiguas celebraciones con motivo del solsticio de invierno (Castro 1997). La población rural de Río Grande se ha mantenido en cerca de 100 habitantes, de acuerdo a los censos, triplicándose con ocasión de festividades. Su economía es agroganadera, con una producción tradicional del cultivo del maíz, alfalfa, habas, trigo y hortalizas; sin embargo, en los últimos años, existe una tendencia fuerte al cultivo del ajo, debido a las demandas del mercado externo. El ganado está compuesto principalmente por llamas, ovinos y algunos caprinos. Parte de las unidades familiares de Río Grande reside por períodos largos en las estancias con buenos pastos para forrajes y a veces con posibilidades para el cultivo (como Peñaliri), sin descuidar la permanencia de otro segmento de la familia para cuidar de los niños que asisten a la escuela. Tanto Peñaliri como San Juan y Agua Buena están permanentemente vinculados al pueblo o "centro" (Serracino y Barón 1979).

\section{Machuca}

Está compuesto de una capilla i una decena de casitas de murallas de piedra i barro, con tijerales i puertas de madera de cardón i es el albergue de los pastores indijenas de llamas y ovejas que pacen en las vegas del mismo nombre, que rodean el caserío, a $4010 \mathrm{~m}$ de altitud, en los oríjenes del río del mismo título; en la parte más baja de las vegas se encuentra pasto dañino para los animales (Risopatrón 1924: 510).

Poco ha cambiado esta localidad, situada a los $22^{\circ} 35^{\prime} \mathrm{S}$ y $68^{\circ} 04^{\prime} \mathrm{W}$, con temperaturas que oscilan entre $\operatorname{los}-5,5^{\circ}$ y $\operatorname{los} 18^{\circ} \mathrm{C}$. Machuca es, al mismo tiempo, un territorio de confluencia y ruptura entre la cuenca del río Salado y el Salar de Atacama. Hay pocas noticias históricas sobre su existencia, a pesar de su importancia como zona de pastoreo. Saliendo desde San Pedro de Atacama por el camino que conduce de Vilama hacia Guatín, localizado a $22 \mathrm{~km}$ de San Pedro, y a una altura de 3.110 msm, se encuentra un cruce hacia el norte que indica la variante "San Pedro - Tatio - Machuca". En este camino se ven restos de varias azufreras hoy abandonadas. Al llegar a Machuca observamos el magnífico bofedal, prácticamente una laguna, con abundante avifauna, burros salvajes y alpacas. Las primeras estancias de Machuca se localizan en las cercanías de las orillas del bofedal; aguas arriba, hacia los $3.895 \mathrm{msm}$, las casas se aglutinan como un poblado, con su sede social. Sobre una de las bandas del pueblo, al lado NE del bofedal, hay una iglesia sobre un pequeño lomaje, detrás de la cual hay estancias dispersas. La iglesia, tiene un muro perimetral de piedra, como toda la construcción que orienta su portal hacia el sur, dominando la única calle que en el bajo tiene viviendas continuas. En su patio interior tiene cuatro descansos, uno en cada esquina, y un calvario al centro, con restos de ofrendas de celebraciones tradicionales. Los machuqueños señalan que los santos de la iglesia son la Virgen de Guadalupe, la del Carmen, la Purísima, San Juan, San Antonio y Santiago, montado en su caballo (Castro 1997). Al sur del sector aglutinado, atravesando un pequeño estero, hay más estancias dispersas y en una hondonada próxima, detrás de un promontorio, se localiza el cementerio en dirección este. Aquí sólo existe una elevación que permite ver los techos de las casas del sector opuesto. En este camposanto hasta 1988 descansaban los restos de aproximadamente 62 adultos, 74 niños y 29 infantes. Registramos algunos apellidos que, como en el caso de Río Grande, son comunes en territorios altiplánicos aledaños. Es muy probable que la gente de Machuca haya sido toda una con 
los habitantes de Río Grande, San Juan y Peñaliri; de hecho, la gente de Machuca señala que estas dos últimas localidades son "dos aguas que se juntan" y que la quebrada donde más siembran es San Juan, bueno para habas y ajos (Castro 1997). Esta localidad es interesantísima para un estudio de largo aliento; sus recursos naturales de caza y recolección debieron usarse desde antes de la época incaica. Este lugar, como posta o descanso entre el Salar de Atacama y la Cuenca del Salado, es prácticamente obligado y los nexos con Río Grande parecen evidentes, así como el acelerado proceso de cambio que está sufriendo en el presente (Rivera 1993; Castro y Martínez 1996). Es probable que su proceso de constitución como pueblo se haya iniciado a fines del siglo XIX o comienzos del XX. En la actualidad, la mayoría de la gente de Machuca reside en San Pedro de Atacama entre los meses de marzo y diciembre, a fin de que sus hijos puedan asistir a la escuela. Habitan en barrios separados de los sampedrinos, quienes los denominan coyas.

\section{Resultados}

\section{Los nombres vernaculares}

La flora de la región de Río Grande es ampliamente conocida por los lugareños. De las 131 especies de plantas consultadas, se consiguió alguna denominación para el $97 \%$ de ellas, obteniéndose un total de 265 vernáculos, los que se reducen a 215 al eliminar las variantes de un mismo nombre. En el Anexo 1 se enumeran las especies consultadas y sus respectivos nombres vernaculares, y en el Anexo 2 se presentan los nombres vernaculares en orden alfabético y con símbolos se indican las procedencias de dichos nombres.

En la Figura 3 se muestran las proporciones de nombres de plantas correspondientes a las distintas lenguas registradas. En dicha Figura 3 se observa que la mayor cantidad de nombres corresponden al idioma español, 118 vernáculos, lo que equivale al $45 \%$ del total de nombres registrados. También existe un importante cantidad de nombres (14\%) que combinan palabras indígenas y españolas. La proporción de nombres indígenas de plantas corresponde al $38 \%$ del total de nombres registrados, sin consideración de aquellos en que se mezclan palabras indígenas y españolas; si sumamos éstos, dicha proporción sube al 52\%. Entre los nombres indígenas, un $8 \%$ corresponderían al idioma quechua, un 5\% al idioma aymara y un $4 \%$ a la lengua kunza, que son los idiomas conocidos o que se hablaron en la zona de estudio en el pasado. Adicionalmente, un $5 \%$ ha sido documentado en más de una de las lenguas ya mencionadas. Sólo un $3 \%$ corresponde a nombres mapuches, lengua indígena del sur de Chile.

Entre los vernáculos indígenas nuevos, exclusivamente registrados en el territorio de Río Grande, figuran: yullucha, acholla, kewayllo, tokora, gallokishka, chajchal y wiskayu o iskayu. También en castellano se presentaron algunos nombres, hasta ahora registrados exclusivamente en Río Grande, como alfambrilla, hoja koka, conchita, lupino, ciénego, cola de michi, rosakishka, zarzaparrilla, espiga y paja alma.

$\mathrm{Al}$ analizar los significados de los vernáculos de plantas en Río Grande (Anexo 1) es posible constatar que la mayoría de los nombres hace alusión a los atributos propios de la especie, tales como el aspecto o forma general de la planta (hábito), o de órganos (tallos, hojas, espinas, inflorescencias, etc.), o algunas de sus propiedades específicas, como tamaño y color, sabor u otras propiedades. Dichos atributos utilizados para nombrar pueden ser aludidos directamente en el nombre, o a través de analogías con formas de animales o de objetos. Por ejemplo, el aspecto general de la planta es considerado en nombres como alfambrilla, que alude al hábito postrado de la planta, "como una alfombra"; enredadera, referido a una forma de vida voluble; achicoria, para una forma de vida en roseta y uso comestible. Nombres como cola de gato o de michi son una analogía de las estípulas espinosas de una especie; gallo kishka, aludiendo a la forma de gallo de la corola amariposada de la planta; pata de perdiz, en analogía a la ramificación y aspecto de los tallos con cicatrices de hojas, que se asemejan a las escamas de una pata de ave; zapatilla o zapatito, por relación a la forma de la corola; lengua de buey y lengua de gallo o de gallina, referidos a la forma de las hojas; peludilla, alude a las barbas espinosas de las espigas. El color atribuido a la especie es un atributo considerado en muchos nombres, como, por ejemplo, añawa colorada, básal rojo, básal rosao, flor blanca, malva rosa, chiritola (tola amarilla), tola amarilla, oqelorenso (gris), pasto blanco, sangrinaria, pasto blanco, vinovino (por el color vino de las flores). El sabor también es significativo al mo- 

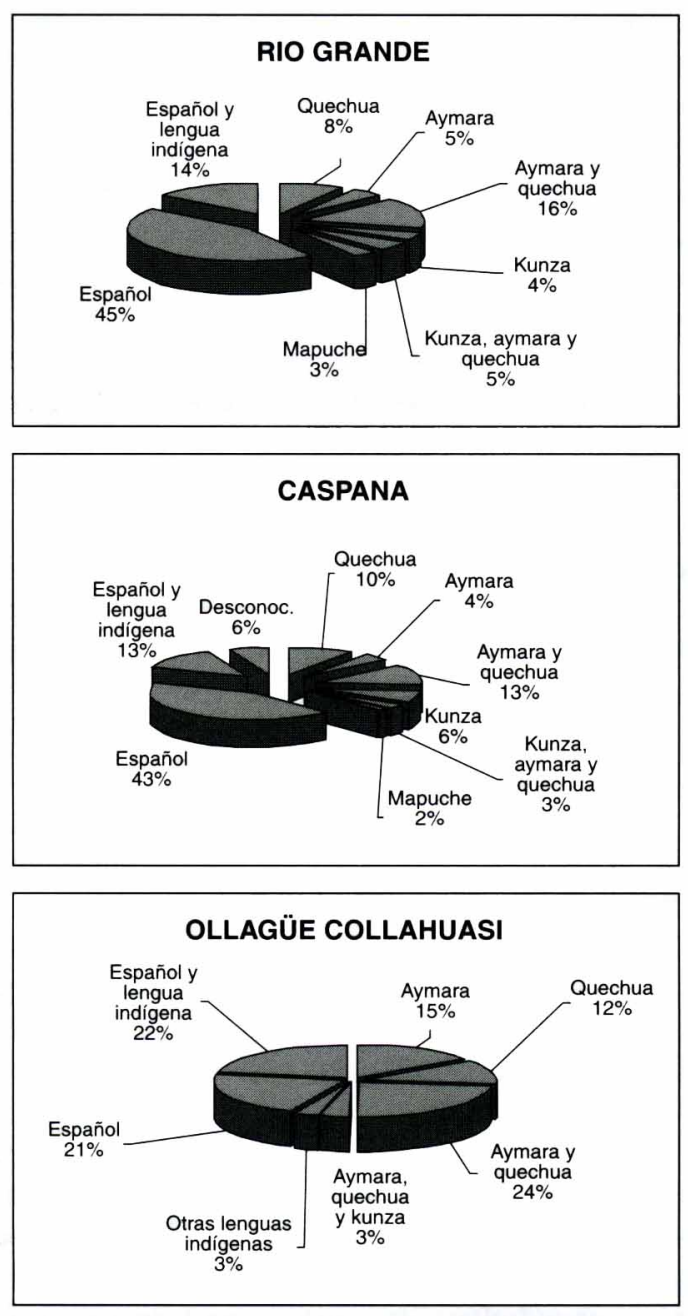

mento de denominar algunas especies: es el caso de básal amargo, básal dulce, espina de agria, pasto amargo y paja dulce. Otras propiedades también concurren a otorgar sentido a los nombres, por ejemplo, pegapega aludiendo a las semillas híspidas que se adhieren a la ropa o lana de los animales; chukchuka, nombre que alude al efecto tóxico sobre el ganado que produce chujcho (temblores); y cortadera, por el borde cortante de las hojas.

El hábitat de la planta es otro de los atributos considerados para nombrar especies. Por ejemplo, flor de la puna, por referencia al hábitat subnival, unutola o tola de agua, aludiendo al hábitat ribereño, añawa de cordillera, por su localización en altura; kachiyuyo, porque se encuentra en hábitats salobres (salares). Otros nombres remiten al hábitat acuático o húmedo y las comunidades asociadas, como flor del agua, flor de la vega, ciénego.
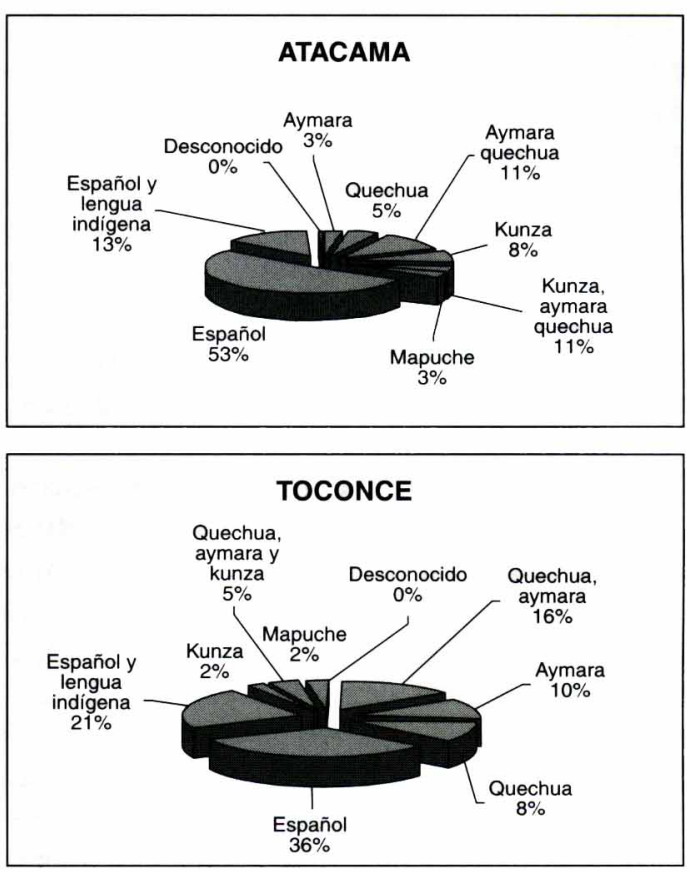

Figura 3. Distribución de las etimologías de los vernáculos en las localidades de Río Grande, Salar de Atacama, Caspana, Toconce y Ollagüe-Collahuasi.

La utilidad de la planta también es una característica usada para nombrar especies, ya sea como forraje para la fauna domesticada y silvestre, o para satisfacer necesidades humanas. El valor forrajero de varias especies queda, por ejemplo, consignado en los nombres como paja vizcachera y pasto de cabra. El valor de algunas plantas para las personas, ya sea como alimento, remedio u otros usos, se expresa en nombres tales como: pingopingo (sano); té y té de burro. Otros usos se expresan en nombres como lejía, léjia o tola lejía, cuya ceniza es usada medicinalmente; quebrolla, por el ruido que hace al ser quemada como combustible; candela o keri, en alusión a las propiedades combustibles; y paja alma, planta ritual en la ceremonia de separación de almas, vinculado con las ceremonias mortuorias. Muchos nombres de especies silvestres, que se parecen a plantas cosmopolitas, con- 
signan este parecido en nombres tales como borraja, alfilla o alfalfilla (de alfalfa), linaza, romarillo (romerillo), maravilla, girasol, garbanzo, algarrobillo, ortiga, cebada, cebadilla o cebadillón.

\section{Comparaciones lingüísticas}

Resulta interesante relatar las afinidades entre los nombres vernaculares obtenidos en nuestro territorio de estudio con los resultados obtenidos en otras áreas de la región. Es así que en Río Grande podemos constatar la existencia de vernáculos característicos del área de Loa Superior, así como también de la del Salar de Atacama, y algunos pocos casos de palabras utilizadas en el altiplano de Iquique. En la Tabla 2 se comparan algunos taxas representativos y los nombres dados en las diferentes localidades. Como puede observarse, coexisten en esta área vernáculos registrados principalmente en el Loa Superior (Aldunate et al. 1981; Villagrán y Castro 1999; Villagrán et al. 1998a) con otros provenientes de los pueblos del Salar de Atacama (Villagrán et al. 1998b), San Pedro, Toconao, Socaire, Talabre, Camar y Peine. Por ejemplo, el caso de Chuquiraga atacamensis que recibe los nombres de chajllampa y lengua de gallo en la $1^{\text {a }}$ Región; candela, lengua de gallina, keri dados en el Alto Loa, y quebraolla y lengua de gallina registrados en el Salar de Atacama. Similar es el caso de las crucíferas de los géneros Sisymbrium y Descurainia, donde aparece el vernáculo chóchar, denominación registrada exclusivamente en el Atacama, y kashawe, kashawi o kashavi, nombres dados tanto en el altiplano de Iquique (Villagrán et al. 1999) como en las Quebradas Altas del Loa; el nombre pasto de cabra es registrado, exclusivamente, para la localidad de Río Grande.

Por otra parte, si se comparan las proporciones de vernáculos en las diferentes lenguas reconocidas en el área (Figura 3), nos encontramos que en el territorio de Río Grande-Machuca el porcentaje de vernáculos en las lenguas indígenas aymara y quechua posee una distribución que se acerca a la registrada en los trabajos del Loa Superior (Toconce y Caspana), con alrededor de un tercio de los nombres, aunque con una mayor proporción de vernáculos españoles que en las demás localidades. Eso se contrasta con la situación del Salar de Atacama, con un claro predominio del español, y donde los términos en lengua indígena alcanzan solamente a un $26 \%$, con una marcada presencia de vocablos de probable etimología kunza. La distribución de lenguas en el territorio Río GrandeMachuca, si bien se encuentra en una situación intermedia entre lo que ocurre en el Salar de Atacama y el Loa Superior, se acercaría más a este último.

\section{Etnocategorías}

Tal como ha sido documentado en otros estudios etnobotánicos de los Andes de la $2^{\text {a }}$ Región de Chile (Aldunate et al. 1981; Villagrán y Castro 1999), las agrupaciones de plantas reconocidas con nombres genéricos o colectivos ("categorías etnogenéricas") se construyen, generalmente, sobre la base del contraste de características morfofisionómicas, ya sea la forma de crecimiento de la planta (agrupaciones por "formas de vida") o la morfología total de la planta (agrupaciones "taxonómicas"). Sin embargo, en el trabajo realizado en el Salar de Atacama (Villagrán et al. 1998b) fueron registradas otras clases de agrupaciones, construidas por referencia a la similitud de algún otro atributo, como el uso que se hace de la planta, lo que fue confirmado en la zona de Río Grande. Por otra parte, uno de los criterios más usados para la distinción de especies es el contraste hembra macho. Este contraste se usa para la distinción entre especies más "femeninas" (e.g. pequeñas, gráciles, blandas, con frutos, etc.) y las más "varoniles" (e.g. más altas, robustas, rígidas, sin frutos, con espinas, etc.). Este es un rasgo muy típico de la etnoclasificación andina y ya ha sido destacado en la literatura de la $2^{\text {a }}$ Región (Aldunate et al. 1981; Villagrán y Castro 1999). Algunos ejemplos de Río Grande-Machuca son: ortiga hembra y macho, básal hembra y macho, koba hembra y macho, lejía macho y lejía hembra, chinchirkoma hembra y macho. A continuación se describen las principales etnocategorías genéricas registradas.

Agrupaciones por formas de vida: $\mathrm{Al}$ igual que en otras localidades se registraron diversos nombres vernaculares que agrupan distintas especies que comparten una misma forma de crecimiento, muchos de éstos ya documentados en la literatura, y con una amplia difusión en el altiplano de la $2^{\text {a }}$ Región (ver Aldunate et al. 1981; Villagrán y Castro 1999). Así, por ejemplo, los nombres tola, tolita o tolilla designan a los arbustos y subarbustos leñosos dominantes en los tolares. También en la 
Tabla 2. Comparación de vernáculos por localidades. Subrayados vernáculos registrados exclusivamente en Río Grande, Negrita vernáculos de Río Grande que aparecen en otras localidades, Negrita y subrayado vernáculos afines a los de Río Grande que aparecen en otras localidades, $\mathrm{n} / \mathrm{c}=$ especie no colectada, s/d = especie sin denominación, * = vernáculo escaso en la zona.

\begin{tabular}{|c|c|c|c|c|c|}
\hline Taxa & Río Grande & Iquique & Toconce & Caspana & Atacama \\
\hline Nostoc sp. & Murmunta, yullucha, chukula, lucha, luche, acholla & chungullu, luche, murmunta & chukula, luche & $n / c$ & n/c (chukula para una Prasiola) \\
\hline Opuntia camachoi & $\begin{array}{l}\text { Puskayo, puskayu, kume, espina de agria, maksa, } \\
\text { espina, kisko, tuna (fruto), tunilla (fruto) }\end{array}$ & $\begin{array}{l}\mathrm{n} / \mathrm{c} \text { (piskayu, tuna, tunilla para Opuntia } \\
\text { sphaerica); (maksa para Arequipa } \\
\text { leucotricha y Browningia candelaris) }\end{array}$ & $\begin{array}{l}\mathrm{n} / \mathrm{c} \text { (espina, espina hembra, espina } \\
\text { de suri, tuna del campo para } \\
\text { Tephrocactus ignescens) }\end{array}$ & q'ome, q'omer, espina, agujilla & kume, tuna, quisco, puskayo \\
\hline Atriplex imbricata & ojala, ojalata, ojalar, kachiyuyo, chókil & piyaya, piyaya macho & $\mathrm{n} / \mathrm{c}$ & ojála, kachiyuyo & ojalar, chókel, chókil, kopakopa macho \\
\hline Atriplex madariagae & Kachiyuyo, ojala & piyaya & cachiyuyo & $n / c$ & $\begin{array}{l}\text { kachiyuyo, kachuyo, kachuyo macho, kórial, yuyo, } \\
\text { chókel, chókil }\end{array}$ \\
\hline Chuquiraga atacamensis & $\begin{array}{l}\text { Chajllampa, candela, lengua de gallo, lengua de } \\
\text { gallina, keri, quebraolla }\end{array}$ & chaklamba, ch'ana, lengua de gallo & $\underline{k i r i}, k e r i$ & $\underline{k}$ 'iri, $k^{\prime}$ 'ri, candela, lengua de gallina & $\begin{array}{l}\text { tajtará, tastará, quebrolla, azafrán, lengua de } \\
\text { gallina, rezongón, killokisca }\end{array}$ \\
\hline Haplopappus rigidus & $\begin{array}{l}\text { Bailahuén, bailabien, guailaven, guailavina, } \\
\text { chejchara, chejchajra }\end{array}$ & $\mathrm{n} / \mathrm{c}$ & $\begin{array}{l}\text { baylahuina, baylahuén, } \\
\text { guaylaven }\end{array}$ & bailawen, bailabien & $\begin{array}{l}\text { bailahuén, bailawela, bailawena, bailavin, } \\
\text { wailawen, wailawin, chajchajra, chajchara, } \\
\text { chejchara }\end{array}$ \\
\hline Parastrephia quadrangularis & $\begin{array}{l}\text { Pulika, tola pulika, koba, itola tara?, chirit' ola, } \\
\text { tolilla, tola amarilla chica, koba hembra, chacha }\end{array}$ & $\begin{array}{l}\text { sipu, siput' ola, siput' ula, siput' ula } \\
\text { hembra, chijarwaya, chijarwaya hembra }\end{array}$ & pulika, leña pulika & $\begin{array}{l}\text { tola amarilla, tola amarga, tola, tolilla, } \\
\text { tola de la cordillera, leña del cerro }\end{array}$ & $\begin{array}{l}\text { chacha, chacha hembra, chacha chica, chacha } \\
\text { fina, chachakoa , koa, tola }\end{array}$ \\
\hline Urmenetea atacamensis & $\begin{array}{l}\text { Kotaro, kotora, tokora, conchita, koka del desierto, } \\
\text { kokakoka }\end{array}$ & $\mathrm{n} / \mathrm{c}$ & $\underline{\text { coquilla, coca del suri }}$ & $\mathrm{n} / \mathrm{c}$ & kótar, kokakora, oreja de ratón, kótaro, kotáro, \\
\hline $\begin{array}{l}\text { Crucíferas de los géneros } \\
\text { Sisymbrium y Descurainia }\end{array}$ & $\begin{array}{l}\text { Chóchar, kashawe, kashawi, kashavi, } \\
\text { pasto de cabra }\end{array}$ & gasabe, qasabi, kasawi, kasawe & kashawi & $\underline{\text { k'asawi }}$ & chuchar, chochar, séber, sébir \\
\hline Lupinus oreophilus & $\begin{array}{l}\text { Kontekonte, kontikonti, kontokonto, qela, kela, lupino, } \\
\text { maravilla, flores }\end{array}$ & q'elaq'ela, q'etoqela, kela, pokopoko & flores del campo & $\begin{array}{l}\text { kontokonto, kontukontu, konte, } \\
\text { kontikonto, salkarai, salqarai, flor } \\
\text { del campo }\end{array}$ & konti, konte, kontikonti \\
\hline Cistanthe salsoloides & Básal, básal macho, básal rosao básal amargo & $\mathrm{n} / \mathrm{c}$ & $\mathrm{n} / \mathrm{c}$ & básal $(\mathrm{n} / \mathrm{c})$ & kámin, kámen, básal, hierba sal \\
\hline Fabiana denudata & Tolilla, tara & $n / c$ & $\begin{array}{l}\text { alma tola, leña de alma, } \\
\text { tara hembra }\end{array}$ & tolilla & tolilla, tablilla, tara hembra \\
\hline Fabiana squamata & $\begin{array}{l}\text { Koba, koa, qoba, pata de perdiz, } \\
\text { koba macho }\end{array}$ & $\begin{array}{l}\text { kipa, orqokipa, kipa macho, } \\
\text { kipat'ola, kipat'ula, orqo kipat'ola, } \\
\text { secrado, llink'i kipa macho }\end{array}$ & $s / d$ & $\begin{array}{l}\text { qoba, q'oba, koba, koba Santiago, koa, } \\
\text { koa Santiago, illakowa, koille }\end{array}$ & n/c (pata de perdiz para Fabiana bryoides) \\
\hline Junellia seriphioides & $\begin{array}{l}\text { Cola de gato cola de michi, vinovino, } \\
\text { cardoncillo, rosas, rosakishka, zarzaparrilla }\end{array}$ & kaylla, berreina & $\underline{\text { rosa }}$ & $\begin{array}{l}\text { comida de llamo (a), } \\
\text { rosa, rosas, vinovino }\end{array}$ & perlilla, perdilla, roseta, cardoncillo, tola \\
\hline Tiquilia atacamensis & Malva, malvilla, alfilla, alfambrilla, alfalfilla & $\mathrm{n} / \mathrm{c}$ & catamasa, jatamasa & $\mathrm{n} / \mathrm{c}$ & káuchal \\
\hline Hoffmannseggia doelli & Mutukuru, motokuro & $n / c$ & $\begin{array}{l}\mathrm{n} / \mathrm{c}(\text { mutucuru, motocoro } H . \\
\text { eremophila) }\end{array}$ & $\underline{\text { motokoro }}$ & $\begin{array}{l}\text { bilankichu, kulchau, kulchao, algarrobilla } \\
\text { mutukuru** }\end{array}$ \\
\hline Krameria lappacea & $\begin{array}{l}\text { Sangrinaria, pegapega, chakachaka, mataratón, } \\
\text { chape, cola de ratón }\end{array}$ & wilakuyo, pegapega, pingopingo & $\begin{array}{l}\text { n/c (chakachaka, mata ratón } \\
\text { Krameria iluka) }\end{array}$ & tikara, chakachaka & $\begin{array}{l}\text { tikara, tikara, tikara hembra, tikara negra, } \\
\text { pegapega, monte morado, monte colorado, monte } \\
\text { negro, te colorado, chakachaka, palo colorado, } \\
\text { chipichapi, cadillo }\end{array}$ \\
\hline
\end{tabular}


zona se utiliza la palabra española monte para designar a esta misma forma de vida. Los nombres colectivos, utilizados en la designación de las formas de vida de los pastos del área de estudio, son usados asimismo en extensas regiones de los Andes. Así, por ejemplo, el nombre de paja, iro o iru, para nombrar a las Gramíneas perennes de los Pajonales; pasto, para agrupar a las especies de hierbas anuales y perennes; grama, para nombrar a las distintas especies de Gramíneas perennes, pequeñas, rastreras y de hoja dura, que conforman el césped de los fondos de quebradas y riberas; cebadilla o cebada, para las Gramíneas anuales pequeñas y malezas predominantes en la época de lluvias.

En cuanto a la vegetación palustre y acuática, los nombres registrados poseen, igualmente, una amplia representatividad en los Andes. Así por ejemplo, el nombre de champa, champita o vega, para designar a las especies pigmeas que conforman cojines en torno a los cursos de agua; unquillo, para las especies palustres de Ciperáceas y Juncáceas de los lugares húmedos de quebradas; loroma, para las especies acuáticas flotantes de Angiospermas; lama o lako, para las especies de Algas Verdes filamentosas; ciénego, nombre genérico para distintas especies de humedal, por relación al hábitat cenagoso donde crecen; y chengua, nombre colectivo para especies palustres.

Agrupaciones por similitud de propiedades: En el Salar de Atacama fue registrada la existencia de agrupaciones de plantas sobre la base de propiedades comunes, ya sea la forma de órganos como las raíces, hojas, flores, inflorescencias, frutos, color o algún otro atributo relacionado con el uso (e.g. sabor, olor, efecto terapéutico, etc.) (Villagrán et al. 1998b). Un ejemplo de este tipo de agrupación es el recogido en Río Grande, donde son denominadas koba hembra y koba macho las especies Parastrephia lucida, P. teretiuscula y Fabiana squamata, todas ellas utilizadas como incienso en las distintas ceremonias.

Agrupaciones "taxonómicas": Finalmente, las especies pueden ser agrupadas por su parecido morfológico general, criterio comúnmente usado en Taxonomía Vegetal. Este tipo de etnocategorías ha sido ampliamente documentado para otras regiones andinas y en la zona de estudio se ha registrado también el uso de etnocategorías ya descritas en la literatura, como el nombre de añawa para las especies arbustivas y espinosas del género Adesmia; espina para las especies de Opuntia; el nombre de malva, malvilla para especies de la familia Malvácea; el nombre de tara para especies de Fabiana; pulika para especies del género Parastrephia; kachiyuyo y ojala para especies del género Atriplex; iloka o iluka para las especies resinosas y sin espinas del género Adesmia; y kontekonte, kontokonto o kontikonti para especies tóxicas de la familia Fabaceae.

\section{Utilización de la flora}

Los resultados del estudio consignan que de las 131 especies de plantas consultadas en Río Grande y Machuca, a 116 de ellas se le asignaron una o más formas de utilización (89\%). En la Figura 4 se muestra la distribución de los distintos tipos de usos de las plantas, sobre una base de 231 usos registrados. Los principales usos registrados son los siguientes: forrajero, 33\%; medicinal, 27\%; alimenticio, 13\%; combustible $9 \%$; construcción y artesanías, $4 \%$; ritual, $3 \%$, y veterinario, ornamental, tintóreo y otros usos $11 \%$. El recurso vegetal en el área de estudio es predominantemente de uso forrajero y medicinal. Resulta interesante destacar el porcentaje relativamente alto de especies comestibles. El resto de los usos se distribuye más o menos equilibradamente, no sobrepasando ninguno de ellos el 9\% del total de usos registrados. También destaca que se registraron 4 especies con uso veterinario (Baccharis boliviensis, Tessaria absinthioides, Fabiana denudata y F. squamata), así como elaborados procedimientos de preparación, lo que dice relación con la importancia que la actividad pastoril tiene en la zona.

Las especies, en su mayoría, tienen uno, dos o tres usos, aunque excepcionalmente hay especies con usos múltiples, destacando aquí la tolilla

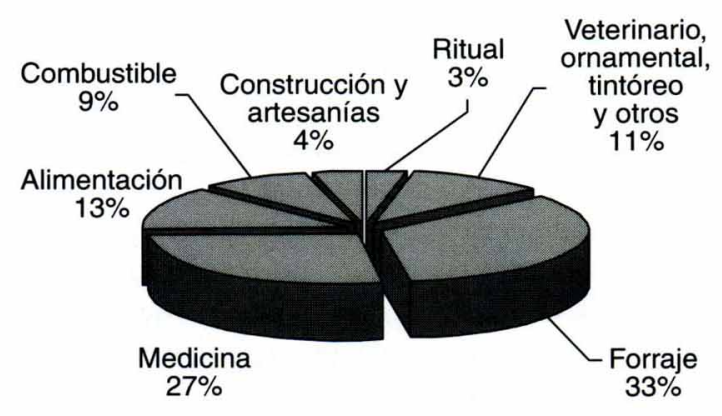

Figura 4. Porcentaje de los distintos rubros de utilización de las plantas, sobre la base de 231 usos registrados. 
(Fabiana denudata) y la cortadera (Cortaderia atacamensis) con 5 usos (ver Anexo 1). Existen tres especies (todas de la familia de las Fabáceas) que fueron calificadas como dañinas para el ganado, a pesar de que pueden ser valoradas en otros aspectos, como el ornamental o medicinal (Lupinus oreophilus, Melilotus indicus, Astragalus cryptanthus).

En cuanto a los usos medicinales de la flora de Río Grande existe toda una concepción de la etiología de las enfermedades que dice relación con las características de las especies medicinales a utilizar. Así, por ejemplo, para todas aquellas enfermedades relacionadas con el frío o "hielo", como, "mal de orines" (enfermedades urinarias), "enfriamiento", "dolores de huesos" (reumáticos), y "dolores de la matriz" (dismenorrea), se recomiendan plantas cálidas "que abrigan" o "hacen calorías", especies como pingopingo (Ephedra breana), kopakopa (Artemisia copa), bailahuén (Haplopappus rigidus), sangrinaria (Krameria lappacea), y la rikarika (Acantholippia deserticola). Existen también plantas frescas como el Schinus molle, capaz de producir "enfriamiento" a las personas que están demasiado tiempo bajo su sombra, aunque es benéfico para ciertos tipos de cultivos que necesitan condiciones más frescas. Otras enfermedades están relacionadas con los desequilibrios de la "yel" (hiel o bilis); por ejemplo, cuando está debilitada y no tiene "fuerza para deshacer los alimentos grasos", es necesario ingerir plantas medicinales muy amargas y fuertes como la chajlampa (Chuquiraga atacamensis) o la sicha (Ombrophytum subterraneum), que sirven para alimentar la hiel; y cuando una persona está enferma de la "yel", con cálculos biliares, es necesario comer los frutos del puskayo (Opuntia camachoi), ya que el fuerte sabor ácido de esta planta disuelve los cálculos.

\section{Discusión}

Desde tiempos prehispánicos, las poblaciones indígenas de la Provincia de El Loa (2 ${ }^{\mathrm{a}}$ Región) han mostrado una dinámica de relaciones que comprende un amplio espacio macrorregional, las subáreas Circumpuneña y Altiplano Meridional, incluyendo territorios de los actuales países de Argentina y Bolivia. Tradicionalmente, la región del Loa Superior fue vinculada a los desarrollos culturales "atacameños". Solamente, a fines de la década de los setenta surgieron evidencias que permitieron sostener que los ocupantes del sitio arqueológico de Likan, en Toconce, procedían de poblaciones originarias de la región de Omasuyo, en la vertiente oriental del lago Titicaca. Pese a esto, esta población altiplánica contenía, entre sus ofrendas funerarias, elementos atacameños (Castro et al. 1979). ¿Se trataría de "atacameños altiplanizados"? ¿Por qué su configuración interna distintiva era tan diferente? ¿Cómo dilucidar este aparente problema de identidades? El hallazgo de varios otros sitios con características similares a Likan, en diversas localidades de la cuenca del río Salado (afluente del Loa), dio luces sobre este dilema, al mostrar claramente la distribución regional alcanzada por esta población. Arqueológicamente, la hemos denominado Fase Toconce, una sociedad de pastores-agricultores que, hacia los años 800 d.C., irrumpen en la prehistoria regional. En nuestro concepto, es "altiplánica" al menos en dos sentidos: en primer lugar, porque sus más remotos orígenes estarían en el altiplano septentrional, a orillas del lago Titicaca. En segundo lugar, porque formó parte de una sociedad cuyo territorio comprendía tanto las quebradas altas del río Salado como la sección meridional del altiplano de Lípez (Castro et al. 1984).

Desde mediados de la década de los ochenta, las investigaciones arqueológicas vienen desechando la supuesta "filiación atacameña" de algunos sitios del Período Intermedio-Tardío en el Loa Superior en favor de una filiación "altiplánica", aspecto que sin duda toca al problema de las identidades. En términos arqueológicos, esta realidad se expresa en un mosaico de fases culturales sincrónicas, cuyas experiencias comparten identidades y diferencias, plasmadas materialmente en sus artes y técnicas (Núñez y Dillehay 1978). En el Loa representan a la población de esta época las Fases Solor y Lasana II, de la Tradición del Desierto; y el Complejo Toconce-Mallku, de la Tradición Altiplánica. El Complejo Lasana agruparía a poblaciones de oasis, como Chiuchiu y Calama, y las localidades de Topain y Turi, situada alrededor de los $3.000 \mathrm{~m}$ en la cuenca del río Salado. Lo más característico de esta fase es que comparte rasgos, tanto de la Tradición del Desierto como de la Altiplánica, con ciertas particularidades. El Complejo Toconce-Mallku representa a las poblaciones de la Tradición Altiplánica, durante el Período Intermedio-Tardío que en la cuenca del Salado se 
inicia hacia los 800 d.C. Sus asentamientos ocupan los territorios situados entre 3.000 y $4.000 \mathrm{~m}$ de altitud, comprendiendo las subregiones de río Salado y río San Pedro, en el sector septentrional de la Provincia de El Loa, y la región de Lípez del Altiplano Meridional, sur de Bolivia.

Con respecto a la filiación étnica de los materiales arqueológicos de la Fase Toconce, y el destino de estas comunidades altiplánicas con posterioridad al arribo de los inkas, debe señalarse que la investigación aún es escasa. Hace más de medio siglo, Hanson (1926) sostuvo que, después de una ocupación "atacameña", se habría asentado en la cuenca del Salado una población "no atacameña" venida de Bolivia, con posterioridad a la llegada de Almagro, la que sería el ancestro de los indígenas quechua o aymara parlantes que residen actualmente en Ayquina, Toconce y Caspana. Su hipótesis es básicamente correcta, por lo menos al identificar un sustrato "atacameño" y una población altiplánica posterior. Pero los predecesores "atacameños" de Hanson seguramente no son los mismos que nosotros consideramos como tales, y que adjudicamos al Complejo Lasana I. Tampoco la población venida de Bolivia arribó inmediatamente después de la llegada de Almagro, como sugiere Hanson, sino que mucho antes, siendo los responsables de los restos arqueológicos que hoy atribuimos a la Fase Toconce. Asimismo, no es seguro que estos últimos constituyan el ancestro de la población indígena moderna, al menos no en un sentido directo, ya que los movimientos de poblaciones producidos durante el Tawantinsuyu, y en la época colonial, originan muchas interrogantes al respecto (Castro et al. 1984).

En efecto, en la medida en que hemos ido accediendo a la información etnohistórica sobre las vecinas provincias de Nor- y Sud-Lípez, estamos menos dispuestos a arriesgar afirmaciones tan categóricas como la de Hanson. Sobre todo, sabiendo que algunas fuentes del siglo XVI hacen referencia no a uno sino a varios grupos étnicos, $\mathrm{y}$ a diversas lenguas, en esas provincias. Por añadidura, se dice que el tronco lingüístico de los habitantes del Omasuyu, la supuesta región de origen de la Fase Toconce, no era el aymara (Lumbreras 1974), sino el pukina (Torero 1970). Desde luego, nunca ha sido fácil visualizar a los complejos arqueológicos en términos de comunidades, etnológicamente identificables. Subsiste en el presente un panorama étnico y lingüístico muy con- fuso en la Subárea Circumpuneña y lo más aconsejable, para el futuro inmediato, es multiplicar las investigaciones en esta dirección. En todo caso, el conjunto de los materiales arqueológicos de la región hacen posible asegurar que hubo lazos constantes entre las diversas poblaciones del Loa, y de éstas con el Altiplano Meridional y el noroeste argentino. En el presente, estos lazos continúan vigentes en términos parentales y de intercambio, en el ámbito de unidades familiares (Castro 1998).

A la luz de los antecedentes expuestos, los resultados de nuestra investigación etnobotánica en Río Grande y Machuca nos permiten destacar dos rasgos relevantes, con relación al problema de las relaciones interculturales. El primer aspecto se desprende del análisis de la nomenclatura botánica, el cual evidencia la importancia diferencial que tienen las lenguas aymara-quechuas versus el español, entre las comunidades atacameñas y las del Loa Superior. Así, considerando el conjunto de los antecedentes que se tienen para la Provincia de El Loa, se percibe una tendencia norte-sur de relevancia creciente de la lengua española, con proporciones de $22 \%$ en el territorio de OllagüeCollahuasi (Villagrán et al. 2001 MS); 36\% y 43\% en el Loa Superior, en Toconce y Caspana, respectivamente (Aldunate et al. 1981; Villagrán y Castro 1999a; Villagrán et al. 1999); en Atacama la proporción asciende a 53\% (Villagrán et al. 1998b), situando a nuestra área de estudio con un $45 \%$ en una posición más cercana a los resultados obtenidos en el Loa Superior. La situación inversa se observa para el componente quechua-aymara, con descenso de su representatividad desde el norte hacia el sur, desde $51 \%$ en Ollagüe, $34 \%$ en Toconce, $27 \%$ en Caspana (proporción muy cercana al $29 \%$ obtenido en este estudio) y descenso abrupto a $19 \%$, en la región del Salar de Atacama. En lo que se refiere a la lengua kunza o atacameña, se observa una tendencia opuesta, con una representación de $13,3 \%$ de vernáculos indígenas de plantas con alguno de sus términos en este idioma en Atacama, en contraste con proporciones entre $7 \%$ y $9 \%$ en el Loa Superior y descenso a 3,6\% en Ollagüe. Además del evidente proceso de hispanización que afecta principalmente a las comunidades de Atacama y de Río Grande, destaca la creciente relevancia de las lenguas aymara-quechua en las localidades del Loa Superior y Río Grande, en comparación con Atacama. Este último rasgo 
acerca a estas comunidades a las altiplánicas de más al norte, en las cuales hasta el $70 \%$ de los vernáculos de plantas provienen de estas lenguas. También la nomenclatura de las plantas del área de estudio está más próxima a la registrada en el Loa Superior que a la de Atacama, como se discutió en los resultados.

El segundo aspecto destacable de este estudio etnobotánico se refiere al ámbito de las plantas ceremoniales. En una esfera tan sensible como la religiosa es significativo resaltar las afinidades entre las plantas rituales utilizadas en Río Grande, Caspana y Atacama. En el caso de la planta ceremonial más importante de los Andes, la koa o koba, en Río Grande es utilizada la misma especie que en Caspana, Fabiana squamata (Villagrán et al. 1999), mientras que en Toconce se utiliza otra especie del género, F. bryoides (Aldunate et al. 1981). Sin embargo, ésta no sería la única koa reconocida en Río Grande, ya que se distinguió también la koa hembra (Parastrephia quadrangularis y $P$. teretiuscula), descrita como "koba simple" y utilizada en los rituales para reemplazar a la $\boldsymbol{k o b a}$, cuando no es posible conseguirla. Es significativo acotar que Parastrephia quadrangularis es la koa o chacha, utilizada en las ceremonias del ciclo anual en el Salar Atacama (Mostny 1954; Munizaga y Gunckel 1958; Serracino et al. 1974; Villagrán et al. 1998b). Otras plantas ceremoniales que conectan a las comunidades del Loa Superior con Río Grande son las usadas en la ceremonia de "separación de almas", con ocasión del fallecimiento de una persona. Así, en Río Grande, durante estas ceremonias se utiliza la tolilla (Fabiana denudata), como también en Caspana y Toconce (alma tola, leña de alma, tara hembra), junto con las plumas de chururo (Phoenicoparrus jamesi) y guano de ratón $\mathbf{a m o}^{2}$. En contraste, en los pueblos del Salar de Atacama la planta utilizada durante este ritual sería la tara macho (Fabiana ramulosa), junto a la paja sikuya y las plumas de tokoko (Phoenicopteris chilensis) (Castro 1986). Por el nombre, probablemente la paja alma (Stipa chrysophylla) también sería utilizada en estos rituales, como se hace en Toconce con esta especie, a saber... "el "yatiri" escoge las ramas más blancas y secas de la especie, las anuda con paja sikuya (Stipa subaristata, Anatherostipa venusta), y con este ramillete limpia a los familiares del difunto. Este rito se desarrolla durante la ceremonia del "lavatorio" y con él se pretende tranquilizar el alma del difunto para que no perturbe a sus parientes" (Aldunate et al. 1981).

Los antecedentes antropológicos y etnográficos publicados son igualmente consistentes con la idea de una más estrecha relación de Río Grande y Machuca con las comunidades del Loa Superior, altiplano y regiones limítrofes. A continuación se presentan varios datos publicados, extraídos de Castro (1997). Así por ejemplo, los apellidos de los difuntos en los cementerios de ambas localidades muestran predominio de apellidos españoles (e.g. Cruz), también con fuerte presencia en Río Salado y territorio de Sud-Lípez. Asimismo, son conspicuos también los apellidos aymara Ayavire, Ansa y Guaca, recurrentes en la subregión de río Salado. Lo mismo sucede con los apelativos aymaras, Condori, Colque y Choque, de amplia dispersión en el altiplano de la I Región y desde la zona de Carangas al sur, por la vertiente oriental. Estos registros refuerzan, aparentemente, la idea de un territorio culturalmente compartido con la subregión de río Salado y Lípez.

Otras situaciones que apoyarían esta relación se refieren a algunos elementos de la cristiandad, que fueron apropiados tempranamente por las poblaciones indígenas, como es el caso de San Santiago, patrono de localidades tales como Uyuni, en Bolivia; Jujuy, en el NW argentino y Toconce, en la subregión de río Salado. Significativamente, Toconce y Río Grande, al norte y al sur de la cuenca del Loa, respectivamente, son los únicos dos pueblos ancestralmente reconocidos como aldeas de alfareros, produciendo cerámica hasta el presente. Además, dentro del circuito que significa la celebración de Limpia de Canales, Río Grande abre e inaugura esta ceremonia, después de la festividad de Santiago en julio, y Toconce la cierra, hacia la segunda semana de octubre. También en el ámbito de la esfera religiosa-ceremonial, en el presente, el anciano yatiri Don Pablo Terán, caspaneño y casado con toconceña, es buscado por gente de Río Grande y otras localidades para realizar las costumbres y sanaciones. Curiosamente, reside casi todo el tiempo en su estancia de Pila, pequeña quebrada en donde confluyen la mayoría de los senderos que van a distintos puntos de la cuenca del Salado y del Loa. En la memoria colectiva, estos senderos articularían estos espacios desde tiempos prehispánicos: "Por todos estos senderos traficaban a los reinka en andas" (Castro 1997). 
Profundizando en el tiempo en estas relaciones interdigitadas, contamos con narraciones sobre los senderos que unen distintos espacios dentro de la cuenca del río Loa. Por referencia al vínculo Río Grande-Caspana, hay concordancia entre diferentes personas de que, desde Caspana, sale un camino con varios ramales, que es del tiempo de los Inka. Uno de esos caminos conectaba Caspana, San Pedro de Atacama, San Juan de Peñaliri y Río Grande, pasando por Lari y Tuina, por nombrar algunos puntos centrales dentro de este recorrido. Aun hasta cerca de la mitad del siglo $\mathrm{XX}$ los caminos antiguos eran limpiados por "minga". Así sucedía con el ramal que conecta Caspana con Santiago de Río Grande. A la comunidad de Caspana "le tocaba limpiar por K'ablor y K'oiller" hacia el lado de Río Grande; se trata de un camino tropero, no muy ancho, que puede transitarse con animales en hilera y también es un camino que fue muy transitado con fines de intercambio. Se usaba, por ejemplo, para viajar desde Caspana a Tatio con yareta para venderla en Calama o San Pedro de Atacama (Castro 1997).

Hasta la actualidad, Río Grande, y naturalmente los comuneros de sus localidades de estancias, como Peñaliri y San Juan, tiene nexos significativos con Caspana. Por años, personas originarias o residentes en Toconce, Caspana y Turi nos han relatado sobre estos nexos (Castro 1997). En cuanto a relaciones con la gente del Salar de Atacama, éstas segregan a las personas de Machuca llamándolos coyas, probablemente orientados por situaciones identitarias surgidas a partir de la creación de la CONADI. En los últimos años, gran parte de los machuqueños han debido asentarse en San Pedro de Atacama, durante el período escolar, y lo hacen en un barrio separado del resto de la población. También discriminan a otros pueblos del Salar, como talabreños, socairinos y de Río Grande, que residen en San Pedro. En este discurso coloquial, sólo los sampedrinos se consideran atacameños. Ello ha generado, dentro de una dinámica interna, una jerarquía social de centro-periferia, en donde los coyas representan a esta última (Rivera 1993).

A la luz de los resultados de la investigación, $\mathrm{y}$ antecedentes reseñados, a nuestra pregunta ini- cial: “¿Dónde se sitúa la transición entre las tradiciones "altiplánica" y "atacameña"?", la respuesta parece ser la postulación de una tercera tradición cultural con interdigitaciones múltiples y que llamaremos, provisoriamente, de las "Quebradas Altas Circumpuneñas". Así, reconocemos ahora con mayor fuerza ciertas singularidades de la población históricamente asentada en San Pedro de Atacama y sus ayllus, como atacameños. Marcados por una vida de oasis, probablemente con una lengua "por sî", una flora nombrada, clasificada y utilizada de manera singular (Villagrán et al. 1998b) y el uso e intercambio preponderante de ciertos recursos muy únicos, como el chañar y el algarrobo (Mostny 1954; Martínez 1998). En el otro extremo, una "Tradición Altiplánica" (sensu strictu) más pura que en el presente y que dentro del territorio chileno estaría mayormente representada en el altiplano de la $1^{\text {a }}$ Región, por una población aymara parlante y con una ganadería de camélidos y alticultivos, como papa y quinoa. Entre ambas, una profunda y muy amplia tradición, también de raigambre altiplánica, distribuida en ambas vertientes de la región circumpuneña, en un territorio culturalmente compartido y situado alrededor de los $3.000 \mathrm{~m}$ de altitud, históricamente con predominio de las lenguas aymara-quechua, construcciones en piedra, dedicación al ganado camélido, a veces casi exclusivamente, desarrollo de la agricultura en terrazas en las quebradas altas. Es la interdigitación cultural lo que parece definirla y marcaría su carácter de transición, en primer lugar para la comunidad de Caspana y por relaciones con ésta, hacia Río Grande, en el caso de estudio. Los orígenes se pierden entre tantas transformaciones a lo largo de la historia. Cada pueblo tiene sus particularidades, incluso en la elección de cómo practican su cristiandad, y el tema de las lenguas por sí solo no define toda una tradición cultural. Hay énfasis diferenciados en el uso y producción de recursos y un modo de habitar el espacio, acorde con las condiciones físicas de cada territorio. Nos enfrentamos una vez más a esta unidad en la diversidad de las culturas andinas, que no permite ser categórico por la vía de la definición, sino más bien incita a la búsqueda de sutilezas, para encontrar las diferencias. 


\section{ANEXO 1}

\section{CATÁLOGO SISTEMÁTICO E INFORMACIÓN ETNOBOTÁNICA DE LAS ESPECIES VEGETALES COLECTADAS EN EL TRANSECTO SAN PEDRO DE ATACAMA-MACHUCA-RÍO GRANDE-CERRO JORQUERAL, $2^{\text {a }}$ REGIÓN, CHILE}

Las especies han sido agrupadas en grandes categorías sistemáticas (Criptógamas (Algas), Gimnospermas, Angiospermas-Dicotiledóneas y AngiospermasMonocotiledóneas). Dentro de cada uno de estos grupos, las Familias, Géneros y Especies se ordenaron alfabéticamente. Se han escrito con negrita los nombres vernaculares correspondientes a plantas. Se destacan con asterisco $(*)$ las especies cosmopolitas e introducidas, sean cultivadas o malezas. Con doble asterisco (**), las malezas originarias de Sudamérica. La información de cada especie se ha organizado de la siguiente manera:

1. Número de la especie en el catálogo. Sigue el nombre científico, autor y familia. A continuación, se proporcionan los números de colección correspondientes al Herbario de C. Villagrán (depositado en la Facultad de Ciencias de la Universidad de Chile, con duplicados en el Herbario de la Universidad de Concepción). Además, se cita el número de referencia de los muestrarios de plantas (Cuadernos 1 y 2) utilizados en las entrevistas etnobotánicas.

2. Nombres vernaculares con que se conoce a la especie, de acuerdo a las entrevistas realizadas en Río Grande.

3. Usos asignados a la flora del territorio de estudio: forrajero, medicinal, alimenticio, combustible, construcción, artesanía, ritual, veterinario, ornamental, tintóreo y otros.

4. Información etnobotánica de acuerdo a las entrevistas realizadas en este estudio. Se proporciona información etnobotánica adicional del territorio de estudio, procedente de Guatín, con la sigla SSL (Serracino et al. 1974).

5. Etimologías de los nombres vernaculares con siglas para los idiomas involucrados y citas de los diccionarios consultados. Claves correspondientes a las lenguas involucradas $(\mathrm{A}=$ aymara; $\mathrm{Q}=$ quechua; $\mathrm{M}=$ mapuche; $\mathrm{E}=$ español; $\mathrm{K}=$ kunza; $\mathrm{O}=$ otras lenguas americanas) y los diccionarios consultados: Albó = Albó (1988); Ba = Ballón et al. (1992); B = Bertonio (1612); $\mathrm{Ca}=$ Cárdenas (1989); JC $=\mathrm{J}$. Corominas (1973); C = Cusihuamán (1976); $\mathrm{DL}=$ De Lucca (1987); DT = Manual Trilingüe, Editorial Mercurio (1981); G = Girault; GH = González Holguín (1952); LE = Lehnert (1994); L = Lenz (1910); Li = Lira (1945); M = Mösbach (1992); MA = Martín Alonso (1981); MLQ = Manual de la Lengua Quechua al Castellano, Editorial Mercurio (1981); $\mathrm{Mu}=$ Munizaga y Gunckel (1958); Pe =
Perroud (1970); DRAE = Diccionario Real Academia Española (eds. 1970 y 1992, vol I y II); R = Antonio Ricardo (1951); SR = San Román (1890); $\mathrm{SO}=$ Soukup (1970); $\mathrm{Sch}=$ Schuller $(1908) ; \mathrm{T}=$ Torero (1982); V = Vaisse et al. (1896).

\section{ALGAS (CRIPTÓGAMAS)}

1) Nostoc sp., CYANOP, 9506, Cuaderno $2 \mathrm{~N}^{\circ} 28$ murmunta, yullucha, chukula, lucha, luche, acholla alimenticio

Los vernáculos señalados a continuación corresponden a nombres propios de esta importante especie alga verde-azulada comestible: murmunta (probablemente derivado de su morfología, hábitat y uso), yullucha (nombre registrado exclusivamente en Río Grande), chukula (nombre atacameño), y acholla (probable alusión metafórica a su forma de crecimiento como talo esférico). El nombre luche y su variante lucha, es un símil con un alga roja, marina y comestible (Porphyra columbina). Planta alimenticia, cocinada en cazuela.

Etimología: Murmunta, A, Q. En aymara, murmuta, chuncuro, yerba de las ciénagas como granillos negros (B (2): 228); buñuelos o tortillas de quinoa, a semejanza de un bonete de clérigo (Ibid.); murmu, liso, ni muy delgado ni muy grueso (Ibid.). En quechua, murmu, tubérculo pequeño, tubérculos de la papa, olluco y mashua que tienen una dimensión menor que los huevos de gallina y se destinan a la deshidratación (Ba: 153); murmunta, señal de carestía, alga comestible que aparece en las orillas del lago Titicaca cuya abundancia anuncia un año de sequía, hambre y miseria en la población del altiplano (Ba: 170); murmuntu, las ovas que crían, uvillas de comer (GH (1): 251). Yullucha, A. De llullu, vocablo aymara usado para referirse a formas vegetales que empiezan a desarrollarse o que se pasman, como, por ejemplo, llullu amca, papa pequeñita que aún no ha crecido; llullu tonco, maíz pequeñito que no llega a su crecimiento y se queda así (B (2): 208). Yuyu, aymara, planta acuática comestible (Albó: 607). Chukula, K. Nombre atacameño de la cianobacteria comestible Nostoc. Tchuckula, kunza, planta acuática que hay en la cordillera (V: 34). Tchuckula, kunza, luche (LE: 35). Luche, M. Símil con un alga roja, marina y comestible (Porphyra columbina) para designar a un alga verde-azulada de agua dulce, también comestible (Nostoc). Luche, un alga comestible. Mapuche, yerba del mar que se come (L: 439). Luche, voz araucana, alga marina comestible (DRAE: 815). Lucha, M. Variante de luche. Acholla, A, Q. Achulla, en aymara, ratón grande (B (2): 7). Hachu, la coca mascada que echan en la boca (B (2): 
108). Hakhchu, unas como cebollitas con que las indias curan sus cabellos para que no se enmarañen (B (2): 109). Achoqlla quechua, comadreja (Pe (2): 2).

\section{2) Cladophora glomerata (L.) Kützing, CHLORO, 9507,} Cuaderno $2 \mathrm{~N}^{\circ} 1 \mathrm{a}$

lako, lakolako, flor de agua, lama, lucha forraje

Lako, lakolako y lama son nombres genéricos para especies de algas verdes y filamentosas que cubren la superficie de ríos y riachuelos. Flor de agua es un nombre genérico para diminutas especies acuáticas y flotantes. Etimología: Lako, Q, A, K. Lakho, quechua, correspondería a las algas verdes del género Cladophora (G: 96). Laqhu, quechua, alga comestible que crece en los lagos (Ba: 168). En el Lago Titicaca, el repliegue del alga significa año con escasa lluvia, es señal de sequía o lluvia (Ba: 267). Lako, aymara, ovas de la laguna, o yerba verde como estopa, o lana, y suelen comerla en locros (B (2): 187). Lacko, kunza, una planta acuática en las lagunas y ríos de la cordillera (V: 24; LE: 40). Lakolako, Q, A, K. Variante de lako. Lama, E. Lama, mapuche moderno, tejido de lana, generalmente negro, cubierto de flecos largos en toda su extensión (L: 421, 422). Del latín, lama, cieno blando, suelto y pegajoso, de color oscuro, que se halla en algunos lugares del fondo del mar o de los ríos, y en el de los recipientes o lugares donde hay o ha habido agua por largo tiempo. Otra acepción es: alga u ova de los lamedales o charcales. En Colombia, Chile y Honduras, capa de plantas criptógamas que se cría en las aguas dulces. En Colombia, Chile, Honduras, México y Puerto Rico, musgo, planta Briófita. En Bolivia, Colombia y México, moho, cardenillo (DRAE: 1225). Flor de agua, E. Lucha, M. Variante de luche, ver 1 .

3) Enteromorpha intestinalis (L.) Link, CHLORO, 9509, Cuaderno $2 \mathrm{~N}^{\circ} 1 \mathrm{~b}$

lako, lakolako, flor de agua, lama, lucha

forraje

Etimología: Lako y lakolako Q, A, K;. Ver 2. Flor de agua E. Ver 2. Lama, E. Ver 1.

Lucha, M., Variante de luche, ver 1.

\section{GIMNOSPERMAS}

4) Ephedra breana Phil., EPHEDR, 9491, Cuaderno 1 $\mathrm{N}^{\circ} 1$

\section{pingopingo, tume}

forraje, medicinal, alimenticio, combustible y otros usos. En los Andes, pingopingo es el nombre genérico para las especies de Ephedra, mientras que tume también es la denominación para este género en la zona del Alto Loa. La especie consultada corresponde al pingopingo macho, existiendo una planta macho y una hembra. La hembra es más fina y da los frutos más espaciados. Cuando llueve "carga mucho" (da muchos frutos). Es forraje y también medicina para el dolor de estómago de los niños; remedio para la anemia, dolor de espalda, tos y resfrío. Para pasado de frío (mal de orines), "hielo", la planta abriga. El fruto se come, es como granada (por su color rojo). Es el principal combustible de Río Grande y se utiliza seca. También se la lleva a vender a Calama. Serracino et al. (1974) citan para Guatín a $E$. andina con el nombre pingo-pingo y cuya raíz se utilizaría como remedio para la vesícula.

Etimología: Pingopingo, Q, A. Pinco pinco (sano sano): aymara, yerba buena para desecar las flemas (B (2): 308). De acuerdo a Rosales: yerba de media vara de alto que ni echa flor, ni hojas ni semilla (L: 1097). Pingopingo: un arbusto sin hojas que crece en las cordilleras de todo el país. Ephedra spec (L: 600). Pingopingo. Chile. Arbusto de la familia de las Efedráceas con flores pequeñas, y por fruto unas nuececitas que, así como sus hojas son diuréticas y depurativas (DRAE: 1604, 1605). Tume, A, Q. Tumi, aymara, cuchillo de los indios, al modo de aquel que usan los zapateros (B (2): 364). Tumi, quechua, cuchillo de cobre, podía servir de cuchillo ritual o para cortar el cuero en zapatería (Pe (2): 175).

\section{ANGIOSPERMAS DICOTILEDÓNEAS \\ 5) Schinus molle var. areira (L.) DL., ANACAR, 9540, Cuaderno $2 \mathrm{~N}^{\circ} 25$ \\ molle, pimiento}

medicinal, combustible y construcción

El vernáculo molle corresponde al nombre propio de este abundante árbol de los subtrópicos de Sudamérica, también denominado pimiento, por la similitud de sus frutos con los de una planta cultivada como aliño (la pimienta). Es un árbol "aireoso", esto quiere decir helado, ya que produce enfriamientos a la gente que se descuida y se pone a su sombra; por esta misma cualidad, también es buena para el ajo, el cual crece bien junto al pimiento, mientras que otros cultivos no. Medicinal para el dolor de estómago. Buena leña para hacer pan. Para hacer ramadas, da sombra. Algunos entrevistados señalaron que el pimiento y molle serían dos plantas distintas: el primero tendría la hoja más grande que el segundo. Esta distinción se corresponde con la información etnobotánica de otras regiones andinas, en que se reconocen dos formas para la especie.

Etimología: Molle, Q. Nombre propio de una importante especie de un grande y hermoso árbol del Perú y del norte de Chile, cultivado también en el centro, donde se denomina pimiento, Schinus molle. Molli, quechua, nombre de un árbol de los valles de madera dura; de las pepitas negras de la fruta se prepara una bebida fermentada. Mulli (molli): nombre de un árbol cuya fruta infundida con agua se usa contra los males de la vejiga (L: 510, 511). Molle, del quechua molli, árbol de mediano tamaño de la familia de las Anacardiáceas, propio de América Central y Meridional, con hojas fragantes y frutos rojizos; su corteza y resina se estiman como nervina y antiespasmódicas. El mismo nombre se aplica a otro árbol de la misma familia en Bolivia, Ecuador y Perú cuyos frutos se emplean para fabricar una especie de chicha (DRAE: 1391). 
Molle, voz quechua y vulgar de un hermoso árbol del Perú de la familia de las Anacardiáceas (Schinus molle L.). Pimiento, E. Del latín, pigmentum, color para pintar. Planta herbácea anual de la familia de las Solanáceas, de fruto rojo y amarillo. El fruto es usado como alimento por su sabor, picante en algunas variedades (DRAE: 1803).

6) *Apium graveolens L., APIACE, sin número de herbario, Cuaderno $2 \mathrm{~N}^{\circ} 43$

apio

\section{alimenticio}

Hortaliza usada para complementar la cazuela. También se bebe en infusión.

Etimología: Apio, E. Del latín apium. Planta de la familia de las Umbelíferas; aporcado es comestible (DRAE: 167).

7) Azorella compacta Phil., APIACE, 9556, Cuaderno 1 $\mathrm{N}^{\circ} 30$

yareta, yaretawaqa (resina)

medicinal y combustible

Yareta es el nombre propio de este conspicuo cojín de los Andes de Chile; yaretawaqa, "llanto de yareta", nombre metafórico asignado a la resina de la planta, consignando su flujo (como lágrima) por la superficie del cojín. La palabra waka, tanto en aymara como en quechua, tiene múltiples significados, siendo el principal su referencia a lo sagrado. Esta significación esencial tiene sentido de acuerdo al valor que se le asigna a la resina de la yareta en contextos ceremoniales, en donde se la usa como incienso y, probablemente, por sus usos medicinales. Medicinalmente, la raíz se utiliza para la diabetes. También la raíz sería buena para las dolencias propias de las mujeres y, además para la tos, combinada con el chukikan (Mulinum crassifolium) y la chachakoma (Senecio nutans). La resina es utilizada como sahumerio y también sirve para dolor de huesos, hinchazones, e hígado. La resina, usada como parche, sirve para el dolor de espalda y es encargada mucho por estos importantes usos. Siendo un excelente combustible, antiguamente la vendían mucho para ser utilizada en las calderas en Calama y Chuquicamata.

Etimología: Yareta, Q, A. Del quechua yarita (Li: 1184). Yarita, yareta, quechua, vegetal punero, que es una hierba forrajera de primera clase para el ganado alpacunero. Se emplea como un excelente combustible en la cocina arequipeña. Es barbarismo decir llareta (Li: 1184). Yareta, yaretilla, voces americanas de procedencia discutida (M: 98). Yarita, aymara, resina de la puna (B (2): 412). Llareta, nombre vulgar de varias Umbelíferas de la cordillera en cojines (L: 447). Barba (citado por Lenz) llama llareta al estiércol de carneros de la tierra (llamas) que se usa para combustible, también señala que la yareta es un excelente combustible, el único que se usa en la puna de Atacama, lo que puede explicar la definición anterior (L: 880). Llareta, plan- ta de Chile de la familia de las Umbelíferas, de hojas sencillas, enteras y oblongas; destila de su tallo una resina transparente de olor agradable, que se usa como estimulante estomacal y también para curar heridas (DRAE: 1280). Yaretawaqa, Q, A. Del aymara, huacani, llorar, ladrar, sonar la campana, cantar las aves, gañir, chillar (R: 45). Waka, quechua. "Toda clase de ídolos, santuarios, cosas extrañas reverenciadas por los indígenas" (Pe (2): 186). Wakka, quechua, lloro, llanto, lágrimas (Li: 1080).

8) *Daucus carota L., APIACE, sin número de herbario, Cuaderno $2 \mathrm{~N}^{\circ} 70$

\section{zanahoria}

alimenticio

Hortaliza plantada en las huertas.

Etimología: Zanahoria. E. Nombre español derivado del árabe de esta importante hortaliza (DRAE: 2122).

9) *Foeniculum vulgare Miller, APIACE, sin número de herbario, Cuaderno $2 \mathrm{~N}^{\circ} 75$

\section{hinojo}

alimenticio

Nombre propio de esta planta introducida. Se toma como té.

Etimología: Hinojo, E. Del latín, fenuculum. Planta herbácea de la familia de las Umbelíferas; toda la planta es aromática, de sabor dulce, y se usa en medicina y como condimento (DRAE: 1110).

10) Lilaeopsis macloviana (Gand.) A.W. Hill, APIACE, 9565, 9498, Cuaderno $2 \mathrm{~N}^{\circ} 12,29$

chengua, vega, ¿wiskayu o iskayu?

forraje y alimenticio

Chengua y vega son nombres colectivos para pequeñas especies palustres, en general. Los nombres propios wiskayo o iskayo han sido registrados hasta el momento solamente en Río Grande; pudiera estar relacionado con sus rizomas, ya sea por con su forma alargada, como soga, o con la multiplicación de varias plantitas erectas a partir de sus rizomas. Se hizo una distinción entre dos formas de esta especie, una de hoja ancha que corresponde al ejemplar mostrado, y otra de hojas más angostas. Forraje. Las raíces dulces son comestibles.

Etimología: Chengua, Q. Chingua. Probablemente una variante local de la palabra quechua: quinua, quinoa, Chenopodium quinoa (L: 414). Vega, E. Vega, del ibérico vaica. Parte de tierra, baja, llana y fértil. En Chile, terreno muy húmedo (DRAE: 2065). Wiskayu, Q. Wiskayu, de wichayo, quechua. "Planta coparidácea, antiespasmódica e hipnóptica" (Li: 1142). Wiska, aymara, soga hecha con lana de llama. Wiskhalla, largo, que tiene cierta longitud, prolongado, dilatado, oblongo, más largo que ancho. Wiskullu, ovalado, más largo que ancho (DL (1): 174). Iskayu, Q, A. Iskayu, de iskay, quechua, dos, uno más uno (Li: 287). Iskallu, revesero, falso, doble (Li: 288). Jisk'a, aymara, corto, de poca extensión, chico, pequeño, diminuto (DL (1): 75). 
11) Mulinum crassifolium Phil., APIACE, 9552, Cuaderno $1 \mathrm{~N}^{\circ} 27$

chuchikandia, chukikaña, chukukaylla, chukikanlla, chukikan, chuchikaylla

medicinal

Chukikandia y sus variantes es el nombre de este importante arbusto medicinal. Remedio utilizado para la tos, el resfrío, diabetes y para los nervios, "cuando la persona es rabiosa" (para los nervios). La planta se tuesta y se hierve, agregándose enseguida azúcar tostada o miel de abeja, ya que es amarga. También se puede preparar con leche. Se mezcla con bailahuén (Haplopappus rigidus) para la tos. En San Pedro de Atacama la compran.

Etimología: Chuchikandia, Q. Chukikanlla, quechua, planta sudorífica que ostenta espolines ganchudos en el tallo (Li: 138). En quechua, chuuqui, lanza (GH (1): 122). Kanlla, aymara, espina (Ca: 279). Chukikan, chukikaña, chukukaylla, chukikanlla, chuchikaylla. Q. Variantes de chuchikandia.

12) Ombrophytum subterraneum (Aspl.) B. Hansen, BALANO, no se colectó

sicha

medicinal y ritual

Especie mencionada por los entrevistados y no coleccionada por nosotras en esta área de estudio. Es buena para la vesícula, cuando la "yel (hiel) está debilitada". "La yel hay que alimentarla con cosas fuertes; la sicha sirve para alimentar la yel, para que tenga fuerza para deshacer los alimentos grasos, ya que cuando éstos no se pueden disolver es cuando se forman las piedras (cálculos biliares)". La harina resultante de la molienda de la sicha se usa también para los "pagos"3 . De acuerdo a Lagos et al. (1995-1996) se denomina chuya-passia en Río Grande a la harina confecionada con la sicha, utilizada en la chuya $\boldsymbol{a}^{4}$ del floreo.

Etimología: Sicha, Q. Quechua, ciça, flora, todo lleno de flores; ciçani ciçamuni, florecer, hechar flores; ciça ciça pampa, campo florido; ciça chantascca, ramillete (GH (1): 82). Aymara, sicha mayu, descuidado, andrajoso (B (2): 315).

13) Tiquilia atacamensis (Phil.) A.T. Richardson, BORAGI, 9485, Cuaderno $1 \mathrm{~N}^{\circ} 7$

malva, malvilla, alfilla, alfambrilla, alfalfilla

forraje, alimenticio y ¿medicinal?

Cuando llueve, la planta conforma extensas alfombras $\mathrm{y}$, probablemente, de ahí se desprende el vernáculo alfambrilla para la especie. Es forraje, cuando aparece con las lluvias. Su raíz es dulce y, probablemente, comestible. Aparentemente, algunas personas confundieron a la planta con la viravira (especies de Gnaphalium) y la borraja (¿Lactuca serriola o Sonchus asper?), por el color plomo de la especie consultada. Los que la llamaron viravira le atribuyeron uso medicinal como mate. Para la presunta borraja se asignó uso medicinal para el resfrío y la fiebre.
Etimología: Malva, E. Del latín, malva. Planta muy abundante, de la familia de la Malváceas con flores moradas, es usada en medicina por el mucílago que contiene las hojas y las flores (DRAE: 1300). Malvilla, E. Diminutivo de malva. Alfilla, E. La palabra es derivada de alfalfa. Alfambrilla, E. Palabra que deriva de alfombra. Alfalfilla, E. Palabra derivada de alfalfa.

\section{4) Cactaceae sp. 1, CACTAC, no se colectó cardón chico \\ alimenticio}

Especie mencionada por las personas, pero no observada por nosotras. Tiene la espina fina y da una pasakana rosada, de buen sabor. No tenemos claridad con respecto a la especie correspondiente a este cardón chico, muchas veces citado por las personas. El cardón grande es Echinopsis atacamensis. También se nos mencionó acerca de la existencia de un cactus delgadito de nombre kopao.

Etimología: Cardón chico, E. Símil con el cardón, pero más pequeño, ver 16 .

15) Cactaceae sp. 2, CACTAC, sin número de herbario, Cuaderno $1 \mathrm{~N}^{\circ} 8 \mathrm{~b}$

cardón, kewayllo, cardón de espina, pasakana (fruto) medicinal, alimenticio y artesanía

El nombre propio kewayllo ha sido registrado sólo en Río Grande, para una Cactácea con largos pelos y comestible, probablemente, Echinopsis. Esta especie de cactácea, que no hemos podido determinar, fue colectada en la Quebrada de Río Grande y "tiene pelos como de abuelitos". Sería buena para la fiebre. Se come la pulpa y su sabor sería igual que un melón. Tiene una fruta como "sigra" ( $i$ ?), ácida, buena para comerla, de color verde. Las espinas se utilizan para tejer y la lana (pelos) para hacer pinceles.

Etimología: Cardón, E. Ver 16.

Kewayllo, A, Q. Qhuehuayllo, aymara, la yerba que llaman cerrajas, o semejante a ella (B (2): 292). Quihuayllo, quechua, la yerba que seca se pega a la ropa y verde es de comer ( $\mathrm{GH}$ (1): 308). Cardón de espina, E. Ver cardón (16). Pasakana, ¿Q?, ¿A?

16) Echinopsis atacamensis (Phil.) Fiedrich et G.D. Rowley, CACTAC, sin número de herbario, Cuaderno 1 $\mathrm{N}^{\circ} 8 \mathrm{a}$ cardón, kisko, kewayllo, captus, pasakana (fruto) alimenticio, construcción y artesanía

Cardón y pasakana son nombres de las especies más conspicuas de Cactáceas, aquellas de grandes formas columnares. Este es el cardón grande y da pasakanas verdes, mejores que las del cardón chico (ver taxa anterior), aunque son más difíciles de sacar. Se utiliza en construcción en las techumbres, puertas y vigas de los techos. Aún se conservan los techos de las casas antiguas, construidos de cardón. De la madera también se hacen artesanías, como lámparas y otras. Los entrevistados insisten sobre la existencia de varias clases de car- 
dón. Por ejemplo, algunos pequeños que dan frutos verdes, como la pera, y le dicen pasakana; otros que crecen con hartos brazos laterales y con pelos, usados para agujas de tejer (ver Cactaceae sp. 2). Existiría también un cardón blanco que da una pasakana blanca.

Etimología: Cardón, E. Aumentativo de la palabra castellana cardo, proveniente del latín, cardus, plantas con cuerpos espinosos de la familia Compuestas. En Argentina, especie de cacto gigante que sirve para setos espinosos y como planta forrajera (DRAE: 412). Kisko, Q. Quisco, derivado del quechua quichca, la espina (GH (1): 307). Middendorf anota para quisca, espinas grandes de las especies de Cactáceas y quisca, la espina (L: 675). Quisca, del quechua quichca, espina. Quisco, en Chile, especie de cactos espinoso que crecen en forma de cirio cubierto de espinas, que alcanza más de treinta centímetros de largo. Kichka, quechua, broza espinosa, quepo, espina; también cabello lacio y tieso (Ba: 124). Quisco, palabra quechua, derivada de quisca cualquier cosa provista de espinas o púas; denomina en Chile a numerosas especies de género Cereus (M: 94). Captus, E. Variante de cactus, español, del latín cactos y éste del griego (hoja espinosa), planta de la familia de las Cactáceas, procedente de México, con tallo globoso provisto de costillas y grandes surcos meridianos y con grandes flores amarillas (DRAE: 220). Kewayllo, A, Q. Ver 15. Pasakana, ¿Q?, ¿A? En Bolivia se conocen como pasakanas varias especies de Trichocereus con frutos comestibles (Ca: 182,183).

17) Opuntia camachoi Espinosa, CACTAC, 9511, Cuaderno $1 \mathrm{~N}^{\circ} 2 \mathrm{a}$

puskayo, puskayu, kume, espina de agria, maksa, espina, kisko, agria (fruto), tuna (fruto), tunilla (fruto) medicinal y alimenticio

Los nombres puskayo y puskayu corresponden a denominaciones colectivas para las Cactáceas altoandinas con frutos comestibles y que conforman grandes cojines (especies de Opuntia) registrados en la $1^{\mathrm{a}}$ y $2^{\mathrm{a}}$ Región, mientras que kume es el nombre para este mismo género en el Salar de Atacama. Al fruto se le denomina agria (por su sabor ácido), tuna o tunilla. Es medicinal, ácido y bueno para la fiebre. Para usarlo como remedio se estruja la pulpa del fruto en un jarro y se le agrega agua y azúcar. La pulpa, disuelta en agua con azúcar, se puede tomar también como limonada. Se toma "cuando la persona cría piedras en el hígado, está enfermo de la yel con dolor", entonces se debe comer en ayunas, durante seis días. Limpia, porque su ácido es muy fuerte.

Etimología: Puskayo, Q, A. Según un informante, significaría cactus en aymara. Puede ser deformación de sankayu, nombre de Cactáceas espinosas. En aymara, sankayo, la frutilla del hachacana, que es una mata espinosa, es agria y buena de comer (B (2): 308). En quechua, en la provincia de Puno, sank'ayu, espina (C: 234); çanka, el paladar y el gangoso (GH (1): 78). Puskayu, Q, ¿A? Variante de puskayo. Kume, ¿K? Ckummi planta que parece de la familia de las tunas (V: 21). Ckumi, látigo, penca (V: 21). Espina y espina de agria, E. del español. Agria, del español agrio. Maksa, A. Los nombres de maksa y makso son genéricos para los frutos de las grandes Cactáceas columnares del desierto (e.g. Browningia y Arequipa) y parecieran aludir al sabor de los mismos. Su equivalente castellano sería tunilla. Maxa, aymara, arpón o caña para pescar (DL: 111). Moxsa, aymara, azucarado, dulce; delicioso, muy agradable; suave (DL: 113). Mokhsa, aymara, sabroso. Mokhsa mokhsa, aymara, sabor (Be (1): 419). Tuna, O. Palabra de origen taíno. Fruto del candelabro, planta cactácea (DRAE: 2038). Voz caribe que designa en Chile a una cactácea cultivada (Opuntia vulgaris Hill.), juntamente con su fruto comestible (M: 94). Tunilla, E, O. Diminutivo de tuna.

18) Opuntia sp., CACTAC, 9510, Cuaderno $1 \mathrm{~N}^{\circ} 2 \mathrm{~b}$ espina del agria chiquitita, tuna de burro, espina medicinal

Este cactus es parecido al anterior pero tiene los artículos más pequeños y las espinas más cortas y ralas. Tendría una raíz engrosada, una especie de papa gruesa y blanca, parecida a la sicha pero más "secarroncita", menos jugosa, que se come para que "limpie por dentro”. Sería comida del suri (avestruz).

Etimología: Espina de agria chiquitita, E. Un tipo de espina de agria. Ver 17.

Tuna de burro, E. Un tipo de tuna. Ver 17. Espina, E. Denominación genérica dada a las plantas con espinas. Ver 17.

19) Hoffmanseggia doelli Phil., CAESAL, 9544, Cuaderno $2 \mathrm{~N}^{\circ} 20$

\section{mutukuru, motokuro}

forraje y alimenticio

Las palabras mutukuru y motokuro son nombres propios de esta planta. La gente destacó que la especie se parece al algarrobo, por la vaina. Forraje. Su "fruto" (papa) es dulce y se come.

Etimología: Mutukuru, A, Q. Nombre propio de Hoffmanseggia doellii, plantita silvestre que invade los cultivos. En aymara, mutu, arbolillo de alcaparras de esta tierra; buñuelos o tortillas de quinoa a semejanza de un bonete de clérigo (B (2): 228). En quechua, mutu, desorejado (R: 63); mutu, orejas, o cuernos pequeños, o por no haber acabado de nacer o por estar cortados (GH (1): 253). Mutuy (salliwa), quechua, sallihua, señal de buena cosecha, planta silvestre cuya abundancia de flores es interpretada como anuncio de buena producción de habas y cebada (Ba: 170-174). Qurur, quechua, ovillos (GH (1), I: 56). Qura, quechua, broza, mala hierba para los cultivos en general, pero puede ser útil como forraje para el ganado (Ba: 128-129). Motokuro, A, Q. Variante de mutukuru.

20) Lobelia oligophylla (Wedd.) Lammers., CAMPAN, 9503, Cuaderno $2 \mathrm{~N}^{\circ} 5$

unquillo, ciénego

sin uso reconocido 
Ciénego es nombre genérico para distintas especies de humedal, aludiendo al hábitat cenagoso donde crecen. Etimología: Unquillo, E. Variante de junquillo. Nombre genérico para especies del género Juncus y otras especies palustres de apariencia similar. Junquillo, derivado del castellano junco (M: 67). Junquillo, español, de junco (del latín juncus) (DRAE: 775). Ciénego, E. Del español ciénaga.

21) *Cannabis sativa L., CANNAB, Sin número de herbario, Cuaderno $2 \mathrm{~N}^{\circ} 73$

¿payko?

sin uso reconocido

Se trata del cáñamo que proporciona la marihuana, plantado en una huerta de Río Grande. Probablemente, el nombre payko sea una confusión con Chenopodium ambrosioides, especie medicinal también plantada en las huertas y, además, de crecimiento espontáneo.

Etimología: Payko, Q. Ver 37.

22) Arenaria serpens Kunth, CARYOP, 9570, Cuaderno $2 \mathrm{~N}^{\circ} 34$

vega, ¿linaza?

¿medicinal?

El nombre de linaza, buena para la fiebre, puede ser una confusión con Linum usitatissimum, usada medicinalmente.

Etimología: Vega, E. Ver 10.

Linaza, E. Nombre específico del lino y de su semilla (DRAE: 1260).

23) Pycnophyllum bryoides (Phil.) Rohrb., CARYOP, 9532, Cuaderno $1 \mathrm{~N}^{\circ} 32$

yaretilla

forraje

Yaretilla es diminutivo castellanizado de yareta y usado en el área andina para designar cojines blandos y pequeños de distintos grupos taxonómicos. Comida de la vizcacha. El ganado lo come poco.

Etimología: Yaretilla, Q, A, E. Diminutivo castellanizado de yareta. Ver 7 .

24) Atriplex imbricata (Moq.) D. Dietr., CHENOP, 9487, Cuaderno $1 \mathrm{~N}^{\circ} 5$

ojala, ojalata, ojalar, kachiyuyo, chókil

forraje, combustible y otros usos

Los nombres ojala, ojalata y ojalar poseen significado oscuro; esta misma planta en la $1^{\text {a }}$ Región se llama piyaya, que significa ojal, agujero. Pareciera que el término consigna su crecimiento en hondonadas y quebradas. Mientras que el vocablo kachiyuyo, que significa hierba de la sal, alude a los hábitats de salares donde abunda la planta. Mientras que el nombre chókel es la denominación atacameña de las especies del género Atriplex. Es más amargo que el kachiyuyo. Este forraje es apreciado porque, aunque no llueva, se mantiene disponible para los animales. Se le atribuyen cualidades nutritivas debido a su sabor salado. La ceniza de la raíz se utiliza para pelar maíz y trigo. El tronquito seco se usa como leña, cuando no hay otras plantas disponibles. Etimología: Ojalar, ¿O?, E. Si fuese español, ojalar vendría de ojal. Si proviniera de oja (comer), tal vez consigna que la planta es comestible. Ojalar, E, hacer y formar ojales (DRAE: 938). El vocablo oja sería voz kallawaya y pukina y significa "comer" (T: 187). Ojala, ojalata, ¿O?, E. Variante de ojalar. Kachiyuyo, Q. Kachiyuyo, en quechua significa hierba de la sal, varias especies de Chenopodiáceas (M: 76). Kacha yuyu, quechua, yerbas secadas a mano (GH (1): 149). Kachi yuyo, aymara, corresponde a Chenopodium murale (G: 174). Del kunza, ckacktch; bueno, agradable, yuyo, variedad de quinoa (LE: 22); Cachi, quechua, sal (R: 19). Q’ächi, quechua, arista (Ba: 86). Chókil, ¿K? Kunza, tchocke apus, harina tostada; Choque, apellido actual aparentemente aymara (V: 34$)$.

25) Atriplex madariagae Phil., CHENOP, 9545, Cuaderno $2 \mathrm{~N}^{\circ} 21$

\section{kachiyuyo, ojala}

forraje, alimenticio y otros usos

Forraje. La ceniza de la raíz se utiliza para pelar maíz y trigo. Se comen las hojas, cuando están tiernas y recién creciendo, en forma de ensalada.

Etimología: Kachiyuyo, Q, A. Ver 24. Ojala ¿O?, E. Ver 24.

26) *Chenopodium album L., CHENOP, 9546, Cuaderno $2 \mathrm{~N}^{\circ} 19$

yuyo, yuyo chapi, chape, quinoa

forraje, alimenticio, ritual y otro

En los Andes del norte de Chile yuyo es un nombre genérico para hierbas ruderales del género Chenopodium. Es una mala yerba, parecida a la quinoa cultivada. Sirve para hacer tchile o llipta ${ }^{5}$. Para hacer la llipta, la ceniza de la planta se moja y luego se coloca en moldes para confeccionar los panes con que se masca la coca. Forraje. Para hacer caldo, se hacen hervir las hojas, también es comido como ensalada. Se utiliza en los wakis $^{6}$, para hacer los pagos a los "tatarabuelos", y a los gentiles 7 y a los cerros para pedir lluvia; se hace con la semilla madura (como si fuera quinoa).

Etimología: Yuyo, A, Q, K. Yuyu, quechua y aymara, hojas y tallo verdes y tiernos del nabo (C.169), (B: 208). Yuyo, kunza, variedad de quinoa, llamada también sacksaholor (V: 29); dícese también de otra planta comestible parecida al bledo español (V: 36). Llullu, quechua, tierno, tubérculo no maduro (Ba: 113). Yuyu, quechua, bledo, hojas tiernas, comestibles, de la quinoa (Ba: 121). Yuyo, quechua, denominación dada a Brassica rapa L., maleza comestible (M: 80). En Argentina, Chile y Uruguay, yerbajo, hierba inútil; en Perú, hierbas tiernas comestibles (DRAE: 2118). En aymara, yuyu, hortaliza (B (1): 341), también yerbas de comer cocidas (B (1): 472). Yuyo chapi, A, Q, K. Ver yuyo y chape. Chape, A. Cchapi, aymara, espina, abrojo; chappilahua, leña espinosa (B (2): 77). Quinoa, Q, A. En quechua, quinua, 
quiuna, cierta legumbre llamada así (R: 76). En aymara, quinua semilla de esta tierra (B (1): 396). Quinoa, nombre vulgar de un cereal cultivado por los indios peruanos y los chilenos desde la época precolombina. La planta alcanza unos dos metros de altura y sus granos, usados como arroz o mijo, hoy se usan principalmente para las aves (L: 669).

27) *Chenopodium murale L., CHENOP, 9608, Cuaderno $2 \mathrm{~N}^{\circ} 52$

yuyo, chape, chapi

otros usos

Probablemente, esta especie también se usa para confeccionar llipta, uso común para todas las especies de Chenopodium andinos.

Etimología: Yuyo A, Q, K. Ver 26. Chape, A. Ver yuyo chape (26).

Chapi, A. Variante de chape.

28) Ambrosia artemisioides Meyen et Walp., COMPOS, 9488, Cuaderno $1 \mathrm{~N}^{\circ} 4$

tikara, pegapega, ¿payko?

forraje y tintóreo

El nombre pegapega alude a unidades de dispersión de las plantas, que se pegan a la vestimenta de la gente o pelaje de animales. Según los entrevistados, hace sicha, así como la brea (Tessaria absinthioides), la chilka (Baccharis scandens) y la paja (es poco probable que las Gramíneas formen sichas). Cuando llueve crece como "la alfa" (Medicago sativa). Forraje, especialmente para los corderos. Planta utilizada como tintura, teñiría de colores verde y amarillo. Según otro informante, se la usaría como mordiente.

Etimología: Tikara, Q, K. Tticka, kunza, señal, flor (V: 33). Técara, kunza, nueve (SR: 9). En quechua, tica, flor o plumaje (R (1): 83). T'ika, flor (Ba: 119). T'ikaray, florecer (Ba: 119). En aymara, ttica, escudilla de hicho de que usan en los caminos porque no se quiebra; es también una cazuela redonda de hicho (paja) en que los hechiceros guardan cosas para sus embustes (B (2): 354$)$. Tica, adobe de barro (B (2): 353); la misma grafía y significado en quechua (R (2): 83). Pegapega, E. Del castellano pegar, adherir. Payko, Q. Ver 37.

29) *Anthemis arvensis L., COMPOS, sin número de herbario, Cuaderno $2 \mathrm{~N}^{\circ} 67$

manzanilla

medicinal y alimenticio

Se nos informó que existirían dos tipos de manzanilla. Se utilizaría como medicina para las guaguas y para el dolor de estómago. Es como un calmante. Como bebida es ingerida en forma de té o mate.

Etimología: Manzanilla, E. Derivado del español manzana, hierba de la familia de las Compuestas, con flores olorosas con centro amarillo y circunferencia blanca; también recibe este nombre la flor de esta planta y la infusión de esta flor, que se usa como estomacal, antiespasmódica y febrífuga (DRAE: 843).
30) Artemisia copa Phil., COMPOS, sin número de herbario, Cuaderno $1 \mathrm{~N}^{\circ} 45$

\section{kopakopa, kopa}

forraje, medicinal y alimenticio

Remedio para dolor de estómago, para el aire y dolor de muelas, usada en forma de baños o sahumerios. Se toma también como té. Es buena contra "el hielo" y con ella se bañaban las guaguas. Para el dolor de estómago que se produce, por ejemplo, cuando se come fruta con leche o queso, se usa la infusión de esta planta que "purifica" el organismo. Sirve también para lavarse los pies, cuando se tiene "hielo" y se siente dolor en los huesos: se echa una ramita en el lavatorio y luego el agua caliente. Es forraje.

Etimología: Kopa, K, Q, A. Ckopa, kunza, puño, mango. Una planta arborescente de la cordillera, muy abundante. Es la primera que se encuentra al salir del llano de Atacama, después de Peine, vía Antofagasta de la Sierra (V: 19). K'opa, una planta arborescente de la cordillera (Sch: 34; Mu: 17). Copa, palabra quechua (Artemisia copa Phil.), arbusto aromático del Norte Grande, envuelto en un tomento blanquizco (M: 113); también en Lenz (L: 209). Bebestible en forma de té o mate. Kopakopa, K, Q, A. Reiteración de kopa.

31) Baccharis alnifolia Meyen et Walp., aff., COMPOS, 9505, 9599, Cuaderno $2 \mathrm{~N}^{\circ} 3,56$

chilka

forraje, medicinal, combustible y construcción

Chilka es el nombre genérico para especies arbustivas del género Baccharis. Es forraje ocasional, cuando el ganado tiene mucha hambre. Se usa para confeccionar cataplasmas, contra golpes o machucones. También se ingiere contra la amigdalitis. Es combustible y, además, se usa para techar estancias.

Etimología: Chilka, A, Q. En quechua, chillca, mata de hojas amargas llamada así (R: 36). Aymara, cchillca, una mata espinosa (B (2): 85); chillquitha, brotar, nacer el sembrado, y cualquiera planta (B (2): 82). Chilca, del quechua, chillca, arbusto de hojas pegajosas. En Colombia y Guatemala, nombre que se da a un arbusto resinoso de la familia de las Compuestas que crece en las faldas de las montañas de todo el continente americano (DRAE: 645). Chilca, voz quechua, pero de uso corriente entre los mapuches, que reúne ejemplares de hojas delgadas, en su mayoría estrechas y lineares aplicada a diversa especies de Baccharis, Eupatorium y Pluchea (M: 109, 110). Ch'illca, plantas de unas hojas de un sabor muy amargo se emplean machacadas en cataplasmas sobre articulaciones hinchadas; también se usan para teñir de verde (L: 278).

32) Baccharis boliviensis (Wedd.) Cabrera, COMPOS, 9513, Cuaderno $1 \mathrm{~N}^{\circ} 10$

chijuachijua, monte, tola, tola tara, tolita del campo forraje, medicinal y veterinario

Los nombres monte y tola son genéricos para las formas de vida de arbustos. Utilizado para lavarse la cabe- 
za. Además, es usado para sahumar a las ovejas cuando tienen gusanos en la cabeza: "con el humo estornudan y botan los gusanos". También se utiliza el humo cuando la oveja está ciega. Forraje. Se nos informó que esta especie sería parecida a la unut'ola, pero esta última es de la cordillera y crece más pequeña. El vernáculo chijuachijua es citado para Guatín, con los mismos usos medicinales reseñados, y lo adjudican al sinónimo de esta especie Psila boliviensis (SSL: 58).

Etimología: Chijuachijua A, ¿Q? Cchihua, aymara, yerbas de comer cocidas, las crudas (B (2): 84). Monte, E. Del latín mons, montis, tierra inculta cubierta de árboles, arbustos o matas. Monte bajo, denominación dada tanto al monte poblado de arbustos matas o hierbas como a estas matas o hierbas (DRAE: 1398). Tola, Q, A. Ttola, planta sudamericana (JC: 571). Ttola, quechua, árboles que se llaman tola, que sirven de leña y todo el año está verde (G: 484). Tola, en América Meridional, nombre de diferentes especies de arbustos de la familia de las compuestas, que crecen en las laderas de la cordillera (DRAE: 1989). Tola, voz quechua, se refiere según el Dr. Reiche (Geografía Botánica) al hábito, más que a caracteres sistemáticos, de un grupo de arbustos xerófilos del extremo norte (M: 105). Tola tara, ¿K?, Q, A. Ver tola y tara (95). Tolita del campo Q, A, E. Tolita diminutivo castellanizado de tola; del campo alude al hábitat de la planta.

33) Baccharis juncea (Lehm.) Desf., COMPOS, 9503, Cuaderno $2 \mathrm{~N}^{\circ} 64$

chukchuka, unquillo

forraje ¿alimenticio?

El nombre chukchuka aludiría al efecto tóxico que tiene sobre el ganado. Forraje. Se comería la parte interior del tallo, la médula, y es dulce.

Etimología: Chukchuka A, Q. Chhukhchu, aymara, temblor de todo el cuerpo, enfermedad que da en los yungas (B (2): 91). Chucchu, quechua, frío de calentura (R: 38). Unquillo, E. Del español junquillo. Ver 20.

34) Baccharis santelices Phil., COMPOS, 9539, Cuaderno $1 \mathrm{~N}^{\circ} 22$

lejía, léjia, tola lejía, léjia hembra, tola chijua

forraje, medicinal, combustible y alimenticio

Produce una miel (resina), y en invierno, cuando hace frío, corre esta miel por el tallo y es dulce y comestible, siendo también usada como remedio. La ceniza de la planta, lejía, se usa para curar el empacho. Se nos describió el empacho de la siguiente manera: "la guagua tiene vómito, nada, ni el doctor, le saca eso... La guagua siempre está con digestión [diarrea], le vomita... Usted calcula que es el empacho..." El procedimiento consiste en hacer una ulpada (cocho o ulpo $^{8}$ ) con la ceniza y agua, dejar asentar, pasar por un colador y tomarla. También se puede ingerir como infusión, es amarga. Es combustible y forraje. Etimología: Lejía, E. Lejía, del latín, (aqua) lixiva. Agua en que se han disuelto álcalis o sus carbonatos. La que se obtiene cociendo ceniza sirve para la colada (DRAE: 1241). Léjia, E. Variante de lejía. Tola lejía,
Q, A, E. Ver tola (32) y lejía. Léjia hembra, E. Hemos comprobado que es el nombre propio para designar a Baccharis santelices en Río Grande. Ver lejía. Tola chijua. Ver tola (32) y chijuachijua (32).

35) Baccharis scandens (Ruiz et Pavón) Pers., aff., COMPOS, 9504, Cuaderno $2 \mathrm{~N}^{\circ} 4,57$

chilka, hoja koka

forraje y medicinal

El nombre de hoja koka, probablemente, proviene de su uso medicinal para el estómago, para la diarrea (para que "se pare la digestión"). Forraje.

Etimología: Chilka, A, Q. Ver 31. Hoja koka, E, A. Coca, nombre propio de la importante planta andina, Erythroxylon coca. Del aymara, hoja de un árbol así llamado que los indios mascan. Árbol cualquiera que sea (B (2): 49). Coca, cocacoca, cuca, cucacuca, pussachpan, nombres de Erythroxylon coca, derivados de $\boldsymbol{k k o k a}$ aymara, árbol por excelencia (SO: 127). Del aymara kkoka, arbusto del Perú, de la familia de las Eritroxiláceas, esta planta es cultivada y de ella se extrae la cocaína (DRAE: 494).

36) Baccharis tola Phil. subsp. tola, COMPOS, 9553, Cuaderno $1 \mathrm{~N}^{\circ} 26$

lejía, tola lejía, léjia macho

medicinal, combustible y otro

Se nos informó que habría dos clases de lejía, una gruesa y otra fina. Efectivamente, el complejo Baccharis santelices- $B$. tola exhibe toda una gama de variación, desde especies con hojas totalmente enteras hasta hojas con numerosos dientes. Es medicinal; la ceniza (de ahí el nombre lejía) es remedio para el empacho, "saca los empachos que están pegados”, haciéndose una ulpada con la ceniza. La ceniza se ocupa para hacer mote, para pelar el maíz y trigo. Leña.

Etimología: Lejía, E. Ver 34. Tola lejía, Q, A, E. Ver tola (32) y lejía (34). Lejía macho, E. Ver lejía (34).

37) *Bidens laevis L., COMPOS, 9598, Cuaderno 2 $\mathrm{N}^{\circ} 55$

té, té de burro, payko

alimenticio

En infusión es una bebida, como el té; su sabor sería algo amargo. Payko es el nombre asignado generalmente a la importante especie medicinal aromática Chenopodium ambrosioides; en este caso es asignado a otra especie aromática.

Etimología: Té, E. Té, del chino tscha, pronunciado en ciertas provincias te. Arbusto del Extremo Oriente, de la familia de las Teáceas, la hoja de este arbusto seca, arrollada se sirve en infusión como bebida estimulante, estomacal y alimenticia (DRAE: 1949). Té de burro, E. Ver té. Payko, Q. Payco, quechua, hierba medicinal (R: 69). Paico, del quechua, payqu. En América meridional, planta herbácea de la familia de las Chenopodiáceas, usada como antihelmíntico en la medicina popular (DRAE: 1500). Paico, quechua, comprende la sección Ambrina 
del género Chenopodium, planta muy aromática, su infusión es eficaz para afecciones estomacales y digestivas (M: 75). En Perú y Bolivia, el paico, paicco, payco corresponde a Chenopodium ambrosioides (SO: 77; Ca: 278).

38) Chaetanthera sphaeroidalis (Reiche) Hicken, COMPOS, no se colectó.

\section{flor de puna}

medicinal

Especie mencionada por los entrevistados y no coleccionada por nosotros. Es conocido su uso contra el mal de puna. El calificativo de puna alude al hábitat subnival de esta diminuta especie medicinal.

Etimología: Flor de la puna, E, Q. Puna, voz quechua, tierra alta próxima a la cordillera de los Andes. También se aplica a una extensión de terreno grande, raso y yermo; y al mal de altura, soroche (DRAE: 1082). Puna, la sierra o tierra fría o páramo (GH (1): 293).

39) Chuquiraga atacamensis Kuntze, COMPOS, 9525 , Cuaderno $1 \mathrm{~N}^{\circ} 16$

chajllampa, candela, lengua de gallo, lengua de gallina, $k e r i$, quebraolla

forraje, medicinal y combustible

Los nombres chajllampa, candela, keri, quebraolla aluden a sus excelentes cualidades como combustible, $o$ al sonido de pequeñas explosiones que efectúa al quemarse; mientras que las denominaciones lengua de gallo $o$ de gallina dicen relación con la forma de las hojas. Remedio para el dolor de estómago, dolor de cuerpo, mal de orines y cistitis. También sirve "para alimentar la hiel". Se toma como infusión y es amarga. También se bebe para los dolores después del parto. Se tuesta, se flambea con alcohol y se toma con carbón de piedra molido y agua. Buena para cuando a la mujer no le llega su visita [¿abortiva?]. Se utiliza también en sahumerio. Forraje. Etimología: Chajllampa, Q. Chaclla, quechua, varillas para cubrir el techo (GH (1): 90); junco, varillas largas que sirven de techo como carrizos, cañas, palos; chaqlalan, ruido desagradable producido por algo ( $\mathrm{Pe}$ (2): 29). Candela, E. Tanto los nombres aymaraquechuas de keri o kiri de las especies de Chuquiraga como el español de candela hacen alusión a las excelentes propiedades combustibles de esta planta. Lengua de gallina, E. Lengua de gallo, $\mathrm{E}$.

Keri, A. En aymara, queri queeri, el fogón para guisar (B (2): 290), lo que hace sentido con las excelentes propiedades combustibles de esta planta; kero, madera, palos, o vigas, y cosas semejantes (B (2): 196). Quebrolla, E. Del español quebra olla. En Perú se les llama quiebra-olla a distintas especies de los géneros Cestrum, Dunalia y Lycium (SO: 286).

40) Haplopappus rigidus Phil., COMPOS, 9512, Cuaderno $1 \mathrm{~N}^{\circ} 9$

bailahuén, bailabien, guailaven, guailavina, chejchara, chejchajra

forraje y medicinal

El nombre bailahuén y sus variantes es un préstamo del mapuche para asignar a una especie de Haplopappus ( $H$.
Rigidus), parecida al famoso arbusto medicinal, Haplopappus bailahuen. Se utiliza muy poco como forraje. Los nombres chejchara, chejchajra serían variantes de chajchajra, nombre usado para esta especie en el área del Salar de Atacama; si el nombre tuviese una raíz kunza, podría aludir al color oscuro de la planta; mientras que si fuera quechua se referiría al uso medicinal de la especie, contra la hinchazón de estómago y aires. Es remedio para la fiebre, la vejiga, hígado, el mal de orines, dolor de estómago, "para botar el hielo", la menstruación con dolores (ya que duele porque se tiene "hielo acumulado"). Esta planta "hace calorías", es muy fuerte. También para la epilepsia y para el dolor de apéndice. Se toma en infusión. Para la tos, el resfrío y bronconeumonía se hierve con limón y se toma con una aspirina y azúcar tostada.

Etimología: Bailahuén, M. Failahuén, baylahuén, vailahuén, nombre mapuche que significa fermento (Haplopappus baylahuen Remy), subarbusto de la zona marítima del norte, contiene una resina medicinal, usada en aplicaciones externas para curación de heridas, $\mathrm{e}$ ingerida como estimulante, digestivo y sudorífico (M: 110). Bailabien, guailaven, guailavina, $M$. Variantes de bailahuén. Chejchara, ¿K? ¿QQ Variante de chajchajra, nombre usado en el Salar de Atacama para una especie llamada comúnmente bailahuén en otras zonas andinas, Haplopappus rigidus. Si el nombre fuese kunza podría aludir al color oscuro de la planta. El término quechua pareciera referir al uso medicinal de la especie, contra la hinchazón de estómago y aires. Seckschar, kunza, oscuro (V: 29). Chhakchay, quechua, desinflarse, reventarse una pelota (C: 47). Chejcheraja, topónimo Quebrada de Chejcheraja, $3 \mathrm{~km}$. S.E. de Socaire (V: 18). Del antiguo quechua chacra, moderno chajra (DRAE: 632). En Bolivia, chajhura es nombre colectivo para arbustos ramosos sin tronco grueso que se utilizan como combustible para calentar rápidamente los fogones de las chicherías y los hornos primitivos caseros, por ejemplo, Baccharis boliviensis, B. tola (Ca: 234). Chejchajra. ¿K?, ¿Q? Variante de chejchara.

41) Mutisia hamata Reiche, COMPOS, 9589, Cuaderno $1 \mathrm{~N}^{\circ} 43$

chinchirkoma, copihue, copihue silvestre, chinchirkoma hembra

forraje y medicinal

Crece entremedio de las tolas o el pingopingo.

Chinchirkoma es el nombre propio del género Mutisia, mientras que es llamada copihue por similitud de sus flores con las de nuestra flor nacional (Lapageria rosea). Esta planta sería la hembra, el macho tiene hojas más anchas y largas. Sale cuando llueve. Forraje. Remedio para la tos. También para la recaída después del parto, junto con carne de zorro.

Etimología: Chinchirkoma, A, Q. Chinchirccuma, aymara, flor amarilla, o anaranjada (B (2): 83). Chinchircuma, flor pequeña colorada (B (1): 243). En quechua, chinchircuma, una mata preciada de los indios (R: 37); una flor amarilla que es plumaje (GH (1): 111). En Perú, Mutisia acuminata se llama chinchilcuma, 
chinchircuma, chincumpa, tintilma; M. hastata, huayurcuma; $M$. hirsuta, chinchilcuma, chinchircuma (SO: 223, 224). Copihue, M. Del mapuche copiu. Planta de tallo voluble, de la familia de las Liláceas, que da una flor roja, a veces blanca, y una baya parecida al ají antes de madurar. Es planta de adorno (DRAE: 566).

42) Parastrephia lucida (Meyen) Cabrera, COMPOS, 9538, Cuaderno $1 \mathrm{~N}^{\circ} 21$

tola amarilla, unut'ola, tola del agua, tola, tolatola forraje, medicinal, combustible y tintóreo

Los nombres unut'ola y tola del agua aluden a su hábitat cerca del agua. Serviría como tintórea, tiñe verde y el color es resistente. Forraje. Medicinal, en forma de baños. También es bebida en infusión, con limón y azúcar quemada. Unut'ola es amarga y se toma también para el pulmón y dolor de muelas, con tres dientes de ajo. Buen combustible.

Etimología: Tola amarilla, Q, A, E. Ver tola (32). Unut'ola, Q,A.Uno, quechua, agua, aguanoso (C: 178). Ver tola (32). Tola del agua, Q, A, E. Ver unut'ola y tola (32). Tola, Q, A. Ver (32). Tolatola, Q, A. Reiteración de tola.

43) Parastrephia quadrangularis (Meyen) Cabrera, COMPOS, 9551, Cuaderno $1 \mathrm{~N}^{\circ} 28 \mathrm{a}$

pulika, tola pulika, koba, ¿tola tara?, chirit'ola, tolilla, tola amarilla chica, koba hembra, chacha

forraje, medicinal, combustible y ritual

El nombre pulika es genérico para las especies de Parastrephia en el Loa Superior, mientras que chacha es el nombre genérico en el Salar de Atacama. La koba se utiliza como sahumerio en los "floramentos"9. $P$. quadrangularis es "como una koba simple". Es la koba hembra, más simple, por oposición a la koba macho, $F$. squamata. Se usa para sahumar ganado, pero muy poco, "de reemplazo no más". Poco utilizada como forraje. Medicinal para los cólicos, dolor de muelas. Serracino et al. (1969) citan para Guatín el vernáculo coba para la especie y agregan que 'se usa para humear las cabras'. Se quema la coba en las proximidades del corral y bajo el humo desprendido se hacen pasar las cabras' (:58).

Etimología: Pulika, Q. En quechua, pilicani, andar, volver el rostro a otra parte. Pilicani, pilicanca, rodela o adarga o otra cosa defensiva (R (1): 72). Tola pulika, Q, A. Ver pulika y tola (32). Koba, Q, A. Ver koba (97). Tola tara, Q, A, ¿K? Ver tola (32) y tara (95). Chirit'ola, Q, A. Chiri, quechua, el frío (GH (1): 113). En Perú, chchirichchiri es Grindelia boliviensis (SO: 109). Tolilla, Q, A, E. Tolita, diminutivo castellano de tola. Tola amarilla chica. Ver tola (32).

Koba hembra, Q, A, E. Ver koba (97). Chacha, A. Chacha, aymara, varonil; varón o marido (B (2): 68). En Perú, los vernáculos chacha o chachas, chachacomo, chachacoma y chachacuma corresponden a especies arbóreas del género Escallonia (SO: 108).

44) Parastrephia teretiuscula (Kuntze) Cabrera, COMPOS, 9554, Cuaderno $1 \mathrm{~N}^{\circ} 28 \mathrm{~b}$

pulika, tola pulika, koba, ¿tola tara?, chirit'ola, tolilla, tola amarilla chica, koba hembra, chacha

forraje, medicinal, combustible y ritual
No la distinguen de $P$. quadrangularis y se le asignan los mismos usos y nombres.

Etimología: Ver $P$. quadrangularis (43).

45) Perezia atacamensis (Phil.) Reiche, COMPOS, sin colectar en esta área de estudio

maransel

medicinal

Especie mencionada por los entrevistados y no observada por nosotras en esta área de estudio. El nombre maransel es usado para designar especies medicinales de la familia de las Compuestas, géneros Perezia, Werneria y Coniza, sería un símil con otra planta, si derivara de maransera. Además de Werneria glaberrima, se nos informó de la existencia de otra planta llamada maransel, que podría corresponder a Perezia atacamensis, llamada así en la $1^{\mathrm{a}}$ y $2^{\mathrm{a}}$ Región, de acuerdo a nuestras referencias. Sería remedio para los ovarios o para cuando al varón se le "corren los compañones" (testículos), y "cuando adentro le crían algún apostema" (abceso supurado). "Con la agüita de maransel le va deshaciendo, le hace expulsar con la caca, botan lo malo". Esta planta no puede sacarla la mujer porque se le "desparrama la matriz". Solamente puede extraerla el hombre porque éste no tiene matriz. Tiene una raíz muy grande. También serviría para los tumores.

Etimología: Maransel, Q. Maransera, planta lobelia de la familia de las Campanuláceas, que se usa a manera de especia (Li: 630). En quechua, maran (batán), piedra plana en forma circular, cuadrada o triangular, de aproximadamente un metro de diámetro, que se utiliza para pelar o triturar los granos (Ba: 83; C: 86).

46) Senecio atacamensis Phil., COMPOS, 9588, Cuaderno $1 \mathrm{~N}^{\circ} 44$

chachakoma de la cabra, burro chachakoma, cacho de cabra, pasto amargo

forraje

Parecida o "pariente" de la chachakoma medicinal, los nombres chachakoma de la cabra y burro chachakoma aluden a la inutilidad medicinal y olor de esta especie (S. atacamensis) de chachakuma, nombre genérico para especies suculentas, y con fuerte olor, del género Senecio. Forraje especialmente para la cabra.

Etimología: Chachakoma de la cabra, Q, E. Ver chachakoma (47). Burro chachakoma, Q, E. Ver chachakoma (47). Cacho de cabra, E. Pasto amargo, E. Ver pasto (67).

47) Senecio nutans Sch. Bip., COMPOS, sin colectar en esta área de estudio

\section{Chachakoma}

medicinal y alimenticio

Mencionada por los entrevistados y no coleccionada por nosotros en esta área de estudio, chachakoma es el nombre genérico para especies suculentas y con fuerte olor del género Senecio. Remedio para problemas urinarios, para el aire ("un aire así inflamao las orejas"). Se utiliza como aliño para las comidas. 
Etimología: Chachakoma, Q. Nombre genérico para especies suculentas y con fuerte olor del género Senecio. Aymara, q'oma, neto, puro, limpio (DL: 255). Chachakuma, quechua, Chachacomo, árbol pequeño de altura. Arbusto medicinal (C: 34); Chachacuma, árbol de esta tierra (R (1): 33). Chachacoma, nombre vulgar de una planta de la alta cordillera de Coquimbo y Atacama (Senecio eriophyton) usada en la medicina casera, balsámica, excitante, estomacal, contra la puna, etc. Uso medicinal contra la puna (L: 237). Chachak'uma, Q, nombre de un árbol de 20 a 30 pies de alto, de madera muy pesada y de color morado, que tiene muchos usos en la carpintería, y no puede ser la misma planta (L: 237 Ibid.). Chachacoma, en Chile, planta de la cordillera andina, de flores amarillas y de uso en la medicina casera (DRAE: 632). Chachacoma, voz quechua, según el Dr. Lenz significa hombre pobre (Senecio eriophyton; S. hirtus), indicados para el estómago, el mal de puna y la presión alta de la sangre (M: 113). En Perú, los vernáculos chachacomo, chacha o chachas, chachacoma y chachacuma corresponden a especies arbóreas del género Escallonia (SO: 108). En Bolivia, chachacoma es el nombre de dos plantas muy distintas: Escallonia resinosa y Senecio graveolens (Ca: 279).

48) Senecio rosmarinus Phil., COMPOS, 9535, Cuaderno $1 \mathrm{~N}^{\circ} 25$

romarillo, oqelorenso, maravilla chica

forraje

Oqelorenso, nombre propio de Senecio rosmarinus, en Río Grande, el cual consigna el color plomo del arbusto, la significación de la palabra lorenso es oscura, en relación con la planta. El nombre maravilla chica es un símil con otra planta por analogía con la flor de la maravilla o girasol. Hay abundancia de la especie hacia Peñaliri y Machuca. Esta planta sería pariente de la wirakoba ${ }^{10}$, una planta medicinal también cubierta de tomento blanquecino. Forraje.

Etimología: Romarillo, E. En América, nombre de varias especies de plantas silvestres; la mayor parte de ellas se utilizan en medicina (DRAE: 1808). Oqelorenso, Q, A. Oqe, quechua, color plomo, plomizo, gris (C: 98; DT: 32); oque, color pardo o de sayal (R: 66). Oqque, de color pardo (B (2): 239). A, Q. Lurinso, A. Lorenzo, nombre dado al colibrí, principalmente en los cuentos. Luri pájaro tominillo, o semejante, casi negro y la garganta verde (B (2): 197). Maravilla chica, E. Del latín mirabilia, plural de mirabilis, admirable. Planta herbácea de la familia de las Compuestas, de treinta a cuarenta centímetros de altura, con hojas abrazadoras y lanceoladas, flores terminales con pedúnculo hinchado, circulares y de color anaranjado. El cocimiento de las flores se ha usado en medicina como antiespasmódico. También se llama maravilla a una especie de enredadera, originaria de América, que se cultiva en los jardines y tiene flores azules con listas purpúreas. El mismo nombre se da a la planta don Diego de la noche (DRAE: 1321).
49) *Sonchus oleraceus L., COMPOS, 9609, Cuaderno $2 \mathrm{~N}^{\circ} 45$

cerraja, girasol

forraje y medicinal

Cerraja nombre de malezas con características similares (hojas runcinadas y dentadas como sierra) a las especies cosmopolitas llamadas cerrajas. Mientras que el nombre girasol asignado en Río Grande es dado por su similitud de su capítulo con el del girasol (Helianthus annus). Mala yerba. Forraje para los conejos. La cerraja es utilizada como medicina para la fiebre.

Etimología: Cerraja, E. Del latín serralia. Hierba de la familia de las compuestas, de sesenta u ochenta centímetros de altura, con tallo hueco y ramosos, hojas lampiñas, jugosas, oblongas y con dientecillos espinosos en el margen, y flores amarillas en corimbos terminales (DRAE: 465). Girasol, E.

50) Tessaria absinthioides (Hook. et Arn.) DC., COMPOS, 9602, Cuaderno $2 \mathrm{~N}^{\circ} 65$

brea

forraje, medicinal, veterinario y construcción

Maleza. Forraje, como complemento "cuando no hay pasto". Es remedio para los conejos. Se utiliza la hoja para el hígado. Con pimiento (Schinus molle), alivia los cólicos y vesícula. Se usa también para hacer techumbres.

Etimología: Brea, E. Del castellano brear. Arbusto de Chile, de la familia de las Compuestas, del cual se extraía una resina que se usaba en lugar de brea (DRAE: 323).

51) Urmenetea atacamensis Phil., COMPOS, 9584, Cuaderno $1 \mathrm{~N}^{\circ} 39$

kotáro, kotora, tokora, conchita, koka del desierto, kokakoka

forraje, medicinal y otro

Se utilizaría como sustituto de la $\boldsymbol{k o k a}$; los nombres $\boldsymbol{k o k a}$ del desierto, kokakoka hacen alusión a esta propiedad. Los nombres kotáro, kotora serían variantes de kótar, nombre propio de la especie en el Salar de Atacama; tokora podría ser una variante del anterior o bien referirse a la masticación de esta planta como sustituto de la koka. No tenemos información que se prepare llipta con ella. Existirían dos tipos, uno de flor blanca y otro de flor amarilla. Forraje, sale con la lluvia. Remedio para la fiebre; se mastica (como la koka) para el dolor de huesos y también se ingiere en infusión.

Etimología: Kotáro, ¿K $\mathrm{K}$ ? En kunza, Ckot- es, enfermarse (V: 20). Kotora, ¿K ? Variante de kotáro. Tokora, Q. Nombre propio de Urmenetea atacamensis, registrado en Río Grande. Puede tratarse de una variante de kotáro, o bien referirse a la masticación de esta planta como sustituto de la coca. No tenemos información que se prepare llipta con ella. Tokara, quechua, como tokra, tokra árbol y ceniza del mismo que entra en la llipta ( $\mathrm{Pe}(2)$ 173). Conchita, E. Koka del desierto, A, E. Nombre específico de Urmenetea atacamensis, plantita desértica 
de la familia Compuestas, cuyo nombre (hierba coca) alude a su uso como sustituto de la coca. Del aymara coca árbol cualquiera que sea y hoja de un árbol así llamado que los indios mascan (B (2): 49). Del aymara kkoka. Arbusto del Perú, de la familia de las Eritroxiláceas, esta planta es cultivada y de ella se extrae la cocaína (DRAE: 494). Kokakoka, A. Ver koka del desierto en este párrafo.

52) Werneria glaberrima Phil., COMPOS, 9558, Cuaderno $1 \mathrm{~N}^{\circ} 31$

maransel

forraje y medicinal

Crece cerca de la yareta. Forraje. Se utiliza para el embarazo y para tomar contra el dolor de cintura.

Etimología: Maransel, Q. Ver 45.

53) Werneria pygmaea Gillies ex Hook. et Arn., COMPOS, 9571, Cuaderno $2 \mathrm{~N}^{\circ} 31$

vega, psike

sin uso reconocido

Etimología: Vega, E. Ver 10. Psike, A, Q. Ver 83.

54) **Xanthium spinosum L., COMPOS, sin número de herbario, Cuaderno $2 \mathrm{~N}^{\circ} 44$

cepacaballo

medicinal y otro

Maleza. Es utilizada para el dolor de estómago (su raíz hervida y tomada como mate) y para el mal de orines. Se usa, durante los carnavales, para azotar a las personas que no quieren bailar.

Etimología: Cepacaballo, E. Ajonjera, planta perenne de la familia de las Compuestas, de treinta a cuarenta centímetros de altura, con raíz fusiforme, hojas puntiagudas y espinosas y flores amarillentas (DRAE: 76 y 459).

55) Xenophyllum poposum (Phil.) V. A. Funk, COMPOS, sin colectar en esta área de estudio

\section{pupusa}

medicinal

Mencionada por los entrevistados y no coleccionada por nosotros en esta área de estudio. En el territorio andino, los nombres poposa y pupusa corresponden, generalmente, a especies de Werneria (W. pupusa, W. ciliolata y Xenophyllum weddelli (ex-Werneria weddelli)) y, probablemente, aluden a su uso medicinal en el parto; sin embargo, otros cojines subnivales también han sido llamados pupusa, como Junellia minima. Es una de las medicinas andinas más valoradas. Werneria poposa es citada para Guatín, con el nombre de poposa, utilizada para el dolor de estómago, de cabeza, para "pasar los malos ratos" (SSL: 59).

Etimología: Pupusa, Q. Pupusa, quechua, según Girault (G: 452), corresponde a Werneria poposa. De acuerdo Yacoleff y Herrera (1935), se trataría de W. digitata. En quechua, pupu, ombligo (GH (1): 293; R: 73; C: 105; DT: 44). En aymara, phuphu, vello, pelo suave (DL:
127). En aymara, p'usa inflado o hinchado (DT: 36 y 60). En Perú, se le llama pupusa a Werneria digitata (SO: 370).

56) *Convolvulus arvensis L., CONVOL, 9593, Cuaderno $2 \mathrm{~N}^{\circ} 48$

enredadera, flor blanca

forraje

Enredadera es un concepto colectivo para agrupar especies con forma de vida voluble; el nombre flor blanca, alude a la inflorescencia de la planta. Mala yerba, maleza. Forraje.

Etimología: Enredadera, E. Dícese de las plantas de tallo voluble o trepador, que se enredan en las varas $u$ otros objetos salientes (DRAE: 842). Flor blanca, E.

57) **Lepidium bonariense L., CRUCIF, sin número de herbario, Cuaderno $2 \mathrm{~N}^{\circ} 71$

linaza

medicinal, alimenticio y otro

Alimento para los pajaritos (canarios). Se toma el agüita para la fiebre, como té.

Etimología: Linaza, E. Ver 22.

58) *Sisymbrium austriacus Jacq., CRUCIF, sin número de herbario, Cuaderno $2 \mathrm{~N}^{\circ} 59$

Mala yerba sin nombre ni uso reconocido

59) * Sisymbrium orientale L., CRUCIF, 9611, Cuaderno $2 \mathrm{~N}^{\circ} 58$

Mala yerba sin nombre ni uso reconocido.

60) Sisymbrium philippianum I.M. Johnst., CRUCIF, 9520,9542 , Cuaderno $1 \mathrm{~N}^{\circ} 13$, Cuaderno $2 \mathrm{~N}^{\circ} 23$

chóchar, kashawe, kashawi, kashavi, pasto de cabra forraje

Chóchar variante de chúchar, nombre propio atacameño de otra especie de Sisymbrium (S. lanatum), de acuerdo a nuestros estudios. En tanto el nombre kashawe y sus variantes, en Río Grande serían utilizados como genéricos para las especies de Descurainia y su significado es oscuro. Es un pasto de lluvia que crece como maleza. Hay distintos kashave: algunos crecen pequeños y otros bien grandes. Forraje, "la cabra da mucha leche con este pasto".

Etimología: Chóchar ¿K?, ¿Q? Tchutchar, K, planta de la cordillera (V: 35). Ch'uch'ar, una planta de la cordillera (Sch: 34). Chuchar, probablemente quechua, (Sisymbrium amplexicaule Phil.), planta cordillerana de Tarapacá, llamada también mostacillo (M: 80; L: 317). Kashawe, Q. En quechua, qasawi casahui, enfermedad que consiste en la aparición de manchas oscuras en forma redondeada en la parte aérea, especialmente en las hojas, de las plantas de papa y haba. Es causada por un hongo (Ba: 136). Kashawi, kashavi, Q. Variantes de kashawe.

Pasto de cabra, E. Ver pasto (67). 
61) Adesmia atacamensis Phil., FABACE, 9486, Cuaderno $1 \mathrm{~N}^{\circ} 6$

tamor, tamur, iluka

forraje, combustible y medicinal

De acuerdo a nuestros estudios, tamor y tamur son nombres de Adesmia atacamensis y A. rhameri en el Loa Superior, mientras que en el Salar de Atacama reciben el nombre de iluka distinguiéndose A. atacamensis, la macho, y A. rahmeri, la hembra. El sentido del término es totalmente oscuro. Forraje, especialmente para los corderos. Se prepara una infusión, amarga, contra la tos. Combustible. Probablemente corresponde a esta especie el vernáculo támoro, documentado por SSL para una planta no identificada de Guatín.

Etimología: Tamor, ¿K ? Nombre de Adesmia atacamensis y A. rhameri en el Loa Superior. En kunza, Ttama, caliente (V: 32). Tamur, ¿K ? Variante de tamor. Iluka, Q, A. Iluca (Krameria cistoidea H. Et A., $K$. iluca Phil.) también llamada pacul, ambos son nombres indígenas peruanos de dos arbustos de la provincia de Coquimbo (M: 86); este nombre debe ser indio; pero no está en los diccionarios (L: 411).

62) Adesmia rahmeri Phil., FABACE, 9521, Cuaderno $1 \mathrm{~N}^{\circ} 14$

iloka

forraje, medicinal y alimenticio

Forraje. Hay mucho en tiempo de lluvias. Engorda mucho el ganado, al igual que el tamor (A. atacamensis). Sería bueno para tener energía. Su raíz es dulce y se come. Etimología: Iloka, Q, A. Variante de iluka (61).

63) Adesmia spinosissima Meyen, FABACE, 9527, Cuaderno $1 \mathrm{~N}^{\circ} 17$

añawa, añawa colorada, añawa roja, añawa de cordillera, gallokishka

forraje, medicinal, combustible, alimenticio

Añawa es el nombre genérico para especies espinosas del género Adesmia. El nombre gallokishka asignado en Río Grande a Adesmia spinosissima, consigna la forma de cresta de gallo que tienen las alas y la quilla de la corola amariposada de sus flores; la palabra kishka consigna que la especie tiene espinas. La planta sería la comida del ratón amo. Forraje. Medicinal, como mate, buena para los "machucones internos". Se prepara una infusión con ruda (Ruta chapelensis) y "va cicatrizando por dentro". También para los tos y resfríos. Se utiliza como té. Buen combustible. Se nos comunicó que hay "varias clases" de añawa: una que es amarilla (la mostrada), otra que "casi no da flor" ( $₫$ ?), otra que tiene la espina grande y le llaman espina y, por último, una blanca y chata (probablemente, A. erinacea).

Etimología: Añawa, A. Nombre genérico para especies espinosas del género Adesmia. Añahuaya lahua, mata espinosa (B (2): 21). Añawa colorada, A, E. Ver añawa(63). Añawa roja (63), A, E. Ver añawa colorada (63). Añawa de cordillera(63), A, E. Gallokishka, E, Q. Para kishka ver kisko (16).
64) Astragalus cryptanthus Wedd. (A. arequipensis Vogel ?), FABACE, 9536, Cuaderno $1 \mathrm{~N}^{\circ} 24$ garbanzo, garbancillo, kontekonte, algarrobillo forraje, medicinal, perjudicial, y otros usos En la región, el nombre garbanzo es colectivo para especies de Leguminosas, generalmente del género Astragalus, perjudiciales para el ganado; algarrobillo es un símil usado para designar Leguminosas, seguramente por las vainas parecidas a los importantes árboles llamados algarrobos. Es más fuerte que el kontikonti (Lupinus oreophilus y L. subinflatus) y emborracha más al animal, le da chujchu (temblores) y puede matarlo. Según algunos informantes, afecta más a los corderos y las cabras que a las llamas. Además, cuando se consume un animal que ha comido esta planta, la persona también se enferma. También le llamarían las patitas de llama, porque los niños juegan abriendo sus vainas e imprimiendo marcas en la tierra, con la forma de pisadas de llama. Hay mucho en el lugar denominado Barrial. Es forraje, pero debe ser consumido con cautela por sus propiedades tóxicas. Se fabrica un parche con esta planta, guano de waycho (nombre propio de un ave perteneciente al género Agriornis [sensu Rothmann, en Castro 1986]) y carne de lagarto, cuando hay fracturas de huesos.

Etimología: Garbanzo, E. Español de origen incierto. Planta herbácea de la familia de las Fabáceas, con tallo de cuarenta o cincuenta centímetros de altura, duro y ramosos; hojas compuestas de hojuelas elípticas y aserradas por el margen; flores blancas, axilares y pedunculadas, y fruto en vaina inflada, pilosa, con una o dos semillas amarillentas, de un centímetro aproximadamente de diámetro, gibosa, y con un ápice encorvado (DRAE: 1022). Garbancillo, E. Diminutivo de garbanzo. En Perú, garbancillo es Astragalus garbancillo, también llamado machamacha (SO: 31). Kontekonte, ${ }_{¿} \mathrm{~K}$ ? Ver 66. Algarrobillo, E. diminutivo de algarrobo (80).

65) Geoffroea decorticans (Gillies ex Hook. et Arn.) Burkart, FABACE, 9605, Cuaderno $2 \mathrm{~N}^{\circ} 76$ chañar

sin mención a su utilización en el área de estudio. Árboles con múltiples usos en los Andes de Chile Etimología: Chañar, Q, ¿K? En kunza, tchacknar y tchaynar es chañar, árbol (V: 34). De origen quechua, América Meridional, árbol de la familia de las Papilionáceas, espinoso, de corteza amarilla. Sus legumbres son dulces y comestibles. También se denomina chañar al fruto de este árbol (DRAE: 636).

66) Lupinus oreophilus Phil., FABACE, 9523, Cuaderno $1 \mathrm{~N}^{\circ} 15$

kontekonte, kontikonti, kontokonto, qela, kela, lupino, maravilla, flores

forraje, perjudicial y ornamental

Kontekonte, kontikonti, kontokonto serían variantes de konti, nombre propio atacameño para Lupinus 
oreophilus, mientras que qela o kela es el nombre colectivo aymara para las especies del género Lupinus. La belleza de las flores de Lupinus oreophilus es reflejada en los nombres vernáculos flores y maravilla, mientras que el vernáculo lupino hace alusión al color plateado de la planta. Su flores son azules y sus frutos igual que haba. Forraje. El cordero se emborracha si la come mucho. Sus flores son muy bonitas para adorno y también para llevar al cementerio el día de Todos los Santos.

Etimología: Kontekonte, ${ } \mathrm{K}$ ? A mediados del siglo XX en Socaire, oasis alto del Salar de Atacama, el nombre conte alude también a Lupinus oreophilus y se la connota como la más bella flor silvestre. El cantal, nombre kunza del purikamani, usa esta flor como ornamento en las ceremonias de culto a los cerros con ocasión de la limpia de acequias (Mu:31). Conti, según San Román, significa gente, en kunza. Ckonti, ckonte, es muy usado en kunza y significa gente (V: 19). Kontikonti, kontokonto, ¿K? variantes de kontekonte. Qela, A. Es el nombre colectivo para las especies del género Lupinus. Kela, A, una flor morada, como de altramuzesaltramuces (B (2): 295); varias plantas que sirven de leña (lahua): kela que es algo gruesa; huayrakela; phusa kela, que es hueca por dentro; kello kela, una planta de flor amarilla (B (2): 185). Kela, A. Variante de qela. Lupino, E. Del español lupino, altramuz, plata (DRAE: 1277). Maravilla, E. Del latín mirabilia, plural de mirabilis, admirable. Flores, E.

67) *Medicago sativa L., FABACE, sin número de herbario, Cuaderno $2 \mathrm{~N}^{\circ} 72$

alfalfa, pasto

forraje

Pasto es el nombre genérico para la forma de vida herbácea, en tanto que alfalfa es el nombre propio de éste, el más apreciado forraje cultivado en el territorio andino del norte de Chile.

Etimología: Alfalfa, E. Del árabe al-fasfasa. Melga común que se cultiva para forraje. Es originaria de Italia y se cultiva como planta de adorno y para forraje (DRAE: 95). Pasto, E. Del latín pastus. Hierba que el ganado pace en el mismo terreno donde se cría (DRAE: 1545).

68) *Melilotus indicus (L.) All., FABACE, 9595, Cuaderno $2 \mathrm{~N}^{\circ} 50$

trigol, trébol, trebol

forraje y perjudicial

Esta especie no existía años atrás en Río Grande. Las semillas las trajeron los animales desde San Pedro de Atacama, lugar donde comían la planta y, con sus fecas, arrojaron sus semillas en Río Grande. Perjudicial para los conejos y cuyes (Familia Caviidae), los mata lentamente. Forraje.

Etimología: Trébol, E. Del catalán trébol y este del griego. Planta herbácea anual, de la familia de las Fabaceas, es espontánea en España y se cultiva como planta forrajera muy estimada (DRAE: 2020). Trigol, treból, E. Varientes de trébol.
69) Gentiana sedifolia Kunth, GENTIA, 9572, Cuaderno $2 \mathrm{~N}^{\circ} 33$

vega

sin uso reconocido

Vega es nombre genérico para las plantas de humedales. Etimología: Vega, E. Ver 10.

70) *Erodium cicutarium (L.) L'Hér. ex Aiton, GERANI, 9610 , Cuaderno $2 \mathrm{~N}^{\circ} 46$

alfilerillo, alfiler

otros usos

Los nombres hacen alusión a la forma de alfiler de los frutos. Alimento para los pájaros, especialmente el jilguero.

Etimología: Alfilerillo, E. En Argentina y Chile, planta herbácea que se usa como forraje (DRAE (1): 97). En Perú, el nombre alfilerillo corresponde al género Erodium (SO:14). Alfiler, E. Del español, alfiler. En Perú, el nombre alfiler corresponde al género Erodium (SO:14).

71) Myriophyllum aquaticum (Vell) Verdc., HALORA, 9566, Cuaderno $2 \mathrm{~N}^{\circ} 40$

\section{loroma}

forraje

Loroma es el nombre colectivo en la $2^{\mathrm{a}}$ Región para agrupar algas verdes y plantas acuáticas, filamentosas y flotantes. Entre las loromas se protegen las truchas. Hay mucho en el río Putana. Antiguamente, había también mucho en Machuca, pero ahora se ha secado el sector. Forraje, especialmente para los llamos.

Etimología: Loroma, ¿A? El vocablo loroma puede derivar de larama, aymara, que significa fino, azul (B: (1) 242).

72) Krameria lappacea (Dombey) Burdet et B.B. Simpson, KRAMER, 9585, Cuaderno $1 \mathrm{~N}^{\circ} 38$

sangrinaria, pegapega, chakachaka, mataratón, chape, cola de ratón

forraje, medicinal y tintórea

Se llama pegapega porque sus semillas se adhieren en la lana del cordero. Mataratón porque "a los ratones se les pega tanto [en el estómago] que les endurece el cuerpo, lo aprisionan y mueren"; el nombre cola de ratón probablemente es una confusión con el anterior ya que no parece tener relación con la especie. El nombre cha$\boldsymbol{p} \boldsymbol{e}$ tal vez es proporcionado por lo espinoso de sus frutos. Forraje. La raíz se utiliza para el mal de orines, también para la sangre, "cuando uno pasa mucho frío". Se prepara una infusión cuando "la persona está hinchada y no puede orinar". Sirve para teñir color concho de vino, color té, colorado y, color de vicuña. Serracino et al. citan para Guatín el vernáculo pega-pega para el sinónimo $K$. iluca, reseñada como forraje y "remedio para la constipación" (1969:59).

Etimología: Sangrinaria, E. Sanguinaria, del latín sanguinaria. Centinoidia (DRAE: 1842) planta pequeña de la familia de las Poligonáceas, con hojas enteras, oblongas y pequeñas, tallos cilíndricos con muchos nu- 
dos y tendidos sobre la tierra, y pequeña la semilla que es muy apetecida por las aves; es medicinal (DRAE: 457). Pegapega, E. Ver 28. Chakachaka, ¿K?, ¿A? En kunza, tchackatur, rasguñar (V: 33). Chaaca, aymara, caña de la quinoa (B (2): 67); cchaca, hueso de los animales; gota de algún licor (B (2): 73). En quechua, ch'aka, afónico, ronco (C: (1969) 41). Mataratón, E. Del español matar y ratón. Chape, A. Cchapi, aymara, espina, abrojo; chappi lahua, leña espinosa (B (2): 77). Cola de ratón, E.

73) * Marrubium vulgare L., LABIAT, 9606, Cuaderno $2 \mathrm{~N}^{\circ} 77$

sin nombre vernacular reconocido

medicinal

En otras regiones andinas, la planta es llamada toronjil cuyano y es medicinal.

74) *Mentha aquatica L. $x$ piperita L., LABIAT, $\sin$ número de herbario, Cuaderno $2 \mathrm{~N}^{\circ} 69$

\section{yerba buena}

alimenticio. Se toma como té.

Etimología: Yerba buena, E. De hierba y buena. Planta herbácea de la familia de las Labiadas, se cultiva mucho en las huertas y se la utiliza como condimento. El mismo nombre se da a otras plantas Labiadas parecidas a la anterior como el mastrazo, el sándalo y el poleo (DRAE: 1105).

75) *Mentha suaveolens Ehrn., LABIAT, 9604, Cuaderno $2 \mathrm{~N}^{\circ} 61$

menta, yerba buena pelúa, menta koka

medicinal y alimenticio

Esta es la menta o yerba buena peluda y existe otra pelada (Mentha aquatica $\mathrm{L}$. x piperita por contraste con esta especie glabra). La denominación menta koka es un símil con otras dos plantas que también se beben en infusión y son medicinales (la menta y la koka). Remedio para el dolor de estómago, habitualmente preparada con leche; se le da a las guaguas. En parche sirve para ponerse en la muela. Borraja buena para la fiebre. Se bebe como té.

Etimología: Del latín menta, hierbabuena (DRAE: 1356). Yerba buena pelúa, E. Nombre de Mentha suaveolens, ver yerba buena (74). Menta koka, E, A. Para koka ver koka del desierto (51).

76) Satureja parvifolia (Phil.) Epling, LABIAT, sin colectar

muña

medicinal

Especie mencionada por los entrevistados y no coleccionada por nosotros en esta área de estudio. Es una valorada medicina andina.

Etimología: Muña, poleo de la tierra (GH (1): 249); también en Girault, para la especie que él denomina Satureja boliviana. En Bolivia se designa genéricamen- te como muñas a las plantas impregnadas a olor a menta y que son arbustos propios de la cordillera andina (Ca: 295). En Perú, el nombre muña designa a especies de Satureja, S. boliviana, muña; S. brevicalyx, muña, orégano de los Incas (SO: 306).

77) Caiophora rahmeri Phil., LOASAC, 9519, Cuaderno $1 \mathrm{~N}^{\circ} 12$

ortega, ortiga, ortiga hembra, itapilla

forraje y medicinal

El vernáculo ortiga es un símil con otra planta, la conocida ortiga europea, por lo urticante, siendo itapilla el nombre aymara de las especies con esas características. Cuando llueve crece mucho esta planta. Existe dos tipos, la colectada y consultada en esta área que es de flor blanca, que sería la hembra y otra que da flor roja y crece en Caspana, la macho (Caiophora superba) (Villagrán et al. 1998). Forraje de las llamas. La flor es remedio para la fiebre y contra el exceso de sueño (para la fiebre, para tener el sueño liviano), y se toma como mate. Para las várices, se hierve, se cuela para sacarle las espinas y debe tomarse por nueve días. También es bueno para las mujeres con la menstruación ya que "le saca todo, le corrige". Sería buena para no subir de peso porque, según una señora, "la llama la come mucho y su carne no tiene colesterol"; en cambio, el cordero, la cabra y el vacuno no comen esta planta y "crían tanta sustancia". Sirve también para limpiar la sangre y para el cáncer, porque disuelve todo (machucones interno y tumores). La flor es remedio para la fiebre y contra el exceso de sueño.

Etimología: Ortiga, E. Del latín, urtica. Planta herbácea de la familia de las Urticáceas, con hojas cubiertas de pelos que segregan un líquido urente, muy común en España (DRAE: 1490). En Perú, los nombres ortiga, ortiga macho y ortiga colorada corresponden a varias especies de Caiophora (SO: 55). Ortega, E. Variante de ortiga. Ortiga hembra, E. Itapilla, A. Del aymara, itapallo, ortiga (B (2): 183. Mala yerba o cizaña, y cualquiera cosa que suele deshierbarse (B (1): 303). Itapillo, ortiga; la que tiene flor llámale orco itapallo, y la que no echa flor, que también es blanda, y no escuece, se llama huahua itapallo (B (2): 183). En Perú, Loasa urens es itapallo, ortiga, ortiga brava (SO: 189).

78) *Malva parviflora L., MALVAC, sin número de herbario, Cuaderno $2 \mathrm{~N}^{\circ} 74$

malva rosa, malva

medicinal y ornamental

Malva es el nombre genérico para especies de la familia Malváceas. Maleza. Medicinal. Para los muertos, para las almas. También es ornamental.

Etimología: Malva rosa, E. Especificación de una propiedad de la malva. Malva, del latín, malva. Planta muy abundante, de la familia de las Malváceas con flores moradas, es usada en medicina por el mucílago que contiene las hojas y las flores (DRAE: 1300). 
79) Tarasa? Malva?, MALVAC, 9614, Cuaderno $2 \mathrm{~N}^{\circ} 51$ malva

forraje

Maleza

Etimología: Malva, E. Ver 78.

80) Prosopis alba Griseb., MIMOSA, 9601, Cuaderno 2 $\mathrm{N}^{\circ} 66$

\section{algarrobo}

forraje, combustible, alimenticio y medicinal

Forraje. La aloja (chicha de algarrobo), cuando está "pesadita", es buena para la vesícula. Para hacer la aloja, se muele la vaina en un mortero y se pone en una tina con agua para que fermente. La aloja se bebe en las fiestas y ceremonias rituales. Se consume el fruto y también se prepara con las vainas la añapa o harina de algarrobo (chancando la vaina en un mortero), que sirve para preparar ulpo ("el algarrobo tiene que ser dulce, especial, para ser adecuado para preparar añapa dulce"). Combustible.

Etimología: Algarrobo, E. Derivado del castellano algarroba, árbol de la familia de las Facabeconáceas (sic), originario de Oriente, cuyo fruto denominado algarroba es una vaina azucarada y comestible, de color castaño por fuera y amarillento por dentro, con semillas muy duras y la cual se da como alimento al ganado de labor. En América se da este nombre a varios árboles y plantas, como el curbabil o genízaro (DRAE: 98). En la flora peruana se les llama algarrobos a especies de Leguminosas de los géneros Mimosa, Prosopis, Ceratonia, Piptadenia, etc. (SO: 14).

81) *Plantago lanceolata L., PLANTA ${ }^{11}, 9592$, Cuaderno $2 \mathrm{~N}^{\circ} 47$

llantén

\section{medicinal}

Maleza. Medicinal, para el cáncer, la vesícula, los machucones y las heridas.

Etimología: Llantén, E. Del latín, plantago, -inis. Planta herbácea, de la familia Plantagináceas, muy común en los sitios húmedos, y el cocimiento de las hojas se usa en medicina (DRAE: 1280).

82) *Plantago major L., PLANTA, 9596, Cuaderno 2 $\mathrm{N}^{\circ} 53$

llantén, llantel

forraje y medicinal

Maleza. Medicinal, para friegas contra la fiebre. Con su hoja se preparan parches para los machucones, inflamaciones, también para inflamación de la muela.

Etimología: Llantén, E. Ver 81. Llantel, E. Variante de llantén (81).

83) Plantago tubulosa Decne., PLANTA, 9564, Cuaderno $2 \mathrm{~N}^{\circ} 32$

psike, achicoria

forraje y alimenticio

Psike es nombre genérico para una serie de especies en roseta, que crecen entre los cojines del bofedal y, gene- ralmente, se consumen como ensalada, y el nombre achicoria es una analogía con la forma de vida en roseta y su uso como la verdura llamada achicoria (Lactuca). Se come la parte blanca de la base de la hoja, que tiene sabor a lechuga y también puede cocinarse. Forraje. Etimología: Psike, A, Q. En quechua, sikki corresponde a la lechuga (Lactuca sativa) (G: 863); ciqqui, lechuga silvestre que hay en la sierra (GH (1): 84); siki, significa chicoria, comestible (B (2): 161), también yerba o cizaña (B (1): 303); sikii, sikyi, sacar de raíz lo que está plantado (MLQ: 8). Achicoria, E.

84) *Rumex crispus L., POLYGO, 9607, Cuaderno 2 $\mathrm{N}^{\circ} 79$

romaza

forraje

Esta romaza es de la grande.

Etimología: Romaza, E. Del latín rumex, -icis. Hierba perenne de la familia de las Poligonáceas, es común en España, las hojas se comen en potaje, y el cocimiento de la raíz se ha usado como tónico y laxante (DRAE: 1808). Romaza (Rumex romassa Remy, $R$. sanguineus L.), maleza común. La infusión de sus hojas es refrescante y emoliente, la decocción de la raíz limpia y sana tumores y úlceras malignas, además es usada entre los mapuches como tintórea, tiñendo de color azul (M: 75).

$85)$ *Rumex sp., POLYGO, 9612, Cuaderno $2 \mathrm{~N}^{\circ} 60$ lengua de buey, romaza, icerraja?

medicinal

El nombre lengua de buey alude a la forma de la hoja. Mala yerba. Se utiliza en friegas para la fiebre (cerraja). La romaza es utilizada para la hinchazón.

Etimología: Lengua de buey, E. Planta anual de la familia Boragináceas, de hojas lanceoladas, abunda en los sembrados (DRAE: 794). Romaza, E. Ver 84. Cerraja, E. Ver 49.

86) Calandrinia compacta Barnéoud, PORTUL, 9567, Cuaderno $2 \mathrm{~N}^{\circ} 36$

¿isru?

sin uso reconocido en el área de estudio

Probablemente, el nombre isru proporcionado para esta especie sea una confusión con Lilaeopsis macloviana (10), el isru comestible de los Andes.

Etimología: Isru, A. En aymara hissru, raíz de comer (B (2): 399); hisru, raíz delgada (B (1): 399). Ver istru (10).

87) Cistanthe celosioides (Phil.) Carolin ex Hershk. (C. amaranthoides (Phil.) Hershk.?), PORTUL, 9552, Cuaderno $1 \mathrm{~N}^{\circ} 41$

básal, básal hembra, básal rojo, básal granada

forraje, medicinal y alimenticio

Básal es el nombre asignado a las especies de Cistanthe probablemente por su forma de crecimiento prostrado con varias ramas rastreras que podrían tener relación con palabras del idioma kunza que significan barrer. Sale en 
tiempo de lluvia. Cuando las cabras paren y comen de este pasto, los quesos salen con mejor sabor. Es un forraje dulce. Es medicinal. La persona puede comerlo porque es dulce y gelatinoso, de allí las denominación básal granada en contraposición al básal amargo ( $C$. salsoloides) no comestible. SSL citan también para Guatín el vernáculo basal, sin determinación botánica, y documentan que es "usado para protegerse de los rayos solares, colocándola en la frente".

Etimología: Básal, ¿K?. Kunza: balsantur, escoba; baâlsatur, barrer (V: 14-15). Básal granada, ¿K?, E. Básal hembra, ¿K?, E. Básal rojo, ¿K?, E.

88) Cistanthe salsoloides (Barnéoud.) Carolin ex Hershk., PORTUL, 9551, Cuaderno $1 \mathrm{~N}^{\circ} 40$

básal, básal macho, básal rosao, básal amargo forraje

Los lugareños distinguen este básal macho del básal hembra (Cistanthe celosioides), por ser la primera una forma más robusta y no comestible, en contraposición a la segunda. Casi no lo comen los animales porque es amargo. Sale mucho cuando llueve.

Etimología: Básal, ¿K? Ver básal (87). Básal macho, ¿K?, E. Básal rosao, ¿K?, E. Básal amargo, ¿K?, E.

89) Ranunculus cymbalaria Pursh. fma. cymbalaria, RANUNC, 9499, Cuaderno $2 \mathrm{~N}^{\circ} 11 \mathrm{a}$

ciénego, vega

forraje

Ciénego es un nombre colectivo para especies de humedales.

Etimología: Ciénego, E. Derivado de ciénaga, lugar o paraje cenagoso (MA: 237). Vega, E. Ver 10.

90) Ranunculus cymbalaria Pursh. fma. exilis (Phil.) Lourteig, RANUNC, 9568, Cuaderno 2 № 35

vega

sin uso reconocido en el área de estudio

Etimología: Vega, E. Ver 10.

91) Ranunculus uniflorus Phil. ex Reiche fma. bolivianus (Phil.) Lourteig, RANUNC, 9562, Cuaderno $2 \mathrm{~N}^{\circ} 30 \mathrm{a}$

chengua

forraje

Es vega.

Etimología: Chengua, Q. Ver 10.

92) Ranunculus uniflorus Phil. ex Reiche fma. uniflorus, RANUNC, 9563, Cuaderno $2 \mathrm{~N}^{\circ} 11 \mathrm{~b}, 30 \mathrm{~b}$

ciénego, vega, chengua

forraje

Es vega.

Etimología: Ciénego, E. Ver 89. Vega, E. Ver 10. Chengua, Q. Ver 10.

93) Calceolaria stellariifolia Phil., SCHROP, 9555, Cuaderno $1 \mathrm{~N}^{\circ} 29$

zapatilla, zapatito

medicinal

Zapatilla es el nombre genérico y alude a la forma de zapato de la corola de las especies de Calceolaria. Me- dicinal. La flor es mejor que las hojas, para los riñones, para la matriz, para el parto, para el resfrío y la tos. Abortiva preparada con otros compuestos. Alimento del ratón amo. Habría dos clases, una con flores blancas y otra con flores amarillas.

Etimología: Zapatilla, E. Zapatilla, derivada de zapata. Zapato ligero y de suela muy delgada (DRAE: 2124). En Perú, diversas especies medicinales del género Calceolaria se llaman también sapatilla y variantes como, ayac-sapatilla, nuttusapatilla, pampa sapatilla (SO: 56). Zapatito, E. Variante de zapatilla.

94) **Cestrum parqui L'Hér., SOLANA, sin número de herbario, Cuaderno $2 \mathrm{~N}^{\circ} 68$

palki

medicinal

Se utiliza, en forma preventiva, para bañar a los niños y evitar los resfríos.

Etimología: Palki, M. Nombre propio de la importante especie medicinal Cestrum palqui. Nombre vulgar de un arbusto o arbolillo muy común y de mal olor; es de mucho uso en la medicina casera como diaforético, excelente sudorífico. Etimología mapuche (L: 547). De origen araucano. Arbusto americano de la familia de las Solanáceas de olor fétido. Su cocimiento se emplea en Chile contra la tiña, y como sudorífico, y la planta para hacer jabón (DRAE: 1512).

95) Fabiana denudata Miers, SOLANA, 9528, Cuaderno $1 \mathrm{~N}^{\circ} 18$

tolilla, tara

forraje, medicinal, combustible, ritual y veterinario El nombre tara en los Andes de la $2^{\text {a }}$ Región es asignado a las especies de Fabiana, llamadas kipa en la $1^{\mathrm{a}} \mathrm{Re}$ gión. En Chile y países limítrofes, las llamadas tara son Leguminosas, Caesalpiniáceas, generalmente Caesalpinia spinosa. Conviene a las especies de Fabiana la acepción kunza, puesto que da cuenta de los terrenos calizos donde abundan estas especies. Forraje. Se usa como ungüento cuando se producen fracturas. Se prepara una infusión de esta planta, con verbena (Verbena bonariensis) y ruda (Ruta chapelensis), para los dolores después de una operación. Para los machucones, se muele la planta, se le pone orina de niño y guano de waycho y se aplica, como cataplasma, en el lugar del dolor. Para las fracturas de los animales, se mezcla la tolilla molida con grasa y guano de ratón amo y de waycho. Otra forma de preparación es con orina de niño. Se utiliza también como sahumerio para los difuntos, para separar almas, junto con plumas de chururo (parina) y guano de ratón amo. Buen combustible.

Etimología: Tolilla, Q, A, E. Diminutivo castellano de tola. Tara, ¿K?, ¿Q?, ¿A? Ttarar, kunza, blanco, duro, firme; dícese de un terreno con esflorescencias salitrosas que a la vez que blanco, lo hacen firme y duro (V: 33). En aymara, tara, achatada, aplanada (Ca: 221). En aymara, tara, anchura, dimensión en sentido opuesto a la longitud. Tara apilla, oca chata, como la 
mano, no redonda; Tara suto; chullco, las hojas de esta manera de ocas o apillas (B (2): 338). Tara, en Perú, arbusto con hojas pinadas, flores amarillas, y legumbres oblongas y esponjosas (DRAE: 1944). Tara, quechua, psispalla, ispata; formación no típica de dos yemas separadas que presentan los tubérculos de papas y ocas; se considera que es el espíritu de las plantas tuberosas (Ba: 178). Tara (Coulteria tinctoria H.B. Kth.), árbol del norte; usado en medicina por sus propiedades astringentes y en tintorería para teñir de negro. En Perú, tara corresponde a Caesalpinia spinosa (SO: 54). En Bolivia, la tara es Caesalpinia tara (sinónimos: Caesalpinia tinctoria y Coulteria tinctoria), usada para curtir cueros (Ca: 221).

96) Fabiana ramulosa (Wedd.) Hunz. et Barb., SOLANA, 9518, Cuaderno $1 \mathrm{~N}^{\circ} 11$

tara, tolilla, tola

forraje y combustible

Etimología: Tara, ¿K?, ¿Q?, ¿A? Ver 95. Tolilla, E. Ver 95. Tola, E. Ver 32.

97) Fabiana squamata Phil., SOLANA, 9533, Cuaderno $1 \mathrm{~N}^{\circ} 20$

koba, koa, qoba, pata de perdiz, koba macho

medicinal, combustible, ritual y veterinario

Koa, koba o qoba son nombres genéricos utilizados en los Andes de Chile, para algunas especies de arbustos aromáticos de las Familias Compuestas (Diplostephium, Parastrephia) y Solanáceas (Fabiana), usadas con fines exclusivamente ceremoniales. El vernáculo pata de perdiz es un símil de los tallos afilos y escamosos de la planta, y esta denominación es usada preferentemente en el Salar de Atacama donde esta especie no tiene utilización ritual. Se usa "para chuyar a los animales", mezclada con grasa. Otras personas señalan que con el humo, los animales comienzan a bostezar y botan los gusanos que tienen en la cabeza: "limpia los animales", uso relacionado con la connotación ceremonial de la planta en la tradición andina y, probablemente, transferida a este uso veterinario por las personas recientemente incorporadas a la religión evangélica. Esta planta es usada en el "floreo", la fiesta de los animales: "se hace una comilona, viene gente de afuera, se come asado, se toma chicha". La koba es "muy sagrada, es casi tipo incienso". La compran mucho en Argentina. De acuerdo a algunos informantes bolivianos, esta sería la principal planta ritual utilizada en diversas costumbres, como separar almas, floreos, para curar de la caída del rayo, para hacer que la tormenta de rayos se retire, para esto se utiliza su humo. Al hacer humear se utiliza otra planta $(i$ ?), denominada incienso, la que se compra y probablemente vendría de los Yungas. Existirían dos clases, una macho que es la colectada y consultada en esta área de estudio y una hembra que es más finita (Parastrephia quadrangularis y $P$. teretiuscula). La macho es la usada principalmente para las ceremonias. También es remedio para el dolor de estómago, la diarrea y el vómito, en mate. Es buena para encender el fuego cuando la leña está húmeda.

Etimología: Koa, A, Q. Koa, orégano de acá de esta tierra (B (2): 56). Wira-q'uya, hierba silvestre, hierba para sahumar los cultivos, planta de manchas blancas en los tallos y las hojas que crece en las punas y se la utiliza en los ritos y ceremonias para proteger los cultivos (Ba: 179). En quechua, coya esparto de las Indias (R: 26); koya, ichu largo, correoso como esparto (GH (1): 142); Koya reina (MLQ: 73). En Bolivia, la koa más común es la huirakoa, una especie de Diplostephium. Al sur de Bolivia, la koa es Parastrephia teretiuscula (Ca: 230). Koba, Q, A. Qowa, es la trompa espiral de nube que se cuelga de la masa principal de la misma en la época de lluvias. Es atribuida por la gente de ser la cola de un gato gigante sobrenatural, emparentado con el granizo que en ciertas ocasiones baja a la tierra y suele estar en las orillas arenosas de los ríos, convertido en un pequeño gato (C: 116-117). Qoba, A, Q. Variante de koba. Pata de perdiz, E. Koba macho, Q, A, E.

98) Jaborosa parviflora (Phil.) A.T. Hunz. et Barb., SOLANA, 9537, 9534?, Cuaderno $1 \mathrm{~N}^{\circ} 23$

psike, ¿maransel?

forraje, medicinal, ¿alimenticio? y otros usos

Forraje. Psike es un nombre genérico para especies en roseta, generalmente alimenticias. Se utiliza para dolor de muelas. Los niños usaban las pelotitas (frutos) para jugar. Maransel es una medicina y, probablemente, se trata de una confusión con Werneria glaberrima, el maransel de otras regiones andinas.

Etimología: Maransel, Q. Ver 52. Psike, A, Q. Ver 83.

99) Solanum elaegnifolium Cav., SOLANA, 9541, Cuaderno $2 \mathrm{~N}^{\circ} 24, \mathrm{~N}^{\circ} 54$

chajchal, tomatillo

medicinal y otro

Chajchal es el nombre propio, en Río Grande, de esta especie y parece referirse a los frutitos amarillos que se rompen, tal como se desinfla una pelota, en tanto que el vernáculo tomatillo alude también a la baya carnosa. Los frutos se usan para lavar ropa, se remoja su fruto y sale espuma. Remedio para el pulmón.

Etimología: Chajchal, Q. Chhakchay en quechua es desinflarse, reventarse una pelota (C: 47). Chajcha, quechua, ralo, refiriéndose a tejido (Pe (2): 26). Tomatillo, E, O. Tomate, nahuatl (L: 521) (México, Mesoamérica), en Chile es un arbusto de las Solanáceas (DRAE: 1274). Tomatillo: derivado de tomate, nombre vulgar de un arbustito con bayas amarillentas o lacres (L: 521).

100) Acantholippia deserticola (Phil. ex F. Phil.) Moldenke, VERBEN, 9489, Cuaderno $1 \mathrm{~N}^{\circ} 3$

\section{rikarika}

forraje, medicinal, combustible y alimenticio

Forraje. Remedio para el dolor de estómago y para el resfrío, en infusión. Se prepara también un kocho, re- 
medio para la diarrea, para lo cual se desgranan las hojas, se tuestan, se ponen a remojar en un jarro, luego se tuesta harina flor y se le pone azúcar. Para la tos, se tuesta la rikarika y se prepara con leche. Se toma como mate para el estómago, cuando se come en exceso, se toma como mate. Se bebe también como té o para saborizar la leche. Se prepara con ella un ponche para las fiestas. Esta planta sería cálida. Combustible.

Etimología: Rikarika, ¿Q?, ¿E? Ricarica, denominación quechua, de una planta Verbenácea del norte de Chile, A. deserticola (M: 103). Nombre vulgar de un arbustito del norte, A. punensis (L: 685).

101) Junellia seriphioides (Gillies et Hook.) Moldenk, VERBEN, 9529, Cuaderno $1 \mathrm{~N}^{\circ} 19$

cola de gato, cola de michi, vinovino, cardoncillo, rosas, rosakishka, zarzaparrilla

forraje, medicinal y combustible

Los vernáculos cola de gato y cola de michi hacen referencia a las estípulas que tienen la forma de colas. Cardoncillo es un símil de Junellia seriphioides con otra planta muy importante, el cardón, por las estípulas espinosas. Los nombres rosas y rosakishka (que significa rosa espinosa) son un símil con la flor de la rosa, por la belleza y aroma de sus inflorescencias, mientras que el nombre vinovino parece ser español y aludir al color vino de las flores. Zarzaparrilla, nombre asignado en Río Grande a esta especie parece ser un símil con plantas espinosas, como la zarzamora; en Chile se llaman zarzaparrillas a las especies de Ribes, sin espinas. Es un forraje, especialmente para la llama. Remedio para resfríos, dolor de cabeza, dolor del cuerpo y "clavadas". Se toma en infusión y es amarga. Se ingiere con chakachaka (Krameria lappacea) "cuando uno tiene clara la sangre". Buen combustible.

Etimología: Cola de gato, E. Cola de michi, Q, A, K, E. Aymara, mich'i, aguijón (DL: 185). Mitchi, kunza, gato, león, puma (V: 26). Mishi, Q, gato (Ba: 169). Michi, mapuche, el gato. Lenz afirma que esta voz no es más que una variante del nombre familiar castellano micho, o más bien, la voz con que se llama al gato (L: 497). Micho, cha. De mizo, gato, gata (DRAE: 1369). Vinovino, E. Del castellano vino (DRAE: 2092). Cardoncillo, E. Diminutivo de cardón (Ver 16). Rosas, E. Rosa, español (DRAE: 1813). Rosa kishka, E, Q. Quechua, quichca, la espina (GH (1): 307). Quisca, la espina (L: 675). Quisca, del quechua quichca, espina. Kichka, quechua, broza espinosa, quepo, espina; también cabello lacio y tieso (Ba: 124). Zarzaparrilla, E. Del español, zarza. Arbusto de la familia de las rosáceas. Por extensión, cualquier arbusto espinoso. Rosal silvestre, escaramujo (DRAE: 2127). Zarzaparrilla. Arbusto de la familia de las liliáceas, con tallos delgados, volubles, de uno a dos metros de largo y espinosos. Zarzaparrilla de Indias. Arbusto americano del mismo género que el de España, del cual se distingue en echar las hojas sólo tres nervios cada una (¿Ribes?). Es medicinal. Zarzaparrilla de la tierra, arbusto (DRAE: 2127).
102) Lampaya medicinalis Phil., VERBEN, 9590, Cuaderno $1 \mathrm{~N}^{\circ} 42$

\section{lampaya}

medicinal y combustible

En el lugar denominado "el Barrial" hay abundancia de la especie. Se puede usar en infusión o en baños. También puede tomarse como té. Se toma, en infusión, para el dolor de estómago. También se la utiliza, en baños, para el dolor de huesos. Se la mastica cuando se está cansado. También es buena para la cistitis, para "el hielo" (cuando no se puede orinar) y calma los dolores. Se toma para los riñones, los dolores menstruales y dolores de huesos. Utilizada como leña.

Etimología: Lampaya, Q, A. Lampaya, Q, una Verbenácea medicinal (Li: 550). Lampayo: un arbustito medicinal de la cordillera de Atacama, Verbenácea, Lampaya medicinalis (L: 422). Lampaya, voz aymara (Lampaya medicinalis), arbusto bajo de gruesas hojas ovales, preconizado como antirreumático, sudorífico e indicado contra los resfriados. Crece en la cordillera de Tarapacá (M: 103). En Bolivia, la lampaya corresponde a Lampaya medicinalis (Ca: 274).

\section{ANGIOSPERMAS MONOCOTILEDÓNEAS}

103) Carex sp., CYPERA, 9576, Cuaderno $2 \mathrm{~N}^{\circ} 39$

flor de la vega

sin uso reconocido en el área de estudio

El calificativo vega alude al hábitat palustre de pastos de humedales.

Etimología: Flor de la vega, E. Vega, E. Ver 10.

104) Eleocharis albibracteata Nees et Meyen ex Kunth, CYPERA, 9575, Cuaderno 2 No 37

vega, unquillo

sin uso reconocido en el área de estudio

Etimología: Vega, E. Ver 10. Unquillo, E. Ver 20.

105) Scirpus americanus Pers., CYPERA, 9494, Cuaderno $2 \mathrm{~N}^{\circ} 7$

unquillo chico

forraje

Etimología: Unquillo chico, E. Derivado de unquillo (20).

106) Scirpus atacamensis (Phil.) Boeckeler, CYPERA, 9561, Cuaderno $2 \mathrm{~N}^{\circ} 27$

vega

forraje

Etimología: Vega, E. Ver 10.

107) Scirpus deserticola Phil., CYPERA, 9501, Cuaderno $2 \mathrm{~N}^{\circ} 6$

champita, champa, pajita chica

forraje

Champa es el nombre genérico para la forma de vida de cojín de humedal.

Etimología: Champa, Q, A. Ch'ampa, en quechua, pedazo de césped con la tierra que se pega entre las raíces; 
especies de plantas que tienen raíces largas, tupidas y ordenadas (L: 337). Terrón moldeado y seco que se usa como adobe ( $\mathrm{C}: 42)$. Terrón, masa de tierra compacta de diversa dimensión; también trozo de césped, tierra adherida a la raíz de las plantas cuando se les extrae (Ba: 93). Champita, Q, A, E. Diminutivo castellanizado de champa. Pajita chica, E. Diminutivo de paja ( 109).

108) Scirpus?, CYPERA, sin número de herbario, Cuaderno $2 \mathrm{~N}^{\circ} 38$

champa, ciénego, vega

forraje

Se parece a la lama (especies de algas filamentosas flotantes).

Etimología: Champa, A, Q. Ver 107. Ciénego, E. Ver 89. Vega, E. Ver 10.

109) Achnatherum speciosum Trin. et Rupr., GRAMIN, 9514, Cuaderno $1 \mathrm{~N}^{\circ} 37$

paja, paja gruesa, paja cebadilla, paja banderilla blanca

forraje

Paja es la denominación genérica para la forma de vida de las Gramíneas altoandinas perennes y en champas que proporcionan la fisionomía de Pajonal al Piso Altoandino. Forraje, la come mucho el ganado. Sería comida del ratón amo.

Etimología: Paja, E. Paja del latín palea. Caña de trigo, cebada, centeno y otras Gramíneas, después de seca y separada del grano (DRAE: 1501). Paja gruesa, E. Ver paja. Paja cebadilla, E. Ver paja y cebadilla (111). Paja banderilla blanca, E. Ver paja banderilla (110).

110) Anatherostipa venusta (Phil.) Peñail., GRAMIN, 9549, Cuaderno $1 \mathrm{~N}^{\circ} 33$

paja banderilla, paja fina, paja $i r u$, paja iro, iro, paja brava, paja

forraje y construcción

El nombre paja banderilla corresponde a una especificación de una propiedad de una paja que, probablemente, flamea con el viento como bandera, mientras que los vernáculos iro o iru y paja brava designa a variedades de paja con hojas punzantes. Se usa en construcción, para las techumbres. La paja iro sería térmica ya que, cuando hace calor, las habitaciones estarían frescas y, durante la noche, calurosas. Además, es durable por lapsos de hasta 50 o 60 años. Forraje de la vizcachas. Cuando está verde, la come el llamo, el guanaco, la vicuña. No sería muy apetecida por el ganado.

Etimología: Paja banderilla, E. Bandera, del español, palo delgado de setenta u ochenta centímetros de largo, armado de una lengüeta de hierro y que, revestido con papel picado y adornado a veces con una banderita, usan los toreros para clavarlos en el cerviguillo de los toros (DRAE: 260). Paja fina, E. Ver 109.

Paja iru, A, E. Ver 109, iro. Iro, A. Iru, aymara, cerda, pelo grueso y duro (DL: 206). En aymara, jichu paja (DT: 48); hichu, yerba como esparto (retama) cu- yas especies es bien saberla que son éstas: orco sicuya, cachu sicuya, huaylla, cchillihua, phurqhue, iru (B (2): 130). Paja brava, E. Hierba de la familia de las Gramíneas, que crece hasta tres o cuatro metros de altura. Es propia de las tierras de gran altitud en América Meridional. Es apreciada como pasto, y como combustible en los hornos de minerales (DRAE: 1501). Paja, E. Ver 109.

111) **Bromus catharticus Vahl., GRAMIN, 9547, Cuaderno $2 \mathrm{~N}^{\circ} 18$

cebadilla, cebadilla grande, espiga

forraje

Cebadilla es el nombre genérico para especies anuales de Gramíneas, generalmente malezas de chacras, y espiga es un nombre propio asignado en Río Grande a Bromus catharticus. Forraje.

Etimología: Cebadilla, E. Del español. Identifica una especie de cebada que crece espontáneamente (DRAE: 383). Cebadilla grande, E. Ver cebadilla (111) . Espiga (111), E. Nombre asignado en Río Grande a Bromus catharticus. Del español, conjunto de flores o frutos sostenidos por un tallo común (MA: 451).

112) Cortaderia atacamensis (Phil.) Pilger, GRAMIN, 9492, Cuaderno $2 \mathrm{~N}^{\circ} 17$

cortadera

forraje, medicinal, construcción, ornamental y otros usos El nombre de esta planta alude al borde cortante de las hojas de las especies de Cortaderia. Forraje. Se toma como mate cuando no se puede hablar (¿afonía?). Remedio para la espalda, los riñones, como mate. En construcción, sirve para la techumbre. También como adorno, tiñendo la espiga. También se utiliza para tapar los ajos, una vez cosechados, para que no les dé el sol.

Etimología: Cortadera, E. Cortadera, del español cortar. En Argentina, mata de Gramineae propia de terrenos llanos y húmedos de hojas angostas de color verde-azulado, y flores en panículas fusiformes, grisácea con reflejos plateados (DRAE: 369).

113) Deyeuxia cabrerae (Parodi) Parodi, GRAMIN, 9557, Cuaderno $1 \mathrm{~N}^{\circ} 35$

paja banderilla, paja, paja iro, cebada, cebadilla, chilla, chillawa, ¿waylla?

forraje

Chillawa parece ser el nombre propio de Deyeuxia eminens en Caspana (Villagrán et al. 1998a) y $D$. cabrerae en Río Grande, mientras que chilla sería la contracción de esta mismo vernáculo.

Etimología: Paja banderilla, E. Ver 110. Paja, E. Ver 109. Paja iro, E, A. Ver paja (109) e iro (110). Cebada, E. Planta parecida al trigo con que se alimentan diversos animales (MA: 226). Cebadilla, E. Ver 111. Waylla, Q, A. Ver 114. Chilla, Q, A. Probablemente contracción de chillawa. Chillawa, Q, A. Cchillihua, aymara, hicho gordo y liso como la caña del trigo de que hacen petacas, y otras muchas cosas (B (2): 130, 264). 
114) Deyeuxia eminens J. Presl., GRAMIN, 9493, Cuaderno $2 \mathrm{~N}^{\circ} 16$

waylla, wayawaya, waya

forraje, construcción y otros usos

Waylla y sus variantes wayawaya y waya es el nombre propio de la paja de orillas de ríos y vegas, grande y alta. Forraje. Los tallos sirven para tostar el maíz ("hacer tostado"). Se la utiliza en construcción, para la parte interior de las techumbres (la torta del cielo, mezclada con barro), poniéndose paja brava (Festuca chrysophylla) (Aldunate et al. 1981) o paja iru (Anatherostipa venusta) (Villagrán et al. 1998a) por el exterior. Es más débil que la paja iru (Anatherostipa venusta).

Etimología: Waylla, Q, A. Huaylla, Aaymara, hicho largo y blando con que cubren las casas (B (1): 156). Hicho aún mayor que el que llaman orco sucuya, con el que cubren las casas (B (2): 130). Huaylla, quechua, el prado verde no agostado, o el buen pasto (GH (2): 192). Waylla, quechua, pastizal, prado (C: 163). Waya y wayawaya, Q, A. Variantes de waylla.

115) Distichlis scoparia (Kunth) Arechav., GRAMIN, 9495 , Cuaderno $2 \mathrm{~N}^{\circ} 14$

brama, grama salada, cebadillita chica

forraje y medicinal

Grama o brama es la denominación genérica para la forma de vida de Gramíneas cespitosas, generalmente especies de Distichlis. Es usada para la fiebre, mezclada con la cortadera (Cortaderia atacamensis).

Etimología: Brama, E. Variante de grama, español, del latín grámen (DRAE: 674). En Perú, reciben el nombre de grama, Gramíneas de los géneros Agropyron, Cynodon, Setaria, Distichlis (SO: 144). Grama salada, E. Ver brama (115). Cebadillita chica, Diminutivo de cebadilla (111).

116) **Distichlis spicata (L.) Greene, GRAMIN, 9513, Cuaderno $2 \mathrm{~N}^{\circ} 15$

brama, grama salada

forraje y medicinal

Para la fiebre se utiliza mezclada con cortadera (Cortaderia atacamensis).

Etimología: Brama, E. Ver 115. Grama salada, E. Ver 115.

117) Festuca chrysophylla Phil., GRAMIN, 9530, Cuaderno $1 \mathrm{~N}^{\circ} 36$

paja iru, paja brava, iro, ¿chillawa?, ¿chilla?, ¿waylla? forraje y construcción

La paja brava se usa para techar. También es forraje, la come mucho el ganado. Probablemente, los nombres de chillawa, chilla y waylla sean confusiones de la especie con las grandes Gramíneas de orillas de bofedales y ríos, Deyeuxia eminens, Festuca hypsophila, cuyos tallos son usados para tostar el maíz.

Etimología: Paja iru, A, E. Variante de paja iro (110). Paja brava. Ver 110. Iro, Ver 110.

Chillawa, Q, A. Ver 113. Chilla, Q, A. Ver 113. Waylla, Q, A. Ver 114.
118) Festuca hypsophila Phil., GRAMIN, sin colectar chillawa

sin uso reconocido

Mencionada por los entrevistados y no coleccionada por nosotros en esta área de estudio. Parecida a la waylla. Paja que crece cerca del agua y que puede corresponder a Festuca hypsophila, llamada chillawa en la $1^{\mathrm{a}}$ y $2^{\mathrm{a}}$ Región (Villagrán et al. 1999; 1998a).

Etimología: Chillawa, Q, A. Ver 113.

119) Graminea sp., GRAMIN, sin número de herbario, Cuaderno $2 \mathrm{~N}^{\circ} 41$

banderilla

sin uso reconocido en el área de estudio

Etimología: Banderilla, E. Ver paja banderilla (110).

120) Hordeum comosum J. Presl., GRAMIN, 9543, Cuaderno $2 \mathrm{~N}^{\circ} 22$

peludilla, cebadilla, cebada

forraje

Mala yerba. El nombre peludilla es asignado "porque tiene como pelos" (barbas de las espigas).

Etimología: Peludilla, E. Del español peludo. Cebadilla, E. Ver 111. Cebada, E. Ver 113.

121) Pennisetum chilense (E. Desv.) B.D. Jackson ex R.E. Fries, GRAMIN, 9616, Cuaderno $2 \mathrm{~N}^{\circ} 49$

cebadilla, esporal, cebadillón, paja

forraje

Resulta oscuro el vernáculo esporal para esta Gramínea muy frecuente en las quebradas, Pennisetum chilense. Si la palabra fuese española aludiría a la disposición espiralada, en torno a la espiga, de los estigmas muy oscuros y llamativos de las flores. Si fuese aymara podría evocar su vaivén con el viento. Este pasto no le gustaría a las ovejas. Forraje.

Etimología: Cebadilla, E. Ver 111. Esporal, ¿E?, ¿A? Español, espiral, disposición helicoide de algo. Del aymara, hisppuratha, sacudir el polvo (B (1): 421). Cebadillón, E. Variante del nombre cebadilla (111). Paja, E. Ver 109.

122) *Phragmites australis (Cav.) Trin. ex Steud., GRAMIN, 9619, Cuaderno $2 \mathrm{~N}^{\circ} 78$

¿choclo?

¿forraje?

Se confundió la muestra con las hoja de choclo, usadas como forraje.

Etimología: Choclo, Q. Del quechua choccllo mazorca tierna de maíz (DRAE: 651).

123) Polypogon interruptus Kunth, GRAMIN, 9517, 9496, Cuaderno $2 \mathrm{~N}^{\circ} 8,62$

cebadilla, pasto blanco, cebadilla chica

forraje

Parecido a la cebadilla, "pero no es".

Etimología: Cebadilla, E. Ver 111. Pasto blanco, E. Ver pasto (67). Cebadilla chica, E. Ver cebadilla (111). 
124) *Polypogon monspeliensis (L.) Desf., GRAMIN, 9617, Cuaderno $2 \mathrm{~N}^{\circ} 63$

cebadilla

sin uso reconocido en el área de estudio

Etimología: Cebadilla, E. Ver 111.

125) Puccinellia frigida (Phil.) I.M. Johnston, GRAMIN, 9500, 9573, 9574, Cuaderno $2 \mathrm{~N}^{\circ} 10$

vega, cebada, cebadilla, paja, champa

forraje

Es parte de la vega. Forraje.

Etimología: Vega, E. Ver 10. Cebada, E. Ver 113. Cebadilla, E. Ver 111. Paja, E. Ver 109. Champa, Q, A. Ver 107.

126) *Sorghum sp., GRAMIN, sin número de herbario, Cuaderno $2 \mathrm{~N}^{\circ} 80$

cortadera chica

sin uso reconocido

El nombre cortadera chica es un símil con la cortade-

ra (Cortaderia atacamensis). Sin uso reconocido en el área de estudio.

Etimología: Cortadera chica, E. Ver cortadera (112).

127) Stipa chrysophylla E. Desv., GRAMIN, 9550, Cuaderno $1 \mathrm{~N}^{\circ} 34$

paja, paja alma, paja vizcachera, paja banderilla ploma, paja cebadilla, paja dulce

forraje, riual y medicinal

El nombre paja alma alude al uso de la planta en las ceremonias para separar almas. Es forraje, lo come la vizcacha y todos los animales en general. Con el vernáculo sikoa, se hizo también mención a una paja cuyas hojas cortan, como cortadera (Cortaderia atacamensis) y que sería remedio para la fiebre, en baños, combinada con otras plantas. Probablemente, se trata también de Stipa chrysophylla, llamada sikuya en la $1^{\text {a }}$ Región.

Etimología: Paja, E. Ver 109.

Paja alma, E. Ver paja (109). Paja vizcachera, E, A, Q. Ver paja (109). En aymara, viskacha, ver hiskachu, conejo de la tierra silvestre que corre por las peñas (B

(2): 389). Quechua, vizcacha, conejo de la tierra pardo (R: 87). Paja banderilla ploma, E. Ver paja banderilla (110). Paja cebadilla, E. Ver paja (109) y cebadilla (111). Paja dulce, E. Ver paja (109).

128) Juncus arcticus Willd., JUNCAC, 9502 , Cuaderno $2 \mathrm{~N}^{\circ} 9$

unquillo, pajita del agua

forraje

Pajita del agua hace alusión al hábitat de la especie.

Etimología: Unquillo, E. Ver 20. Pajita del agua, E. Diminutivo de paja (109).
129) Oxychloe andina Phil., JUNCAC, 9560 , Cuaderno

$2 \mathrm{~N}^{\circ} 26$

pakopako, pako

forraje

Pakopako o pako es el nombre de la especie dominante del bofedal, el cojín pulvinado de Oxychloe andina. Muy buen forraje. Los frutos lo comen las llamas, el suri y la vizcacha. Etimología: Pako, A, Q. En aymara, phukhu, manantial de agua; phukhu phukhu, tierra de muchos manantiales (B (2): 280). Paco, en quechua, cosa bermeja, rubia; cierto género de carneros de la tierra lanudos llamados así, el hombre rojo, animal castaño (R: 118). Paco, las yerbas que se comen así crudas (B (2): 242). Pacoy, cualquier yerba de comer (R: 66). En Perú, pacopaco y pacupacu son los cojines pulvinados, altoandinos, del género de Gramínea, Aciachne (SO: 8). Pakopako, A, Q. Variante de pako.

130) Triglochin concinnum Burtt Davy, JUNCAG, 9497, Cuaderno $2 \mathrm{~N}^{\circ} 13$

Vega

¿medicinal?

¿Para la fiebre?

Etimología: Vega, E. Ver 10.

131) *Zannichellia palustris L., ZANNIC, 9508, Cuaderno $2 \mathrm{~N}^{\circ} 2$

alga, loroma

forraje

El nombre alga es proporcionado a una planta acuática con flores, pero de morfología macroscópica simple, como las algas.

Etimología: Alga, E. Alga, español, planta talófita acuática (MA: 52). Loroma, ¿A?. Ver 71.

\section{OTRAS ESPECIES CITADAS PARA GUATÍNY NO REGISTRADAS POR NOSOTROS EN ESTA ÁREA DE ESTUDIO}

Cadillo. SSL cita para Guatín el vernáculo cadillo para Acaena laevigata, probablemente un sinónimo de $A$. magellanica existente en el área de estudio (SSL: 58).

Chuchampe. Especie sin identificación botánica. Se usa para teñir de color amarillo (SSL: 58).

Estrella. Pasto para cabras (SSL: 59).

Malva blanca. Es citado para la malvácea Cristaria andicola, forraje para las cabras (SSL: 59).

Soico. Planta utilizada como té y pasto para las ovejas. Es identificado como Tagetes gracilis, especie que no aparece en la flora chilena. Podría tratarse de $T$. minuta planta o T. multiflora, registradas para la zona con igual nombre (SSL: 59 ).

Uvilla. Planta no identificada botánicamente. Utilizada como forraje de cabras (SSL:59). 


\section{ANEXO 2}

\section{CATÁLOGO ALFABÉTICO DE VERNÁCULOS E IDIOMAS DE LOS MISMOS}

( $\mathrm{A}=$ aymara; $\mathrm{E}=$ español; $\mathrm{K}=$ kunza; $\mathrm{M}=$ mapuche; $\mathrm{Q}=$ quechua; $\mathrm{O}=$ otros idiomas americanos). Los números al lado de cada nombre se refieren al orden de las especies en el Anexo 1.

\begin{tabular}{|c|c|}
\hline achicoria & 83 \\
\hline acholla & 1 \\
\hline agria (fruto) & 17 \\
\hline alfalfa & 67 \\
\hline alfalfilla & 13 \\
\hline alfambrilla & 13 \\
\hline alfiler & 70 \\
\hline alfilerillo & 70 \\
\hline alfilla & 13 \\
\hline alga & 131 \\
\hline algarrobillo & 64 \\
\hline algarrobo & 80 \\
\hline añawa & 63 \\
\hline añawa colorada & 63 \\
\hline añawa de cordillera & 63 \\
\hline apio & 6 \\
\hline bailabien & 40 \\
\hline bailahuén & 40 \\
\hline banderilla & 119 \\
\hline básal & 87,88 \\
\hline básal amargo & 88 \\
\hline básal granada & 87 \\
\hline básal hembra & 87 \\
\hline básal macho & 88 \\
\hline básal rojo & 87 \\
\hline básal rosao & 88 \\
\hline brama & 115,116 \\
\hline brea & 50 \\
\hline burro chachakoma & 46 \\
\hline cacho de cabra & 46 \\
\hline candela & 39 \\
\hline captus & 16 \\
\hline cardón & 15,16 \\
\hline cardón chico & 14 \\
\hline cardón de espina & 15 \\
\hline cardoncillo & 101 \\
\hline cebada & $113,120,125$ \\
\hline cebadilla & $\begin{array}{l}111,113,120, \\
121,123,124,125\end{array}$ \\
\hline cebadilla chica & 123 \\
\hline cebadilla grande & 111 \\
\hline cebadillita chica & 115 \\
\hline cebadillón & 121 \\
\hline cepacaballo & 54 \\
\hline cerraja & 49,85 \\
\hline chacha & 43,44 \\
\hline chachakoma & 47 \\
\hline chachakoma de la cabra & 46 \\
\hline chajchal & 99 \\
\hline chajllampa & 39 \\
\hline chakachaka & 72 \\
\hline
\end{tabular}

\begin{tabular}{|c|c|c|}
\hline champa & $107,108,125$ & $\mathrm{Q}, \mathrm{A}$ \\
\hline champita & 107 & $\mathrm{Q}, \mathrm{A}, \mathrm{E}$ \\
\hline chape & $26,27,72$ & A \\
\hline chapi & 26,27 & A \\
\hline chejchajra & 40 & $\mathrm{Q}, \mathrm{K}$ \\
\hline chejchara & 40 & $\mathrm{Q}, \mathrm{K}$ \\
\hline chengua & $10,91,92$ & Q \\
\hline chijuachijua & 32 & $\mathrm{Q}, \mathrm{A}$ \\
\hline chilka & 31,35 & $\mathrm{Q}, \mathrm{A}$ \\
\hline chilla & 113,117 & $\mathrm{Q}, \mathrm{A}$ ? \\
\hline chillawa & $113,117,118$ & $\mathrm{Q}, \mathrm{A}$ \\
\hline chinchirkoma & 41 & $\mathrm{Q}, \mathrm{A}$ \\
\hline chinchirkoma hembra & 41 & $\mathrm{Q}, \mathrm{A}, \mathrm{E}$ \\
\hline chirit'ola & 43,44 & $\mathrm{Q}, \mathrm{A}$ \\
\hline chóchar & 60 & $\mathrm{Q}, \mathrm{K}$ \\
\hline choclo & 122 & $\mathrm{Q}$ \\
\hline chókil & 24 & $\mathrm{~K}$ \\
\hline chuchikandia, & 11 & Q \\
\hline chuchikaylla & 11 & $\mathrm{Q}$ \\
\hline chukchuka & 33 & $\mathrm{Q}, \mathrm{A}$ \\
\hline chukikan & 11 & Q \\
\hline chukikaña & 11 & $\mathrm{Q}$ \\
\hline chukikanlla & 11 & Q \\
\hline chukukaylla & 11 & Q \\
\hline chukula & 1 & $\mathrm{~K}$ \\
\hline ciénego & $20,89,92,108$ & $\mathrm{E}$ \\
\hline cola de gato & 101 & $\mathrm{E}$ \\
\hline cola de michi & 101 & $\begin{array}{l}\mathrm{Q}, \mathrm{A}, \\
\mathrm{K}, \mathrm{E}\end{array}$ \\
\hline cola de ratón & 72 & $\mathrm{E}$ \\
\hline conchita & 51 & $\mathrm{E}$ \\
\hline copihue & 41 & M \\
\hline copihue silvestre & 41 & $\mathrm{M}, \mathrm{E}$ \\
\hline cortadera & 112 & $\mathrm{E}$ \\
\hline cortadera chica & 126 & $\mathrm{E}$ \\
\hline enredadera & 56 & $\mathrm{E}$ \\
\hline espiga & 111 & $\mathrm{E}$ \\
\hline espina & 18 & $\mathrm{E}$ \\
\hline espina de agria & 17 & $\mathrm{E}$ \\
\hline espina del agria chiquitita & 18 & E \\
\hline esporal & 121 & $\mathrm{E}, \mathrm{A}$ \\
\hline flor blanca & 56 & $\mathrm{E}$ \\
\hline flor de agua & 2,3 & $\mathrm{E}$ \\
\hline flor de la vega & 103 & $\mathrm{E}$ \\
\hline flor de puna & 38 & $\mathrm{E}, \mathrm{Q}$ \\
\hline flores & 66 & $\mathrm{E}$ \\
\hline gallokishka & 63 & $\mathrm{Q}, \mathrm{E}$ \\
\hline garbancillo & 64 & $\mathrm{E}$ \\
\hline garbanzo & 64 & $\mathrm{E}$ \\
\hline girasol & 49 & $\mathrm{E}$ \\
\hline grama salada & 115,116 & $\mathrm{E}$ \\
\hline guailaven & 40 & M \\
\hline guailavina & 40 & M \\
\hline hinojo & 9 & $\mathrm{E}$ \\
\hline hoja koka & 35 & $\mathrm{~A}, \mathrm{E}$ \\
\hline iloka & 62 & $\mathrm{Q}, \mathrm{A}$ \\
\hline
\end{tabular}




\begin{tabular}{|c|c|c|c|c|c|}
\hline iluka & 61 & $\mathrm{Q}, \mathrm{A}$ & mutukuru & 19 & $\mathrm{Q}, \mathrm{A}$ \\
\hline iro & 110,117 & $\mathrm{Q}, \mathrm{A}$ & ojala & 24,25 & $\mathrm{E}$ \\
\hline iskayu & 10 & $\mathrm{Q}, \mathrm{A}$ & ojalar & 24 & $\mathrm{E}$ \\
\hline isru & 86 & $\mathrm{~A}, \mathrm{Q}$ & ojalata & 24 & E \\
\hline itapilla & 77 & A & oqelorenso & 48 & $\mathrm{Q}, \mathrm{A}, \mathrm{E}$ \\
\hline kachiyuyo & 24,25 & $\mathrm{Q}, \mathrm{A}, \mathrm{K}$ & ortega & 77 & $\mathrm{E}$ \\
\hline kashavi & 60 & $\mathrm{Q}$ & ortiga & 77 & $\mathrm{E}$ \\
\hline kashawe & 60 & Q & paja & $109,110,113,121$ & $\mathrm{E}$ \\
\hline kashawi & 60 & $\mathrm{Q}$ & & 125,127 & \\
\hline kela & 66 & Q & paja alma & 127 & $\mathrm{E}$ \\
\hline keri & 39 & $\mathrm{~A}$ & paja banderilla & 110,113 & $\mathrm{E}$ \\
\hline kewayllo & 15,16 & $\mathrm{Q}, \mathrm{A}$ & paja banderilla blanca & 109 & $\mathrm{E}$ \\
\hline kisko & 16,17 & $\mathrm{Q}$ & paja banderilla ploma & 127 & $\mathrm{E}$ \\
\hline koa & 97 & $\mathrm{Q}, \mathrm{A}$ & paja brava & 110,117 & $\mathrm{E}$ \\
\hline koba & $43,44,97$ & $\mathrm{Q}, \mathrm{A}$ & paja cebadilla & 109,127 & E \\
\hline koba hembra & 43,44 & $\mathrm{Q}, \mathrm{A}, \mathrm{E}$ & paja dulce & 127 & $\bar{E}$ \\
\hline koba macho & 97 & $\mathrm{Q}, \mathrm{A}, \mathrm{E}$ & paja fina & 110 & E \\
\hline koka del desierto & 51 & $\mathrm{~A}, \mathrm{E}$ & paja gruesa & 109 & $\mathrm{E}$ \\
\hline kokakoka & 51 & A & paja iro & 110,113 & $\mathrm{Q}, \mathrm{A}, \mathrm{E}$ \\
\hline kontekonte & 64,66 & $\mathrm{~K}$ & paja iru & 110,117 & $\mathrm{Q}, \mathrm{A}, \mathrm{E}$ \\
\hline kontikonti & 66 & $\mathrm{~K}$ & paja vizcachera & 127 & $\mathrm{E}, \mathrm{A}, \mathrm{Q}$ \\
\hline kontokonto & 66 & K & pajita chica & 107 & E \\
\hline kopa & 30 & $\mathrm{Q}, \mathrm{A}, \mathrm{K}$ & pajita del agua & 128 & $\mathrm{E}$ \\
\hline kopakopa & 30 & $\mathrm{Q}, \mathrm{A}, \mathrm{K}$ & pako & 129 & $\mathrm{~A}, \mathrm{Q}$ \\
\hline kotaro & 51 & $\mathrm{~K}$ & pakopako & 129 & $\mathrm{~A}, \mathrm{Q}$ \\
\hline kotora & 51 & $\mathrm{~K}$ ? & palki & 94 & M \\
\hline kume & 17 & $\mathrm{~K}$ & pasakana (fruto) & 15,16 & $\mathrm{Q}, \mathrm{A}$ \\
\hline lako & 2,3 & $\mathrm{Q}, \mathrm{A}, \mathrm{K}$ & pasto & 67 & $\mathrm{E}$ \\
\hline lakolako & 2,3 & $\mathrm{Q}, \mathrm{A}, \mathrm{K}$ & pasto amargo & 46 & $\mathrm{E}$ \\
\hline lama & 2,3 & $\mathrm{E}$ & pasto blanco & 123 & E \\
\hline lampaya & 102 & $\mathrm{Q}, \mathrm{A}$ & pasto de cabra & 60 & $\mathrm{E}$ \\
\hline lejía & 34,36 & $\mathrm{E}$ & pata de perdiz & 97 & E \\
\hline léjia & 34 & $\mathrm{E}$ & payko & $21,28,37$ & $\mathrm{Q}$ \\
\hline léjia hembra & 34 & E & pegapega & 28,72 & $\mathrm{E}$ \\
\hline léjia macho & 36 & $\mathrm{E}$ & peludilla & 120 & E \\
\hline lengua de buey & 85 & $\mathrm{E}$ & pimiento & 5 & $\mathrm{E}$ \\
\hline lengua de gallina & 39 & $\mathrm{E}$ & pingopingo & 4 & $\mathrm{Q}, \mathrm{A}$ \\
\hline lengua de gallo & 39 & $\mathrm{E}$ & psike & $53,83,98$ & $\mathrm{Q}, \mathrm{A}$ \\
\hline linaza & 22,57 & $\mathrm{E}$ & pulika & 43,44 & $Q$ \\
\hline llantel & 82 & $\mathrm{E}$ & pupusa & 55 & $\mathrm{Q}$ \\
\hline llantén & 81,82 & E & puskayo & 17 & $\mathrm{Q}, \mathrm{A}$ \\
\hline loroma & 71,131 & A & puskayu & 17 & $\mathrm{Q}, \mathrm{A}$ \\
\hline lucha & $1,2,3$ & M & qela & 66 & $\mathrm{~A}$ \\
\hline luche & 1 & M & qoba & 97 & $\mathrm{Q}, \mathrm{A}$ \\
\hline lupino & 66 & $\mathrm{E}$ & quebraolla & 39 & $\mathrm{E}$ \\
\hline maksa & 17 & A & quinoa & 26 & $\mathrm{Q}, \mathrm{A}$ \\
\hline malva & $13,78,79$ & $\mathrm{E}$ & rikarika & 100 & $\mathrm{Q}, \mathrm{E}$ \\
\hline malva rosa & 78 & $\mathrm{E}$ & romarillo & 48 & $\mathrm{E}$ \\
\hline malvilla & 13 & E & romaza & 84,85 & E \\
\hline manzanilla & 29 & $\mathrm{E}$ & rosakishka & 101 & $\mathrm{Q}, \mathrm{E}$ \\
\hline maransel & $45,52,98$ & Q & rosas & 101 & $\mathrm{E}$ \\
\hline maravilla & 66 & E & sangrinaria & 72 & $\mathrm{E}$ \\
\hline maravilla chica & 48 & $\mathrm{E}$ & sicha & 12 & $\mathrm{Q}$ \\
\hline mataratón & 72 & $\mathrm{E}$ & tamor & 61 & $\mathrm{Q}, \mathrm{A}$ \\
\hline menta & 75 & $\mathrm{E}$ & tamur & 61 & $\mathrm{Q}, \mathrm{A}$ \\
\hline menta koka & 75 & $\mathrm{E}, \mathrm{A}$ & tara & 95,96 & $\mathrm{Q}, \mathrm{A}, \mathrm{K}$ \\
\hline molle & 5 & $\mathrm{Q}$ & té & 37 & $\mathrm{E}$ \\
\hline monte & 32 & $\mathrm{E}$ & té de burro & 37 & $\mathrm{E}$ \\
\hline motokuro & 19 & $\mathrm{Q}, \mathrm{A}$ & tikara & 28 & $\mathrm{~K}, \mathrm{~A}$ \\
\hline muña & 76 & $\mathrm{~A}$ & tokora & 51 & $\mathrm{~K}, \mathrm{~A}$ \\
\hline murmunta & 1 & $\mathrm{~A}, \mathrm{Q}$ & tola & $32,42,96$ & $\mathrm{Q}, \mathrm{A}$ \\
\hline
\end{tabular}




\begin{tabular}{|c|c|c|c|c|c|}
\hline tola amarilla & 42 & $\mathrm{Q}, \mathrm{A}, \mathrm{E}$ & unut'ola & 42 & Q, A \\
\hline tola amarilla chica & 43,44 & $\mathrm{Q}, \mathrm{A}, \mathrm{E}$ & vega & $10,22,53,69,89$, & \\
\hline tola chijua & 34 & $\mathrm{Q}, \mathrm{A}$ & & $90,92,104,106$ & \\
\hline tola del agua & 42 & $\mathrm{Q}, \mathrm{A}, \mathrm{E}$ & & $108,125,130$ & \\
\hline tola lejía & 34,36 & $\mathrm{Q}, \mathrm{A}, \mathrm{E}$ & vinovino & 101 & E \\
\hline tola pulika & 43,44 & Q, A & waya & 114 & $\mathrm{Q}, \mathrm{A}$ \\
\hline \multirow[t]{2}{*}{ tola tara } & $32,43,44$ & $\mathrm{Q}, \mathrm{A}$, & wayawaya & 114 & $\mathrm{Q}, \mathrm{A}$ \\
\hline & & $\mathrm{K}, \mathrm{E}$ & waylla & $113,114,117$ & $\mathrm{Q}, \mathrm{A}$ \\
\hline tolatola & 42 & $\mathrm{Q}, \mathrm{A}$ & wiskayu & 10 & Q \\
\hline tolilla & $43,44,95,96$ & $\mathrm{Q}, \mathrm{A}, \mathrm{E}$ & yareta & 7 & $\mathrm{Q}, \mathrm{A}$ \\
\hline tolita el campo & 32 & $\mathrm{Q}, \mathrm{A}, \mathrm{E}$ & yaretawaqa (resina) & 7 & $\mathrm{Q}, \mathrm{A} ?$ \\
\hline tomatillo & 99 & E & yaretilla & 23 & $\mathrm{Q}, \mathrm{A}, \mathrm{E}$ \\
\hline trebol & 68 & $\mathrm{E}$ & yerba buena & 74 & E \\
\hline trébol & 68 & $\mathrm{E}$ & yerba buena pelúa & 75 & E \\
\hline trigol & 68 & $\mathrm{E}$ & yullucha & 1 & A \\
\hline tume & 4 & $\mathrm{Q}, \mathrm{A}$ & yuyo & 26,27 & $\mathrm{Q}, \mathrm{A}, \mathrm{K}$ \\
\hline tuna (fruto) & 17 & $\mathrm{O}$ & yuyo chapi & 26 & Q, A, K \\
\hline tuna de burro & 18 & $\mathrm{E}, \mathrm{O}$ & zanahoria & 8 & $\mathrm{E}$ \\
\hline tunilla (fruto) & 17 & E, O & zapatilla & 93 & E \\
\hline unquillo & $20,33,104,128$ & E & zapatito & 93 & E \\
\hline unquillo chico & 105 & $\mathrm{E}$ & zarzaparrilla & 101 & $\mathrm{E}$ \\
\hline
\end{tabular}

Agradecimientos: Se agradece la inestimable ayuda prestada por los habitantes de Machuca y Río Grande, en especial a quienes participaron en las entrevistas: Calixta y Florencia González, Cirilo Colque, Presentaciona Condori, Graciela Colque, hermanos López, Marcelino Colque, Paulina Terán, Filemón Ansa, Juana Mendoza, Hernán Urrelo, Petronila Anza, Esteban Condori, Patricia Albornoz, Jorge Colque, Alberto Cayetano Condori, To- más Solís, y Luis Morales. Se agradece también la valiosa ayuda, en el muestreo de vegetación y entrevistas, de los estudiantes de postgrado, Sres. Felipe Hinojosa y Rodrigo Villa. Asimismo, la colaboración del profesor Gilberto Sánchez en la revisión de las grafías de los vernáculos recopilados y al arquitecto Fernando Maldonado por la confección del mapa. Este trabajo forma parte del proyecto Fondecyt 1970908.

\section{Referencias Citadas}

Albó, J.

1988. Raíces de América. El mundo Aymara. Alianza Editorial, Madrid.

Aldunate C., J. Armesto, V. Castro y C. Villagrán

1981 Estudio etnobotánico en una comunidad precordillerana de Antofagasta: Toconce. Boletín del Museo Nacional de Historia Natural 38:183-223.

Alonso, $\mathrm{M}$.

1981 Diccionario del Español Moderno. Aguilar, Madrid.

Ballón, E., R. Cerrón-Palomino y E. Chambi

1992 Vocabulario Razonado de la Actividad Agraria Andina. Centro Bartolomé de las Casas, Cuzco.

Bertonio, L.

1984 [1612] Vocabulario de la Lengua Aymara. Primera, Parte: Español-Aymara, 1-474. Segunda Parte: AymaraEspañol: 1-397. Ediciones Ceres, Cochabamba.

Cárdenas, $\mathrm{M}$.

1989 Manual de Plantas Económicas de Bolivia. Editorial Los Amigos del Libro, La Paz, Cochabamba.

Castro, V.

1998 La dinámica de las identidades en la subregión de río Salado. En I Encuentro Nacional Interinstitucional de Investigadores de Identidades Culturales, editado por $\mathrm{M}$. Dannemann, pp. 5-50. Publicación del Departamento de
Investigación y Desarrollo, Universidad de Chile.

1997 Huacca Mucchay. Evangelización y Religión Andina en Charcas, Atacama La Baja. Tesis de Magister, Facultad de Filosofía, Universidad de Chile.

1986 An approach to the Andean ethnozoology: Toconce. En Cultural Attitudes to Animals 2:1-17. Allen \& Unwin, Londres.

Castro, V., J. Berenguer y C. Aldunate

1979 Antecedentes de una interacción altiplano-área atacameña durante el período Tardío: Toconce. Actas del VII Congreso de Arqueología de Chile Vol 2:477-498. Ediciones Kultrún, Santiago.

Castro, V., C. Aldunate y J. Berenguer

1984 Orígenes altiplánicos de la fase Toconce. Estudios Atacameños 7:209-235.

Castro, V. y J.L. Martínez

1996 Poblaciones indígenas de la Provincia de El Loa. En Culturas de Chile, Tomo II, Etnografía, Sociedades Indígenas Contemporáneas y su Ideología, editado por J. Hidalgo, V. Schiappacasse, H. Niemeyer, C. Aldunate y P. Mege, pp. 69-109. Editorial Andrés Bello, Santiago.

Corominas, J.

1973 Breve Diccionario Etimológico de la Lengua Castellana. Ed. Gredos S.A., Madrid, España. 
Cusihuamán, A.

1976 Diccionario quechua: Cuzco-Collao. Ministerio de Educación/Instituto de Estudios Peruanos, Lima.

De Lucca, $M$.

1987 Diccionario Práctico Aymara-Español, EspañolAymara. Editorial Los Amigos del Libro, La Paz.

Editorial Mercurio

1981 Manual trilingüe de Aymará Quechua y Español. Lima, Perú.

Editorial Mercurio

1981 Manual de la lengua Quechua al Español. Lima.

Girault, L.

1987 Kallawaya curanderos itinerantes de los Andes. Imprenta Quipus, La Paz.

González-Holguín, D.

[1608] 1952 Vocabulario de la Lengua General de todo el Perú Llamada Lengua Quechua o del Inca. Libro Primero: Quechua-Español: 1-374. Libro Segundo: EspañolQuechua: 375-695. Imprenta Santa María, Lima.

Hanson, E.

1926 Out-of-the-world villages of Atacama. Geographical Review 16:365-377.

Lagos, R., C. Mendoza, N. Ampuero y N. Hernández 1995-1996 Aspectos rituales relacionados con el ganado en Santiago de Río Grande (II Región, Chile). Estudios Atacameños 12:115-134.

Lehnert, R. 1994 Diccionario Toponimia Kunza. Norprint, Antofagasta.

Lenz, R.

1910 Diccionario etimológico de las Voces Chilenas Derivadas de Lenguas Indígenas Americanas, editado por $\mathrm{M}$. Ferreccio. Imprenta Universitaria, Santiago.

Lira, J.

1945 Diccionario Kechuwa-Español. Publicación 369, Instituto de Historia, Lingüística y Folklore, Universidad Nacional de Tucumán, Tucumán.

Lumbreras, $\mathrm{L}$.

1974 Los reinos post-tiwanaku en el área altiplánica. Revista del Museo Nacional de Lima XL: 55-87.

Martínez, J.L.

1998 Pueblos del Chañar y el Algarrobo. Los atacamas en el siglo XVII. Centro de Investigaciones Diego Barros Arana, Santiago.

Mösbach, E.W.

1992 Botánica Indígena de Chile. Editado por C. Aldunate y C. Villagrán, Editorial Andrés Bello, Santiago.

Mostny, G.

1954 Peine, un pueblo Atacameño. Publicación del Instituto de Geografía de la Facultad de Filosofía de la Universidad de Chile 4: 3-170.

Munizaga, C. y H. Gunckel

1958 Notas Etnobotánicas del Pueblo Atacameño de Socaire. Publicaciones del Centro de Estudios Antropológicos 5: 7-53.

Núñez, L. y T. Dillehay

1978 Movilidad Giratoria, Armonía Social y Desarrollo en los Andes Meridionales: Patrones de Tráfico e Interacción Económica. Universidad del Norte, Antofagasta.

Perroud, C.

1970 Diccionario Español Kechwa Español. Talleres Gráficos de Iberia, Lima.

Real Academia Española

1970 y 1992 Diccionario de la Lengua Española. Editorial Espasa-Calpe, Madrid.
Ricardo, A.

1951 [1586] Vocabulario y Phrasis en la Lengua General de los Indios del Perú Lamada Quechua. Ediciones del Instituto de Historia, Lima.

Risopatrón, L.

1924 Diccionario jeográfico de Chile. Imprenta Universitaria, Santiago.

Rivera, F.

1993 Estudio de la Autopercepción de la Marginalidad en San Pedro de Atacama. Informe de Práctica Profesional, Departamento de Antropología, Universidad de Chile.

San Román, F.

1890 La lengua Cunza de los Naturales de Atacama. Imprenta Gutenberg, Santiago.

Schuller, R.

1908 Vocabulario y nuevos materiales para el estudio de la lengua de los indios lican - antai (atacameños) - Calchaquí. Editado por F. Becerra. Tomo II. Imprenta Cervantes, Santiago.

Serracino, G. y A. Barón

1979 Santiago de Río Grande: un tambo atacameño. Tambo 3-4: 15-30, Antofagasta.

Serracino, G., R. Stehberg y G. Libermann

1974 Informe Etnobotánico de Guatin (San Pedro de Atacama). Antropología Nueva Época 1: 55-64.

Soukup, J.

1970 Vocabulario de los Nombres Vulgares de la Flora Peruana. Imprenta Salesiana, Lima.

Torero, A.

1970 Lingüística e historia de la Sociedad Andina. Anales Científicos 8(3-4): 231-264. Universidad Nacional Agraria, Lima.

Torero, A.

1982 Acerca de la familia lingüística uruquilla (Uru Chipaya). Revista Andina 1: 171-191.

Vaisse, E., F. Hoyos y A. Echeverría

1896 Glosario de la Lengua Atacameña. Imprenta Cervantes, Santiago.

Villagrán, C. y V. Castro

1999 Etnobotánica y manejo ganadero de las vegas, bofedales y quebradas en el Loa superior, Andes de Antofagasta, Segunda Región, Chile. Chungara 29(2): 275-304.

Villagrán, C., V. Castro, G. Sánchez, F. Hinojosa y C. Latorre 1999 La tradición altiplánica: estudio etnobotánico en los Andes de Iquique, Primera Región, Chile. Chungara 31(1): 81-186.

Villagrán, C., V. Castro y G. Sánchez

1998a Etnobotánica y percepción del paisaje en Caspana (Provincia de El Loa, Región de Antofagasta, Chile): ¿Una cuña atacameña en el Loa Superior?. Estudios Atacameños $16,107-1709$.

Villagrán, C., V. Castro, G. Sánchez, M. Romo, C. Latorre y F. Hinojosa

1998b La tradición surandina del desierto: Etnobotánica del área del Salar de Atacama: (Provincia de El Loa, Región de Antofagasta, Chile). Estudios Atacameños 16, 7-105. en prensa.

Villagrán, C., M. Romo y V. Castro

2001MS Etnobotánica del extremo sur de los Andes de la primera región de Chile: un enlace entre las culturas altiplánicas y las de quebradas altas del Loa superior. Enviado para publicación en Chungara. Manuscrito en posesión de los autores.

Yacoleff, E. y L. Herrera

$1935 \mathrm{El}$ mundo vegetal de los antiguos peruanos. Revista del Museo Nacional de Lima Tomo IV (1): 31-102, Lima. 


\section{Notas}

1 La colección se encuentra depositada en el Laboratorio de Palinología de la Facultad de Ciencias de la Universidad de Chile.

2 Ratón amo, ratones chinchilla (Abrocoma cinerea), denominados localmente amos.

3 En los Andes se denomina "pagos" a las ofrendas que hacen las personas a las divinidades, cerros tutelares o antepasados, etc., en diversos rituales.

4 Chullapasa. Chuya, en quechua, cosa clara como agua, u otro licor (R: 40). En aymara, chulla manojillo de quinua o trigo (B (2): 92) ; cchulla, lo que esta sin su compañero que había de tener" (B (2): 95). Chuya en quechua (ver GH (1): 126) tiene el sentido de purificación, tanto del alma como del cuerpo; en la práctica, esta "limpia" se realiza con varios elementos, entre los que se incluyen harinas, obtenidas de ciertas plantas. La idea es que siempre que se ofrenda, se haga de "a pares" y en la mayoría de los casos se quemen estas ofrendas (Castro 1997). Chuya, mezcla de agua con harina utilizada en los rituales (Lagos et al, 1995-1996).

5 Llucta o llipta y chile, aymara-quechua y kunza. Llukhta, aymara, ceniza que hacen de la caña de la quinoa, y amasán- dola después la comen con coca (B (2): 207). Lliptta, quechua, panecillos de ceniza quero (un árbol) para comer coca (GH (1): 214). Llipta, quechua, panecillo de ceniza que sirve de excitante para mascar la coca; esta preparación consigue una mayor liberación de la cocaína por la cal que contiene. Se prepara la llipta con ceniza de kinwa, árbol y cal (Pe (2): 98). Tchili o tchile, kunza, ceniza. Así se llama una materia carbonizada que sirve de condimento a la coca durante su masticación (V: 31 ).

6 Wakis o pagos, conjunto de materiales vegetales y de otra índole ofrecidos en las ofrendas.

7 "Gentiles", nombre que se les da en esta zona a los antepasados, también llamados "abuelos".

8 Ulpo, preparación consistente en agua con harina.

9 "Floramentos" o "floreos", ceremonias del ciclo anual relacionadas con la fertilidad del ganado.

10 Wirakoba, una de las plantas ceremoniales más importantes de los Andes de Chile y Bolivia, Diplostephium cinereum.

11 Familia Plantaginaceae 